Florida International University FIU Digital Commons

9-2-2009

\title{
Estrogen and Lithium: Facilitating Factors Involved in Brain Cell Signaling Pathways
}

James J. Valdes

Florida International University, jvald040@fiu.edu

DOI: $10.25148 /$ etd.FI09120801

Follow this and additional works at: https://digitalcommons.fiu.edu/etd

\section{Recommended Citation}

Valdes, James J., "Estrogen and Lithium: Facilitating Factors Involved in Brain Cell Signaling Pathways" (2009). FIU Electronic Theses and Dissertations. 105.

https://digitalcommons.fiu.edu/etd/105 


\title{
FLORIDA INTERNATIONAL UNIVERSITY
}

Miami, Florida

\section{ESTROGEN AND LITHIUM: FACILITATING FACTORS INVOLVED IN BRAIN CELL SIGNALING PATHWAYS}

\author{
A dissertation submitted in partial fulfillment of the \\ requirements for the degree of \\ DOCTOR OF PHILOSOPHY \\ in \\ BIOLOGY \\ by \\ James Jason Valdés
}

2009 
To: Dean Kenneth Furton

College of Arts and Sciences

This dissertation, written by James Jason Valdés, and entitled Estrogen and Lithium: Facilitating Factors Involved in Brain Cell Signaling Pathways, having been approved in respect to style and intellectual content, is referred to you for judgment.

We have read this dissertation and recommend that it be approved.

$\begin{array}{r}\hline \text { Lidia Kos } \\ \hline \text { M. Alejandro Barbieri } \\ \hline \text { Thomas K. Harris } \\ \hline \text { Ophelia I. Weeks, Major Professor }\end{array}$

Date of Defense: September 2, 2009

The dissertation of James Jason Valdés is approved.

\begin{tabular}{r}
$\begin{array}{r}\text { Dean Kenneth Furton } \\
\text { College of Arts and Sciences }\end{array}$ \\
\hline Dean George Walker \\
University Graduate School
\end{tabular}

Florida International University, 2009 


\section{DEDICATION}

This dissertation is dedicated to my parents. I would not exist without their genetic material. 


\section{ACKNOWLEDGMENTS}

I would like to thank my major advisor, Dr. Ophelia I. Weeks, for providing me with the opportunity in receiving the highest academic degree and in the guidance she has provided. The Minority Biomedical Research Support fellowship (NIH) that provided me with a yearly salary and travel expenses making my tenure as a graduate student less stressful and costly. To the intramural funding that provided support needed to conduct my research (e.g. Biomedical Research Initiative and National Institute of Health/National Institute of Child Health and Human Development through the Extramural Associates Research Development Award Program R25GM061347). I would also like to thank the following undergraduate students who participated and assisted in my research Camille Howard, D. Ryan Braham, Katia Rodriguez, Valeska Lahoud, but specifically Barbara Juarez and Franchesca M. Ramirez who not only assisted me immensely in my research but also augmented my mentoring skills. I will also like to acknowledge Alvaro Velandia, Dr. J. G. Mayoral and Dr. J. A. Somarelli, who assisted me in various assays and interpreting my results. Dr. F. Brito for being so generous in providing mice for my experiments, and finally the laboratories of Dr. L. Kos, Dr. R. J. Herrera, Dr. F. Noriega, Dr. L. Kim, Dr. M. A. Barbieri and Dr. R. Lickliter for their immense assistance in providing guidance, equipment, reagents and supplies. 


\section{ABSTRACT OF THE DISSERTATION \\ ESTROGEN AND LITHIUM: FACILITATING FACTORS INVOLVED IN BRAIN \\ CELL SIGNALING PATHWAYS}

by

James Jason Valdés

Florida International University, 2009

Miami, Florida

\section{Professor Ophelia I. Weeks, Major Professor}

Learning and memory in adult females decline during menopause and estrogen replacement therapy is commonly prescribed during menopause. Post-menopausal women tend to suffer from depression and are prescribed antidepressants - in addition to hormone therapy. Estrogen replacement therapy is a topic that engenders debate since several studies contradict its efficacy as a palliative therapy for cognitive decline and neurodegenerative diseases. Signaling transduction pathways can alter brain cell activity, survival, and morphology by facilitating transcription factor DNA binding and protein production. The steroidal hormone estrogen and the anti-depressant drug lithium interact through these signaling transduction pathways facilitating transcription factor activation. The paucity of data on how combined hormones and antidepressants interact in regulating gene expression led me to hypothesize that in primary mixed brain cell cultures, combined $17 \beta$-estradiol (E2) and lithium chloride (LiCl) $(\mathrm{E} 2 / \mathrm{LiCl})$ will alter genetic expression of markers involved in synaptic plasticity and neuroprotection. Results from these studies indicated that a $48 \mathrm{~h}$ treatment of $\mathrm{E} 2 / \mathrm{LiCl}$ reduced glutamate receptor subunit genetic expression, but increased neurotrophic factor and estrogen receptor 
genetic expression. Combined treatment also failed to protect brain cell cultures from glutamate excitotoxicity.

If lithium facilitates protein signaling pathways mediated by estrogen, can lithium alone serve as a palliative treatment for post-menopause? This question led me to hypothesize that in estrogen-deficient mice, lithium alone will increase episodic memory (tested via object recognition), and enhance expression in the brain of factors involved in anti-apoptosis, learning and memory. I used bilaterally ovariectomized (bOVX) C57BL/6J mice treated with $\mathrm{LiCl}$ for one month. Results indicated that LiCl-treated bOVX mice increased performance in object recognition compared with non-treated bOVX. Increased performance in LiCl-treated bOVX mice coincided with augmented genetic and protein expression in the brain. Understanding the molecular pathways of estrogen will assist in identifying a palliative therapy for menopause-related dementia, and lithium may serve this purpose by acting as a selective estrogen-mediated signaling modulator. 


\section{TABLE OF CONTENTS}

$\begin{array}{ll}\text { CHAPTER } & \text { PAGE }\end{array}$

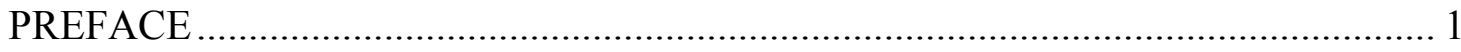

I. Estradiol and Lithium Chloride Specifically Alter Glutamate Receptor Subunit Genetic Expression and Excitotoxicity in Primary Cultures ................ 5

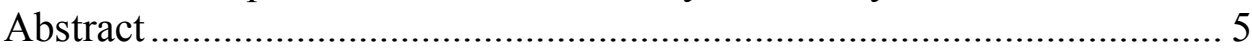

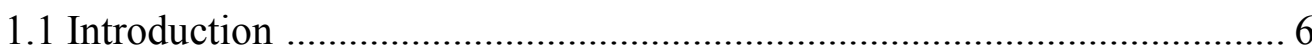

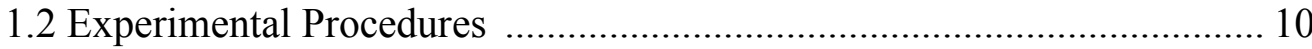

1.2.1 Primary Mixed Brain Cell Culture.......................................... 10

1.2.2 Chemicals and Treatments ..................................................... 11

1.3 Experimental Techniques .................................................................. 11

1.3.1 Total RNA Isolation and cDNA Synthesis ............................ 11

1.3.2 Cell-Typing Cultures using RT-PCR and Gel Electrophoresis ............................................................ 12

1.3.3 Quantitative Real Time RT-PCR ....................................... 13

1.3.4 Cell Viability - Fluorescein Diacetate/ Propidium Iodide Assay ..................................................... 13

1.3.5 Statistical Analysis......................................................... 14

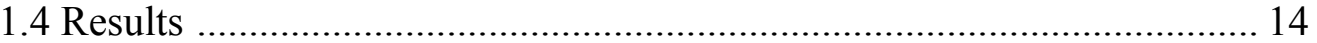

1.4.1 Brain cell typing of primary cultures indicated predominance for glia ....................................................... 14

1.4.2 Combined E2/LiCl treatment reduced NR1 mRNA expression .............................................................. 18

1.4.3 Combined $\mathrm{E} 2 / \mathrm{LiCl}$ and $\mathrm{E} 2$ failed to reduce

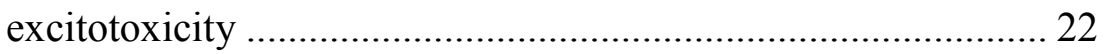

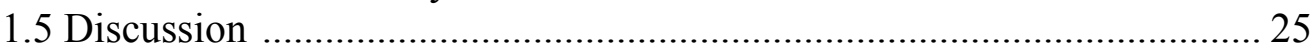

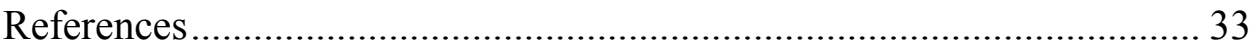

II. Combined Estradiol and Lithium Chloride Specifically Alter Factors Involved in Learning, Memory, but not Neuroprotection in Primary

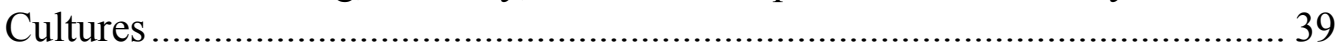

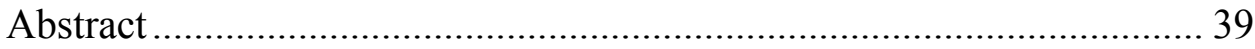

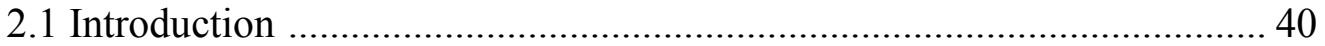

2.2 Experimental Procedures .................................................................. 43

2.2.1 Primary Mixed Brain Cell Culture, Chemicals

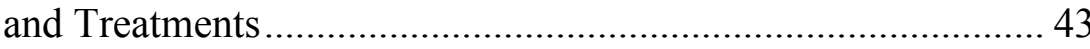

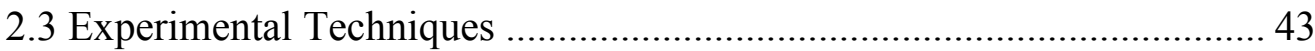

2.3.1 Immunocytochemistry ...................................................... 43

2.3.2 Total RNA Isolation and cDNA Synthesis ........................... 44

2.3.3 Quantitative Real Time RT-PCR ........................................ 45

2.3.4 Statistical Analysis.............................................................. 46

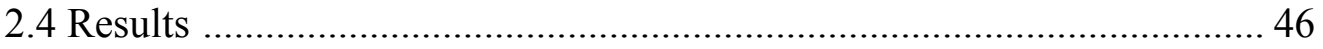


2.4.1 Combined $\mathrm{E} 2 / \mathrm{LiCl}$ increases factors involved in learning and memory ........................................................... 46

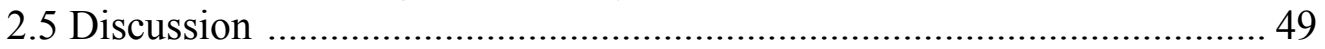

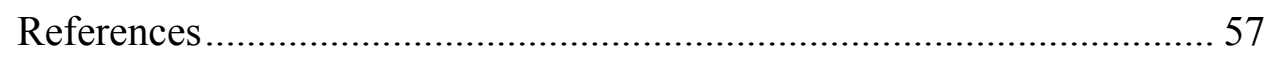

III. Lithium Enhances Episodic Memory and the Expression of Factors Involved in Learning, Memory and Anti-Apoptosis in

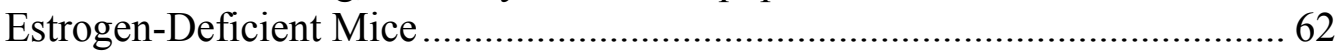

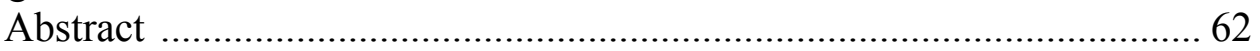

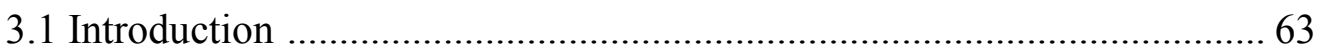

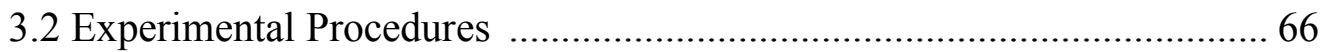

3.2.1 Subjects, Surgery and Treatment .............................................. 66

3.2.2 Object Recognition Task (ORT),

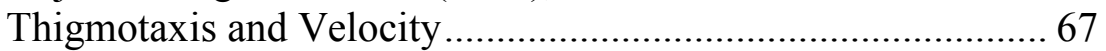

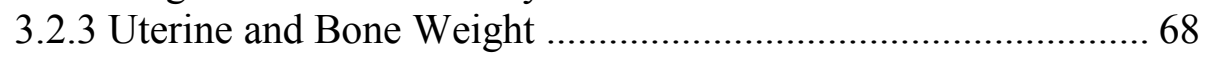

3.2.4 Total RNA Isolation and Reverse Transcription (RT) ............... 68

3.2.5 Quantitative Real Time RT-PCR ……………......................... 69

3.2.6 Protein Isolation and Western Blot ......................................... 70

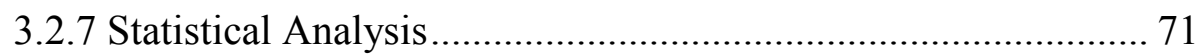

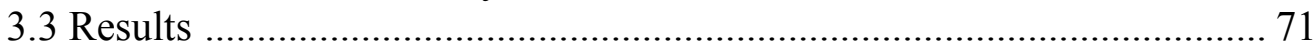

3.3.1 Removal of ovaries from mice resulted in weight gain ............. 71

3.3.2 An increase of episodic memory by $\mathrm{LiCl}$ in estrogen-

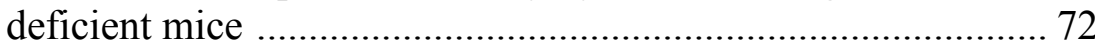

3.3.3 Bones and Uteri ...................................................................... 75

3.3.4 Altered levels of Bcl-2, BDNF, ER- $\alpha$ and NR1 by LiCl in estrogen-deficient mice........................................................... 77

3.3.5 Phosphorylated GSK-3 $\beta$ levels are altered by $\mathrm{LiCl}$................... 78

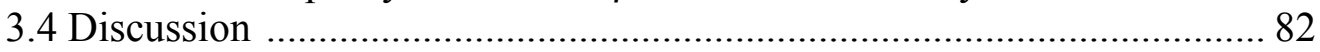

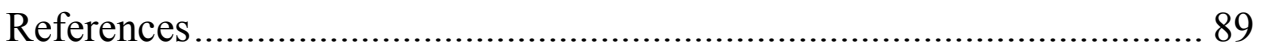

IV. Lithium: A Promising Alternative to Estrogen Replacement Therapy.............. 94

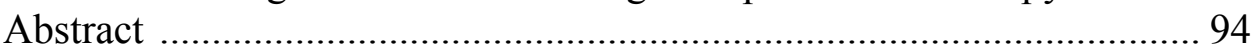

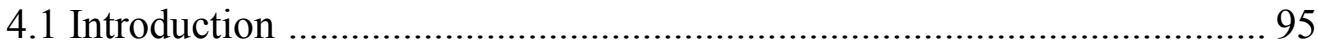

4.2 Neurosteroids and Estrogen Replacement Therapy ................................... 97

4.3 Learning, Memory and Neuroprotection via Estrogen/Estrogen

Receptor-mediated Pathways............................................................... 98

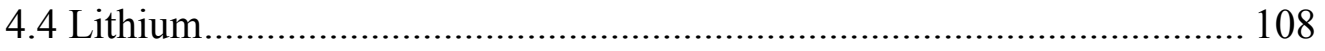

4.5 Estrogen and Lithium; or, Lithium as a Selective Estrogen-

Mediated Signaling Modulator ........................................................... 112

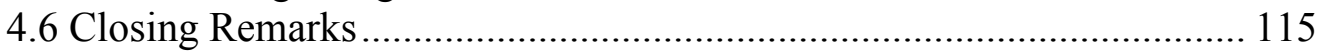

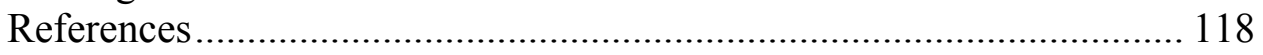

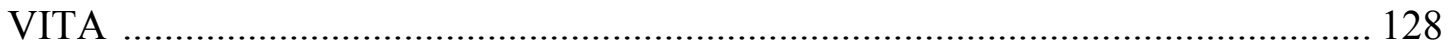




\section{LIST OF FIGURES}

FIGURE

PAGE

\section{CHAPTER I}

1A-D. ImageJ densitometric data obtained from RT-PCR and electrophoresis..... 16-18

2A-B. Quantitative RT-PCR of NR1 mRNA expression..

3A-B. Mean viability for glutamate excitotoxicity from $48 \mathrm{~h}$ treated cortical (grey bars) and hippocampal (black bars) primary cell cultures

\section{CHAPTER II}

1A-C. Real time RT-PCR of BDNF (A), Bcl-2 (B), and ER- $\alpha$ (C) mRNA expression.

2A-B. Immunocytochemical images of hippocampal cultures labeled with GFAP (A; 200X) and; NF-H (B; 400X) antibodies (green).

\section{CHAPTER III}

1. Weekly weight of experimental mice. 73

2A-C. Performance level on ORT (A), thigmotaxis (B) and velocity (C) using EthoVison XT (see Experimental Procedures section).

4A-D. Hippocampal and cortical mRNA expression for ER- $\alpha$ (A), NR1 (B), Bcl-2 (C), and BDNF (D) using quantitative RT-PCR $79-80$

5A-B. Hippocampal protein expression of NR1 (A) and BDNF (B). 81

6A-B. Hippocampal phosphorylated protein expression of pCREB at serine 133 (A) and pGSK-3 $\beta$ at serine 9 (B). 81

7A-B. Lithium and Estradiol blood content of C57BL/6J male mice. $83-84$ 


\section{CHAPTER IV}

1. Phosphorylating CREB at its serine 133 (green) causes a conformational change in its leucine zipper region (cyan) causing CREB to dimerize with CREB binding protein.

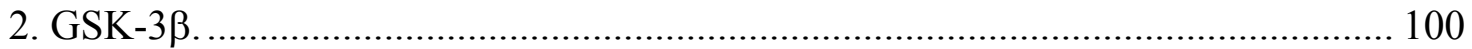

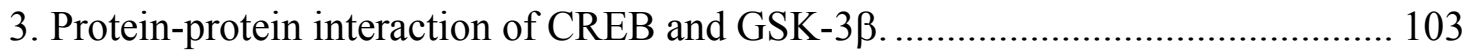

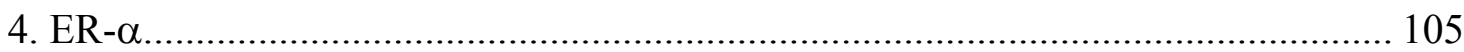

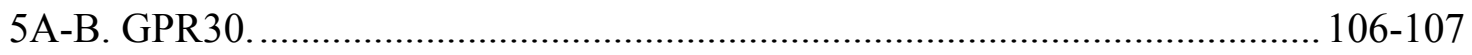

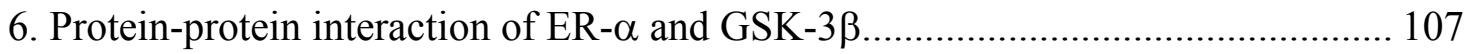

7. A post-synaptic cell signaling schematic of the mechanism described in this chapter. 


\section{LIST OF ACRONYMS AND ABBREVIATIONS}

$\mathrm{A} \beta$

$\mathrm{AD}$

ANOVA

APP

ATP

Bcl-2

bOVX

BDNF

cDNA

CREB

E2

ER

ERT

FDA/PI

Fisher's LSD

GFAP

GPCR

GSK-3 $\beta$ $\beta$-amyloid protein

Alzheimer's disease

Analysis of variance

Amyloid precursor protein

Adenosine triphosphate

B-cell lymphoma/leukemia-2

Bilateral ovariectomy

Brain derived neurotrophic

factor

Complementary

deoxyribonucleic acid

cAMP response element

binding protein

$17 \beta$-estradiol

Estrogen receptors ( $\alpha$, alpha; $\beta$, beta)

Estrogen replacement therapy

Fluorescein

diacetate/propidium iodide

Fisher's least significant difference

Glial fibrillary acidic protein

G-protein coupled receptor

Glycogen synthase kinase3 beta 
HPRT

$\mathrm{LiCl}$

LTP

LTD

MAPK

mRNA

NF-H

NFT

NMDAR

NR1

ORT

PELP1

PI3-K

PKA

Akt/PKB

PKC

qRT-PCR

SP

$\tau$
Hypoxanthine-guanine phosphoribosyltransferase

Lithium chloride

Long-term potentiation

Long-term depression

Mitogen-activated protein kinase

Messenger ribonucleic acid

Neurofilament-heavy chain

Neurofibrillary tangles

$\mathrm{N}$-methyl-D-aspartate receptor

$\mathrm{N}$-methyl-D-aspartate receptor subunit 1

Object recognition task

Proline-, glutamic acid-, and leucine-rich protein-1

Phosphatidylinositol-3-kinase

cAMP dependent protein kinase

Protein kinase B

Protein kinase C

Quantitative Reverse transcription polymerase chain reaction

Senile plaques

Tau protein 


\section{PREFACE}

Prior to my acceptance into the Biological Sciences graduate program at Florida International University I volunteered in the laboratory of my major advisor, Dr. Ophelia Inez Weeks. I was immediately assigned to statistically analyze and interpret a behavioral study conducted by Dr. Claude-Henry Volmar, at the time a former Biology master's graduate. The behavioral study was to test the performance of lithium-treated C57BL/6J male mice on an object recognition task (ORT), a task that measures episodic memory. An ORT involves mice recalling specific objects they were primed to remember and their ability in recognizing novel objects. The hypothesis was that the lithium-treated group will spend a greater amount of time with the novel object compared with the control group. Statistical analysis of these experiments supported the hypothesis that in these mice lithium increases episodic memory (e.g., novel object recognition). Shortly after, an undergraduate at the time, Pablo Penaloza, analyzed lithium content using blood samples from treated and control mice. Lithium-treated mice showed a higher lithium-blood content than control. Later, during my pre-doctoral studies, I showed the lithium dosage used in the ORT study increases inhibition of a multifaceted enzyme controlling transcription, cell death, mood-disorders, and neurodegenerative diseases (a topic discussed throughout this dissertation).

Using the same blood samples from the ORT study, Pablo and I hypothesized that since lithium and estrogen affect similar molecular pathways in the brain, there will be an inverse correlation in estrogen versus lithium content in the blood - low estrogen content 
with high lithium content or vice versa. Results from this analysis rejected our hypothesis, since lithium raised estrogen levels in murine serum (unpublished data) - I was still interested in the molecular relation lithium and estrogen share, though. These molecular relations led to the overarching goal of my dissertation, that is: 1) to provide a better understanding of how lithium and estrogen affect specific molecular markers in the brain related to cell growth and survival (e.g. neuroprotection), learning and memory; and, 2) if lithium alone can increase these molecular markers and increase episodic memory in an estrogen-deficient model. I anticipate that a better understanding of such mechanisms will offer avenues for developing palliative therapies for postmenopausalrelated cognitive decline and neurodegeneration.

To answer whether or not lithium influences estrogen-related pathways I used primary brain cell cultures of fetal $\mathrm{C} 57 \mathrm{BL} / 6 \mathrm{~J}$ mice (the highlights from those experiments are noted in chapters one and two of my dissertation). I initially intended to harvest and culture neurons for these experiments, unfortunately I cultured glia, the dominant brain cell type. Glia not only provides support, nutrition, and maintenance of neurons but also facilitates neuronal communication and growth. Notwithstanding, I continued to analyze these samples and something fascinating happened: I obtained viable and interesting results. I used quantitative polymerase chain reaction ( $\mathrm{qPCR}$ ) and cell viability assays to generate and interpret data, revealing that lithium reduced estrogen-regulated gene expression of glutamate receptors involved in learning and memory. Furthermore, lithium provided protection to glial cells against toxic levels of glutamate, and estrogen 
reduced this protective quality. A manuscript derived from these studies was submitted and accepted to the journal Brain Research.

Using the genetic material from these same experiments I generated another manuscript (chapter two). The second set of analyses addressed how combined treatment of estrogen and lithium affect gene expression of factors involved in learning, memory, and neuroprotection. Using qPCR interpreted data showed that combined treatment of estrogen and lithium increases factors (i.e., transcription factors, proteins) involved in learning and memory, but not neuroprotection among glia-rich cultures. Chapter two is currently under review for publication in the journal Neuroscience Letters.

To test whether lithium alone can enhance learning and memory (and molecular markers involved in these processes), I used estrogen-deficient mice (i.e. both ovaries were removed). Estrogen-deficient mice were treated with lithium for one month. This project utilized all the techniques I acquired up to this point to examine cognitive, neuroendocrine and biochemical parameters. Results are specified in chapter three, and indicate that lithium-treated estrogen-deficient mice, compared with non-treated estrogen-deficient mice, show an increased performance in ORT (e.g. episodic memory). The observed increase in performance coincides with an increase in specific molecular makers in the brain involved in learning, memory and neuroprotection.

The final chapter of my dissertation (chapter four) is a literature review aided by protein modeling techniques and in silico research. Chapter four examines how lithium 
and estrogen affect similar proteins involved in neuroprotection, learning and memory. Extensive reports have examined neurological pathways associated with lithium and estrogen individually, and my review serves as a bridge between lithium and estrogen by recognizing possible links between them - in a molecular sense. I chose this as my last chapter to encapsulate a theoretical mechanism of my dissertation and to provide a platform for future studies incorporating my experimental parameters.

Ultimately, my dissertation investigates how estrogen and lithium affect molecular markers in the brain involved in learning, memory and neuroprotection. Postmenopausal women suffer from a lack of circulating estrogen and are often prescribed hormone replacement therapy; but some also suffer from depression and are often prescribed antidepressants. Understanding the interactions of estrogen and lithium will provide a better treatment regime for post-menopausal women. As I show in this dissertation, lithium alone increases episodic memory in estrogen-deficient mice. This interpretation may market lithium as a palliative treatment for post-menopausal-related cognitive decline - although lithium is traditionally used for treating psychiatric disorders. 


\section{CHAPTER I}

Estradiol and Lithium Chloride Specifically Alter Glutamate Receptor Subunit Genetic Expression and Excitotoxicity in Primary Cultures

\section{Abstract}

Glutamate facilitates calcium influx via $N$-methyl-D-aspartate (NMDA) receptor, and excess calcium influx increases excitotoxicity - a pathological characteristic of neurological diseases. Both $17 \beta$-estradiol (E2) and lithium influence NMDA receptor expression/signaling and excitotoxicity. This led me to hypothesize that combined E2 and lithium will alter NMDA receptor expression and excitotoxicity. I tested this hypothesis using primary cell cultures from the cortex and hippocampus of C57BL/6J fetal mice pretreated with $\mathrm{E} 2$, lithium chloride ( $\mathrm{LiCl})$ and combined $\mathrm{E} 2 / \mathrm{LiCl}$ for 12,24 or $48 \mathrm{~h}$. I examined cultures for brain cell type and changes in cell type caused by experimental procedures using glia and neuron gene specific primers. These cultures expressed increased glial fibrillary acidic protein (GFAP) mRNA with low neurofilament-heavy chain (NF-H) mRNA expression. Subsequent analysis of cortical cell cultures indicated that combined $\mathrm{E} 2 / \mathrm{LiCl}$ decreased NR1 mRNA expression after a 12 and $48 \mathrm{~h}$ treatment period. Combined E2/LiCl also reduced NR1 mRNA expression in hippocampal cultures but only after a $48 \mathrm{~h}$ treatment period. Hippocampal LiCltreated cultures also reduced NR1 mRNA expression after a 24 and $48 \mathrm{~h}$ treatment. I next examined the response of $48 \mathrm{~h}$ pretreated cultures to a toxic level of glutamate. Excitotoxicity was measured using fluorescein diacetate/propidium iodide (FDA/PI) cell viability assay. Results from $\mathrm{FDA} / \mathrm{PI}$ assay revealed that $\mathrm{LiCl}$ pretreatment increased 
viability for cortical cultures while $\mathrm{E} 2$ and combined $\mathrm{E} 2 / \mathrm{LiCl}$ reduced viability. All pretreatments for hippocampal cultures failed to increase viability. My results showed combined $\mathrm{E} 2 / \mathrm{LiCl}$ reduced NR1 mRNA and prevented protection against glutamate excitotoxicity in glial primary cultures.

\subsection{Introduction}

Estrogen-mediated neurobiological processes are involved in a myriad of signal transduction pathways. These pathways result in enhancing synaptic plasticity [31], reducing apoptotic activity in cortical neurons [21], regulating neurotrophic factors [55], and facilitating transcription factor activation - e.g. cAMP response element binding protein (CREB) [36]. Estrogen is considered an activating agent in $N$-methyl-D-aspartate (NMDA) receptor signaling pathways [24], and NMDA receptor forms a heteromeric glutamate receptor composed of the subunits NR1, NR2A-D and NR3 [56]. Expression of NR1, NMDA receptor critical subunit, is increased in estrogen-induced primary hippocampal neuronal cell cultures [24]. Similar cultures show increased levels of intracellular calcium, mediated by the activation of L-type calcium channels, which in turn promote signaling pathways that activate/phosphorylate CREB. This activation/phosphorylation promotes anti-apoptotic events [59]. Estrogen also facilitates a transient activation of glycogen synthase kinase-3beta (GSK-3 $\beta$ ). Estrogen receptor$\alpha($ ER- $\alpha)$, when bound by its ligand estrogen, forms a complex with GSK-3 $\beta$ that facilitates regulation of beta-catenin transcriptional properties [7]. Response element binding of ER- $\alpha$ relies on GSK-3 $\beta$ phosphorylation and this phosphorylation is inhibited in the presence of lithium [37]. Contrary to this synergistic relation of ER- $\alpha$ and GSK- 
$3 \beta$, other studies show estrogen facilitating an inhibition of GSK-3 $\beta$. This inhibition is dependent on kinase phosphorylation mediated by estrogen receptor signaling [16]. Interestingly, GSK-3 $\beta$ activity influences NMDA receptor signaling and NMDA receptor subunit expression. Electrophysiological studies using mouse hippocampal slices report that GSK-3 $\beta$ activity is increased during long-term depression. This increase reduces during NMDA receptor-mediated long-term potentiation [46]. Selective GSK$3 \beta$ inhibitors also reduce NMDA receptor synaptic currents and receptor internalization in cortical cell cultures. Cultures expressing a knockdown of GSK-3 $\beta$ exhibit similar effects [8].

Over a decade has passed since Klein and Melton (1996) demonstrated lithium specifically inhibiting GSK-3 $\beta$ [28]. This inhibition is associated with reducing apoptotic activity [22], increasing neurotrophic factors [2], and facilitating CREB DNA binding $[17,45]$. Though the mechanism remains elusive, lithium indirectly inhibits GSK-3 $\beta$ by activating protein kinases that phosphorylate GSK-3 $\beta$ at serine 9 and/or by inactivating phosphatases that remove this phosphate group [26]. Direct inhibition involves lithium acting as a competitive inhibitor of magnesium; magnesium being a cofactor for ATP in GSK-3 $\beta$ activation [52]. Aside from lithium's inhibitory action on GSK-3 $\beta$, there is an indirect effect on NMDA receptor signaling pathway. This involves reducing phosphorylation/activation of Src tyrosine kinases, potentially affecting any NMDA receptor-regulated excitotoxicity. Phosphorylation of NR2 subunits of NMDA receptor by Src tyrosine kinases is essential for the receptor's signal transduction activity [see 18]. 
Using lithium-treated rat cerebral cortex neurons, Hashimoto et al. (2003) demonstrated that phosphorylated levels of Src tyrosine kinase is decreased in a time-dependent fashion. Lithium, however, does not seem to influence NMDA receptor subunit protein expression [44].

Expression of NR1 increases in estrogen-treated primary hippocampal neuronal cultures [24], and similar cultures also show increase intracellular calcium levels [59]. But lithium reduces NMDA receptor-mediated glutamate excitotoxicity by reducing calcium influx [10]. While NMDA receptor is classically regarded as a neuronal receptor, these receptors are also found on cortical astrocytes [12]. Astrocytes process the neurotransmitter glutamate to reduce excitotoxic insults to neurons; however, astrocytes themselves are not as susceptible to excitotoxicity as are neurons [see 35]. In astrocyte cultures from the rat olfactory bulb, estrogen receptor agonists reduce secretion of specific markers responsible for inflammatory responses (e.g. interleukin-1, tumor necrosis factor- $\alpha$, and matrix metallopeptidase 9) [32]. As well, astrocytes produce and secrete estrogen, influencing communication among neurons. When cultures of rat cortical neurons are exposed to media from cultured astrocytes, neuronal synaptic formation and impulse transmission increase, due to the presence of estrogen in the astrocytic media [23].

Glutamate excitotoxicity mediated by NMDA receptor is a pathological element in many neurodegenerative diseases and analysis of how combined estrogen and lithium influence NMDA receptor regulation and its mediated pathways are wanting. Since 
estrogen and lithium are involved in regulating NMDA receptor activation/function I hypothesized that combined estrogen (specifically 17ß-estradiol; E2) and lithium chloride $(\mathrm{LiCl})(\mathrm{E} 2 / \mathrm{LiCl})$ will alter mRNA expression of NMDA receptor subunit NR1 in primary cultures harvested from mouse cortex and hippocampus. The premise of this hypothesis is that estrogen receptor- $\alpha$ facilitates NMDA receptor subunit expression and studies have shown that estrogen receptor- $\alpha$ response element binding is attenuated in the presence of lithium [37]. My results indicate that combined $\mathrm{E} 2 / \mathrm{LiCl}$ treatment reduce NR1 mRNA expression of primary cultures expressing high levels of glial-specific mRNA. I chose this course of study since glia express NR1 [12], and NR1 is the critical subunit of a functional NMDA receptor. These results led me to further hypothesize that amongst these primary glial cultures combined $\mathrm{E} 2 / \mathrm{LiCl}$ will alter protective features (cell viability) against glutamate insult. I tested this hypothesis using a cell viability assay with $48 \mathrm{~h}$ pre-treated primary cultures exposed to high levels of glutamate. High glutamate concentration was necessary since glia are extremely tolerant to excitotoxicity [see 35]. My results indicated that while LiCl reduced NR1 mRNA in E2-treated cultures, E2 compromised cell viability in $\mathrm{LiCl}$ treated cultures. In many instances postmenopausal women undergoing hormone therapy are also prescribed lithium (for depression) and the interaction of these two agents are poorly understood. This is the first study to note the influence of combined $\mathrm{E} 2 / \mathrm{LiCl}$ on expression of receptors involved in learning, memory and mediating excitotoxic effects. 


\subsection{Experimental Procedures}

\subsubsection{Primary Mixed Brain Cell Cultures}

I used $\mathrm{C} 57 \mathrm{BL} / 6 \mathrm{~J}$ mice bred at Florida International University. Animals were kept in an environment of $22^{\circ} \mathrm{C}$ temperature, $60 \%$ humidity, within polycarbonate transparent cages $(26.7 \mathrm{~cm} \times 20.6 \mathrm{~cm} \times 14 \mathrm{~cm})$ on a $12 \mathrm{~h}$ day-night cycle with free access to water and food. All experiments were approved by the Institutional Animal Care and Use Committee (Approval Number: 08-017). Primary cultures were harvested from E18.5 C57BL/6J mice. Pregnant mice $(n=$ 5) were euthanized by cervical dislocation, E18.5 fetal mice were then removed via caesarian section, decapitated, brains removed, and placed in ice-cold Earle's balanced salt solution (EBSS; Hyclone, Utah). The cortex and hippocampus from each hemisphere were isolated under a dissecting microscope and washed with fresh ice-cold EBSS. Tissue was mechanically triturated, passed through a $70 \mu \mathrm{m}$ pore filter, and cells were counted using a hemocytometer. Disassociated cells were randomly plated $\left(6 \times 10^{6}\right.$ for cortical cultures and $3 \times 10^{6}$ for hippocampal cultures) on poly-D-lysine (100 $\mathrm{g} / \mathrm{mL}$; Sigma-Aldrich, Missouri) coated 12-well plates containing B27/Neurobasal medium (Invitrogen, California) with $0.5 \mathrm{mM}$ L-glutamine and $4 \mu \mathrm{g} / \mathrm{mL}$ gentamicin. Additional 12-well plates, with poly-Dlysine $(100 \mu \mathrm{g} / \mathrm{mL})$ coated coverslips were set aside for viability assessment. Cells were maintained in a humidified, $5 \% \mathrm{CO}_{2}$ atmosphere incubator with a set temperature of $37^{\circ} \mathrm{C}$. After 4 days in culture, the media was removed entirely and replaced with fresh media; half of the media was changed every 4 days, thereafter, until $\mathrm{E} 2$ and/or $\mathrm{LiCl}$ treatment. 


\subsubsection{Chemicals and Treatments}

After twelve days in culture, the media was removed entirely and replaced with media treated with $10 \mathrm{mM} \mathrm{LiCl}$ (Sigma-Aldrich, Missouri), $0.04 \mu \mathrm{M}$ E2 (Sigma-Aldrich, Missouri), or combined E2 and LiCl. Duration of treatment for each group was 12,24 , and $48 \mathrm{~h}$. Additionally, cell viability was measured using $48 \mathrm{~h}$ pretreated cells exposed to $100 \mu \mathrm{M}$ glutamatic acid (Sigma-Aldrich, Missouri) for $1 \mathrm{~h}$ at $37^{\circ} \mathrm{C}$.

\subsection{Experimental Techniques}

\subsubsection{Total RNA Isolation and cDNA Synthesis}

Total RNA was extracted from cultured cells after treatment with TRIzol reagent (GIBCO, California), according to manufacturer's protocol. Briefly, cultures were rinsed with ice-cold DPBS, TRIzol Reagent $(600 \mu \mathrm{L}-1 \mathrm{~mL})$ was added directly into each well, and cultures were homogenized. Homogenized cells were then transferred to a fresh tube, and incubated at room temperature. Chloroform was added and centrifuged at 10, $000 \mathrm{rpm}$ at $4^{\circ} \mathrm{C}$. Total RNA (aqueous phase) was transferred to a sterile tube and allowed to precipitate with isopropanol and glycogen overnight at $-20^{\circ} \mathrm{C}$. The RNA was pelleted via centrifugation at $10,000 \mathrm{rpm}$ at $4{ }^{\circ} \mathrm{C}$, supernatant was decanted and RNA pellet was washed twice with $75 \%$ ethanol. Pellets were then air dried and resuspended with DEPC-treated water. Contaminants of DNA were removed with the RQ1 DNase kit (Promega, Wisconsin). Samples were stored at $-80^{\circ} \mathrm{C}$ until they were further processed. 
Reverse transcription (RT) was performed using SUPERSCRIPT ${ }^{\mathrm{TM}}$ II RNase Hfree reverse transcriptase (Invitrogen, California), according to the manufacturer's protocol. Briefly, 500ng of total RNA was reverse transcribed with $0.05 \mu \mathrm{g} / \mu \mathrm{l}$ of Oligo $(\mathrm{dT})_{12-18}$ at $65^{\circ} \mathrm{C}$ for 5 minutes. First strand cDNA was synthesized with $5 \mathrm{mM} \mathrm{MgCl}_{2}$, $10 \mathrm{mM}$ DTT, and 1.5 units Superscript II and incubated at $42^{\circ} \mathrm{C}$ for 50 minutes; reaction was terminated at $70^{\circ} \mathrm{C}$ for 15 minutes. The RNase $\mathrm{H}$ (Invitrogen, California) was incubated at $37^{\circ} \mathrm{C}$ for 20 minutes once the first strand was synthesized to remove any remaining RNA.

\subsubsection{Cell-Typing Cultures using RT-PCR and Gel Electrophoresis}

First strand cDNA was amplified via real time polymerase chain reaction (PCR) using NF-H (forward primer 5'-AGCCCAAGGACTCTACAGCA-3'; reverse primer, 5'CTTTGGCTTTTCCGTCTCTG-3') and GFAP (forward primer 5'AGAAAACCGCATCACCATTC-3'; reverse primer, 5'-TCACATCACCACGTCCTTGT -3') and GoTaq ${ }^{\circledR}$ (Promega, Wisconsin). Cycling parameters for an Eppendorf Mastercycler Gradient were set for: denaturing at $95^{\circ} \mathrm{C}$ for 30 seconds, annealing temperature of $57^{\circ} \mathrm{C}$ or $64^{\circ} \mathrm{C}$ for 30 seconds, and extension at $72^{\circ} \mathrm{C}$ for 30 seconds, for a total of 30 cycles, followed by a final extension at $72^{\circ} \mathrm{C}$ for 10 minutes. After amplification, samples were subjected to gel electrophoresis using a $1.5 \%$ agarose gel stained with ethidium bromide and photographed using Digital Imaging Filter/Ethidium Bromide (Fotodyne, Wisconsin) under UV light. Resulting band intensities were based on two replicates and analyzed using ImageJ software band analyzer [49]. Measurements

are represented in arbitrary units and obtained by dividing the pixel integrated density 
(integrated density $=$ area $\mathrm{x}$ mean pixel value) from each band of NF-H or GFAP by the absolute intensity of the standard - HPRT.

\subsubsection{Quantitative Real Time RT-PCR}

First strand cDNA was amplified via real time PCR using SYBR Green PCR master mix (ABgene, New York), 200-300nM of forward and reverse primers using iCycler (BioRad, California) with IQ iCycler software (version 3.1). Cycling parameters were set at: $95^{\circ} \mathrm{C} 15 \mathrm{~s}, 57^{\circ} \mathrm{C} 30 \mathrm{~s}$, and extension at $72^{\circ} \mathrm{C}$ for $30 \mathrm{~s}$, for a total of 40 cycles, followed by a final extension at $72^{\circ} \mathrm{C}$ for 10 minutes. The specific primer pairs were: NMDA receptor subunit NR1: forward primer, 5'-ACTCCCAACGACCACTTCAC-3; reverse primer, 5'-GTAGACGCGCATCATCTCAA-3'; HPRT: forward primer, 5'GGAGCGGTAGCACCTCCT-3'; reverse primer, 5'-AATCCAGCAGGTCAGCAAAG3'. All samples were compared with a standard curve comprised of pDNA of HPRT and NR1 with pDNA generated using TOPO TA Cloning ${ }^{\circledR}$ Kit (Invitrogen, California). Readings were normalized by dividing mRNA starting quantity (SQ) of NR1 by the house-keeping gene HPRT mRNA SQ; output is in femtograms (fg) of mRNA.

\subsubsection{Cell Viability - Fluorescein Diacetate/Propidium Iodide Assay}

Cortical and hippocampal cells were cultured on $18 \mathrm{~mm}$ coverslips cultures and pretreated for $48 \mathrm{~h}$ with $\mathrm{E} 2, \mathrm{LiCl}$, and combined $\mathrm{E} 2$ and $\mathrm{LiCl}$ (as described previously). Excitotoxicity was induced for $1 \mathrm{~h}$ with $100 \mu \mathrm{M}$ glutamate. Cell viability of cultures was determined after glutamate excitotoxicity through the use of a fluorescein diacetatepropidium iodide labeling technique [25]. Briefly, cells were quickly rinsed with ice-cold 
Dulbecco's Phosphate Buffer Saline (DPBS). Approximately $150 \mu \mathrm{L}$ cocktail of $2 \mu \mathrm{g} / \mathrm{mL}$ of fluorescein diacetate and $0.6 \mu \mathrm{g} / \mathrm{mL}$ propidium iodide was added directly to the coverslip with adhered cells and incubated at room temperature. Each $18 \mathrm{~mm}$ coverslip was placed against a grid and images were captured from five subdivisions on the grid (upper right, upper left, lower right, lower left, and center). Images were captured from 3 replicates per subdivision - a total of 15 images per coverslip - with a Leica inverted epifluorescent microscope with a QImaging Micropublisher 3.3 cooled RTV camera and processed using ImageJ Cell Counter. For a comparison prior to any experimental procedure I assayed a separate culture designated as Initial Viability.

\subsubsection{Statistical Analysis}

Data are presented as the mean \pm S.E.M and statistical significance was determined by analysis of variance (ANOVA) followed by Fisher's least significant difference (LSD) post-hoc testing. Significant differences have a p-value $<.05$. All results were obtained from two separate experimental procedures - except for glutamate excitotoxicity which was based on triplicates from one experiment (see section 4.3.4 in Experimental Procedures). Each level for all factors was randomly determined.

\subsection{Results}

1.4.1 Brain cell typing of primary cultures indicated predominance for glia

Figures 1A-D depicts densitometric data (gene/HPRT) obtained after RT-PCR and gel electrophoresis (gels represented above the graph). I chose to analyze brain cell type using gene specific primers for neurons and glia. The use of specific primers 
allowed me to monitor brain cell type and to monitor how my experimental parameters affected neuronal and glial gene expression. I used gene specific primers for glial fibrillary acidic protein (GFAP) and neurofilament heavy chain (NF-H), markers readily used for identifying glial and neuronal populations, respectively. Using ANOVA, densitometric data indicated a significant difference in gene expression $(p<.001)$. These primary cell cultures expressed high levels of GFAP mRNA (figures 1A \& C) but with consistently low levels of NF-H mRNA (figures 1B \& D).

My experimental parameters altered genes expression for cortical but not hippocampal cultures. Expression of GFAP mRNA gradually increased for cortical cultures during the 12, 24, and $48 \mathrm{~h}$ period (figure 1A), while hippocampal cultures maintained consistency in GFAP expression (figure 1B). Expression of NF-H, however, was more abundant in hippocampal cultures (figure 1D) compared with cortical cultures (figure 1B) and this was consistent throughout treatment periods. Treatment did not affect GFAP or NF-H mRNA expression within each respective culture type (cortical or hippocampal). Overall, densitometric data demonstrated that both culture types expressed high levels of GFAP mRNA compared with NF-H indicating these cultures were predominantly glial. 
$1 \mathrm{~A}$.

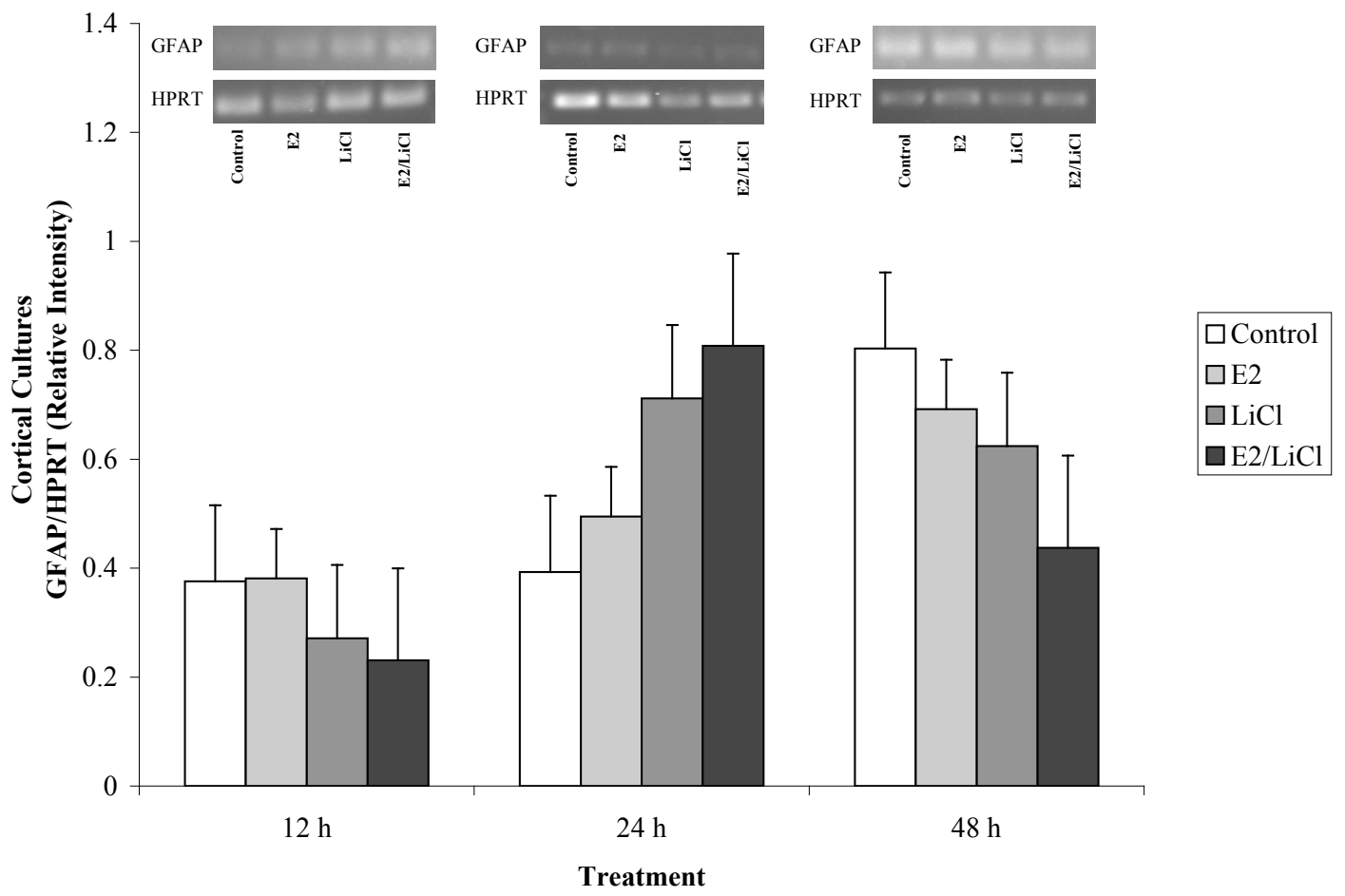

$1 B$.

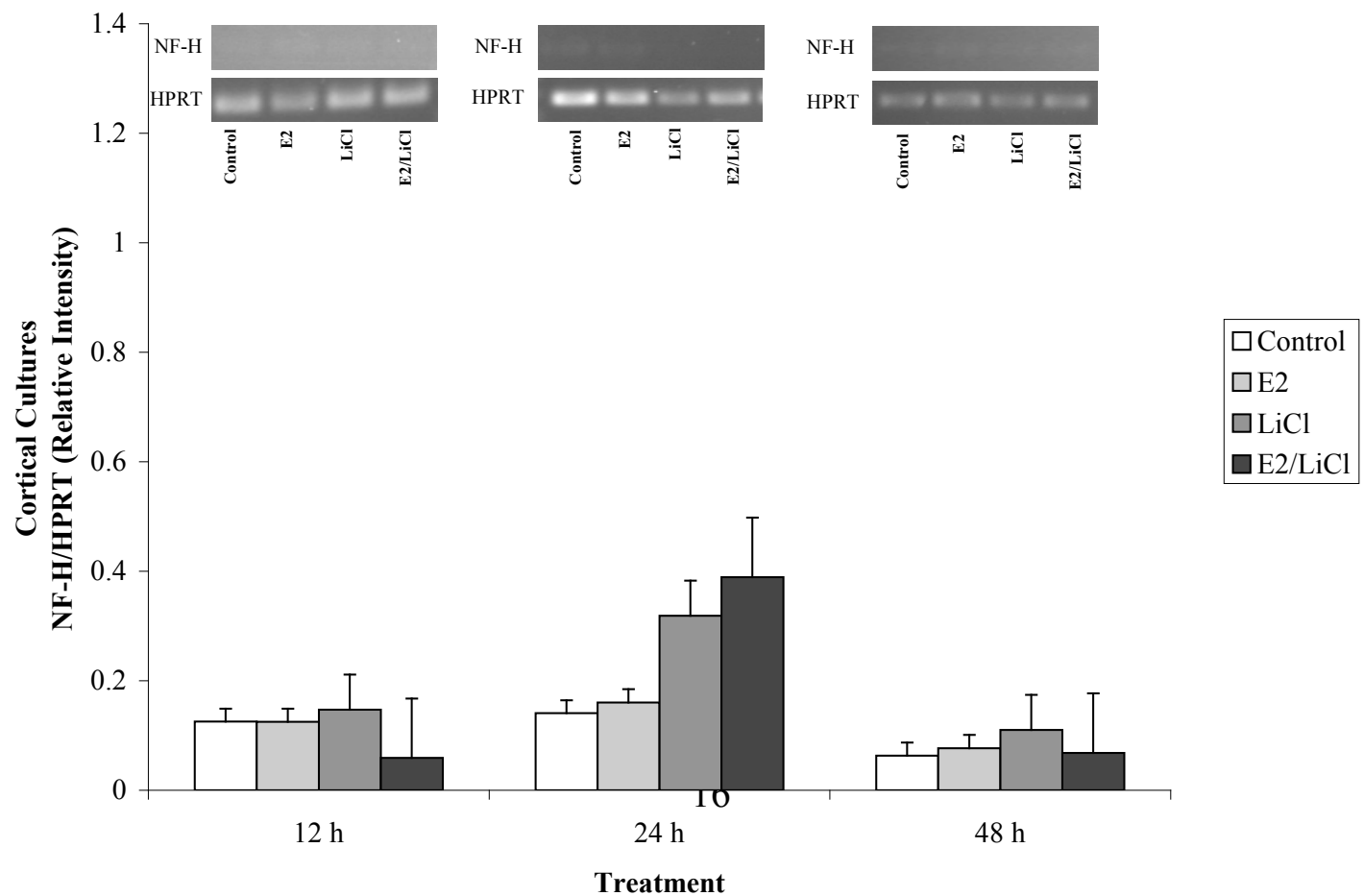


1C.

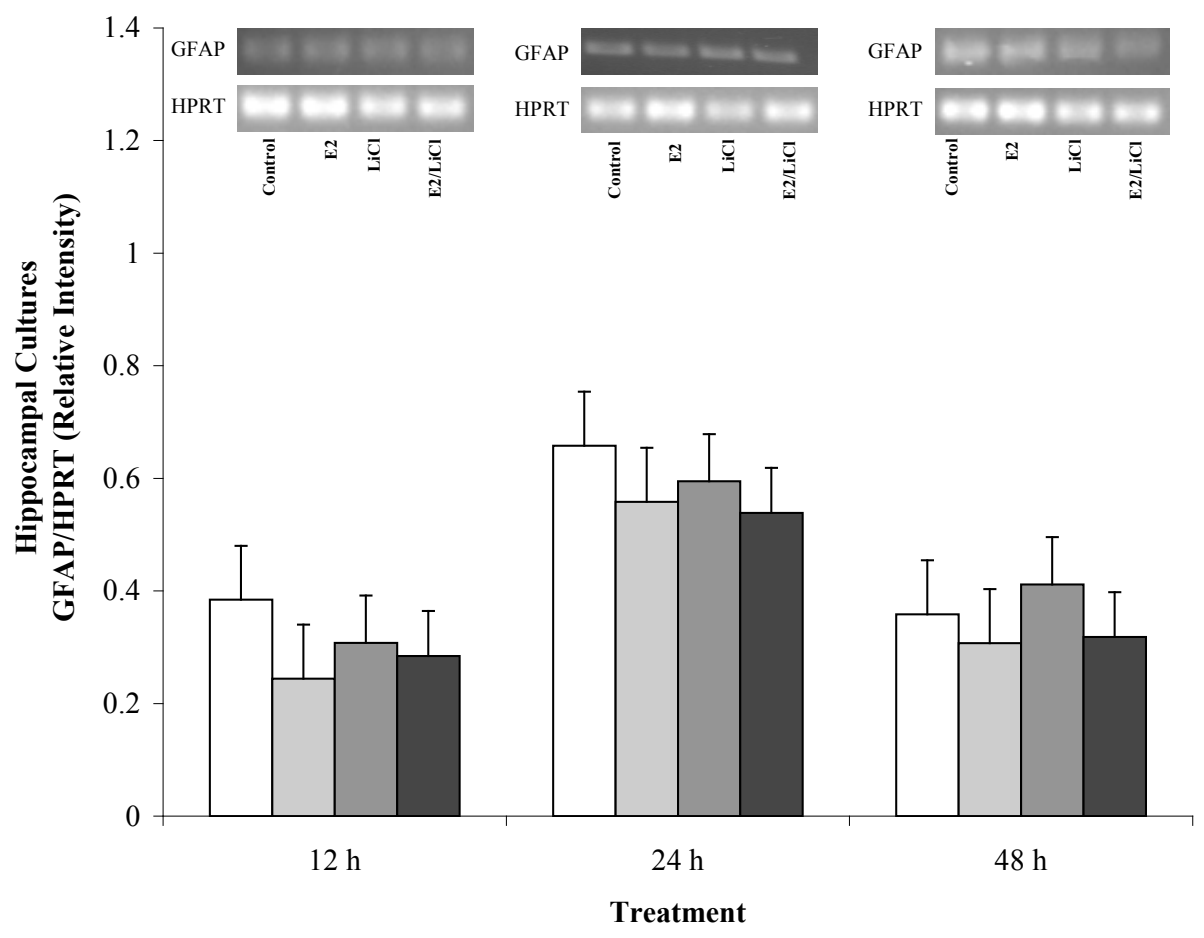

$\square$ Control $\square \mathrm{E} 2$ $\square \mathrm{LiCl}$

$\square \mathrm{E} 2 / \mathrm{LiCl}$

$1 D$.

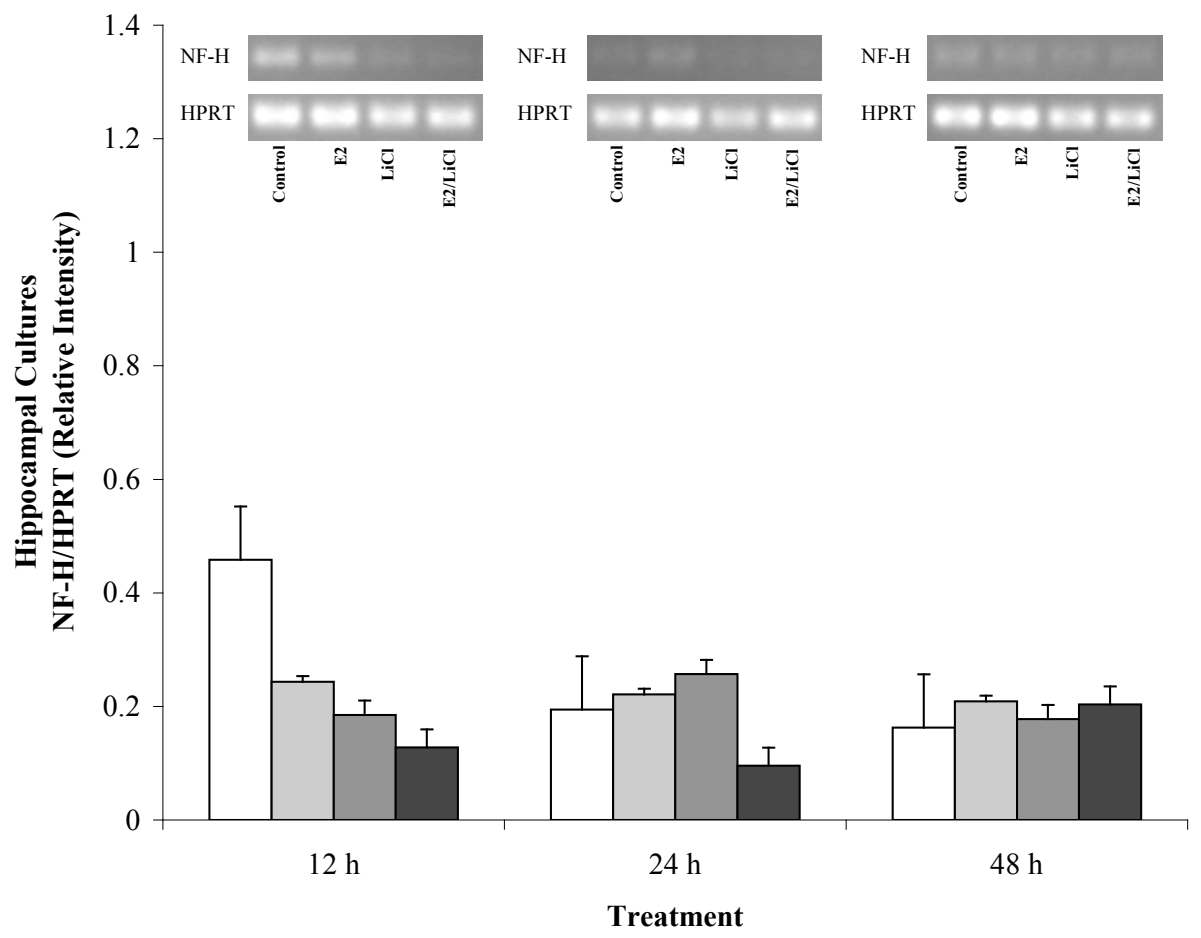

$\square$ Control

$\square \mathrm{E} 2$

$\square \mathrm{LiCl}$

$\square \mathrm{E} 2 / \mathrm{LiCl}$ 
Figures 1A-D: ImageJ densitometric data obtained from RT-PCR and electrophoresis. Analysis was performed via electrophoresis of RT-PCR samples using a 1.5\% agarose gel, gel images captured, and analyzed using ImageJ. Low visibilities of bands are due to low mRNA expression. Total RNA from and reverse transcribed E18.5 cortical (A \& B) and hippocampal (C \& D) primary cell cultures were isolated from Control (no treatment), $0.04 \mu \mathrm{M} \mathrm{E2,} \mathrm{10mM} \mathrm{LiCl,} \mathrm{and} \mathrm{combined} \mathrm{E2/LiCl} \mathrm{treated} \mathrm{for} \mathrm{12,} \mathrm{24,} \mathrm{and} 48 \mathrm{~h}$. cDNA was then amplified via PCR using gene specific primers for GFAP (A \& C) or NF-H (B \& D). Measurements were based on relative pixel intensity (integrated intensity of GFAP/HPRT or NF-H/HPRT) and expressed in arbitrary units. Gels are represented for each gene and treatment period (represented above the graph).

\subsubsection{Combined E2/LiCl treatment reduced NR1 mRNA expression}

Next, I examined the effect of my experimental design on NR1 mRNA expression. The critical subunit of the NMDA receptor is NR1 and no studies have investigated how combined $\mathrm{E} 2 / \mathrm{LiCl}$ affects $\mathrm{NR} 1$ expression in glial cultures. Additionally, in analyzing NR1 gene expression I can postulate transcriptional activity caused by my treatment parameters. Interpretation of ANOVA on real time RT-PCR data showed significant differences $(\mathrm{p}<.001)$ in NR1 mRNA expression related to treatment. 
Both treated culture types (cortical and hippocampal) slightly differed in overall NR1 mRNA expression (figures $2 A \& B$ ), but this difference was not significant $(p>.057)$. No significant changes were noted across treatment periods $(p>.2)-$ e.g., in a timedependent fashion; although, NR1 expression significantly changed among treated culture types at specific time periods $(\mathrm{p}<.001)$.

$2 \mathrm{~A}$.

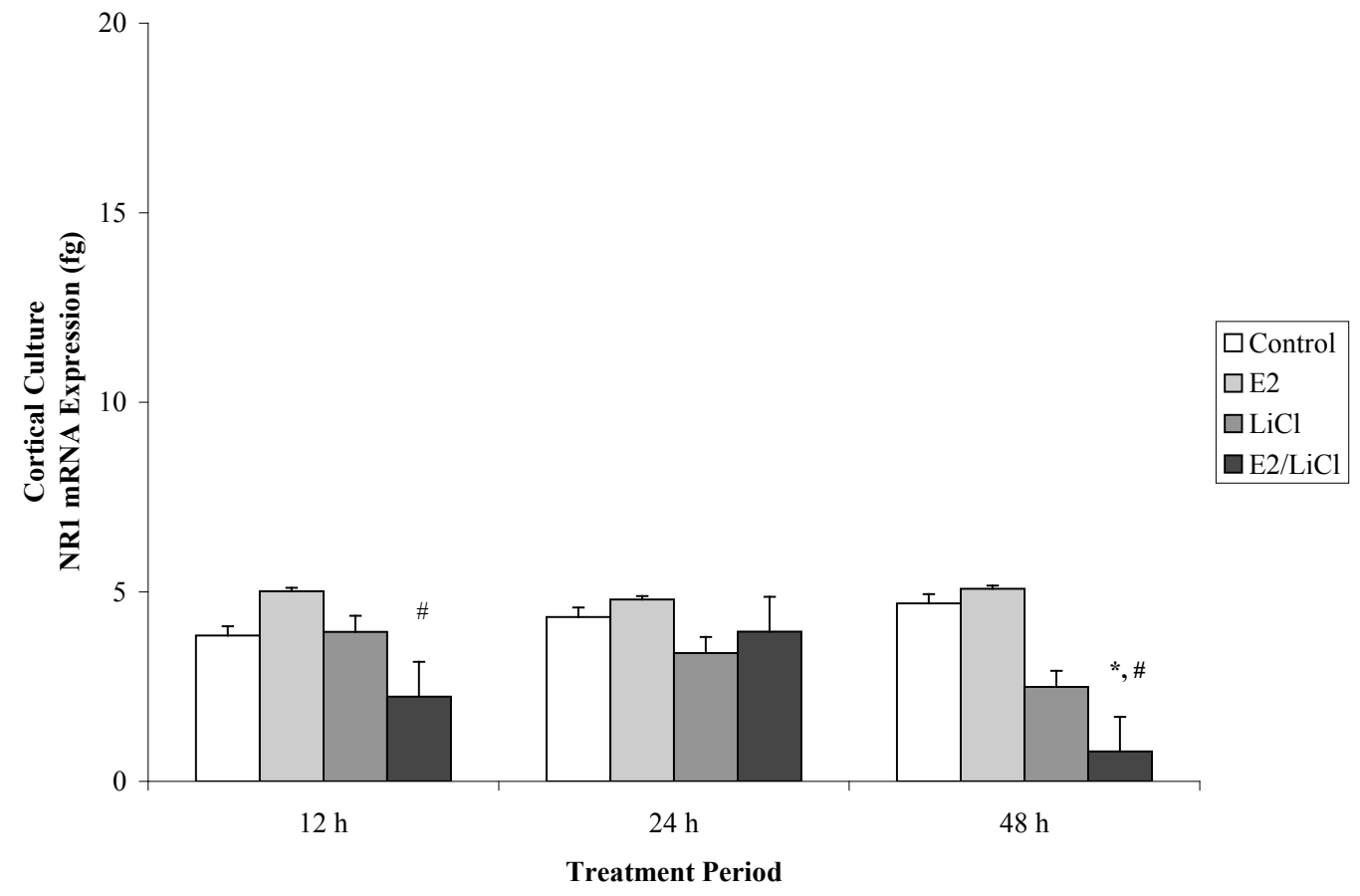

2B.

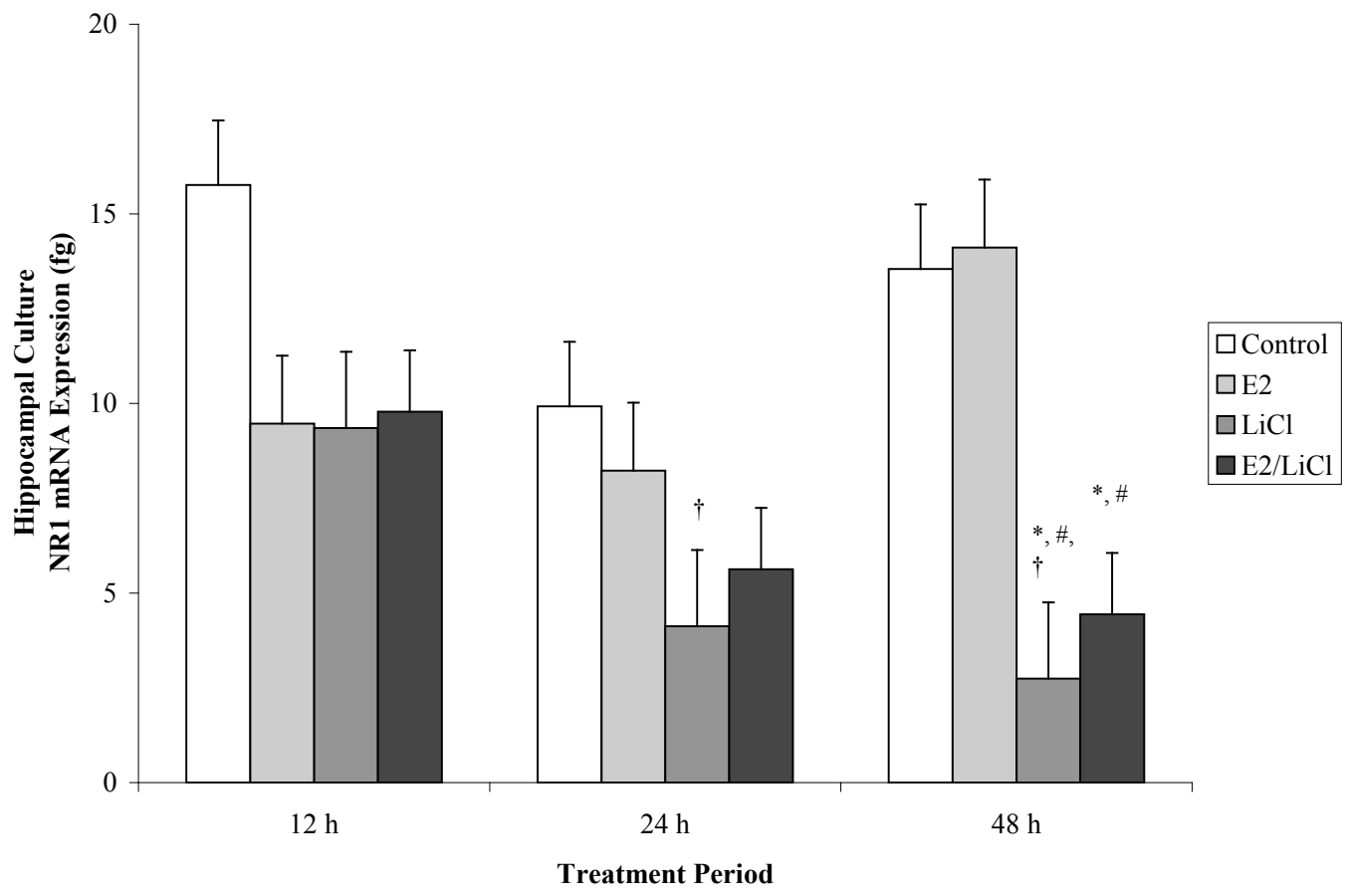


Figures 2A-B: Quantitative RT-PCR of NR1 mRNA expression. E18.5 cortical (A) and hippocampal (B) primary cell cultures treated for 12,24 , and $48 \mathrm{~h}$ with $0.04 \mu \mathrm{M} \mathrm{E} 2$, 10mM LiCl, combined E2/LiCl, or Control (no treatment). After temporal treatment total RNA was isolated and reverse transcribed. The figure denotes NR1 mRNA expression in femtograms (y-axis) and treatment duration (x-axis). * ${ }^{*}$-value $<.05$ compared with control; \#, p-value $<.05$ compared with E2; $\uparrow$, p-value $<.001$ compared with $12 \mathrm{~h}$ treatment.

No significant effects were detected for Control or E2 treatment on NR1 mRNA expression across treatment periods and culture type (figure $2 \mathrm{~A} \& \mathrm{~B}$ ). Expression of NR1 was influenced by $\mathrm{LiCl}$, but this alteration was dependent on culture type. In cortical cultures (figure 2A), $\mathrm{LiCl}$ seemed to reduce NR1 gradually and specifically after a $48 \mathrm{~h}$ treatment period, but according to Fisher's LSD this decrease proved to be nonsignificant $(p>.1)$. For hippocampal cultures, Fisher's LSD indicated that LiCl significantly decreased $(\mathrm{p}<0.05)$ NR1 mRNA expression after a 24 and 48 h treatment period when compared with the $12 \mathrm{~h}$ treatment period (figure 2B). Also, LiCl significantly reduced $(\mathrm{p}<0.05)$ NR1 expression in hippocampal cultures after a $48 \mathrm{~h}$ treatment period when compared with Control and E2 treatments (figure 2B). Although all treatments appeared to reduce hippocampal culture NR1 gene expression after $12 \mathrm{~h}$ when compared with Control (figure 2B), Fisher's LSD indicated this change was nonsignificant $(\mathrm{p}>.05)$. 
Combined $\mathrm{E} 2 / \mathrm{LiCl}$ treatment significantly decreased $(\mathrm{p}<.05)$ NR1 mRNA expression in both cortical and hippocampal cultures (figure 2A \& B). Fisher's LSD showed that combined $\mathrm{E} 2 / \mathrm{LiCl}$ treatment significantly reduced cortical NR1 mRNA expression after $12 \mathrm{~h}$ when compared with E2 treated cultures (figure 2A). This significant decrease reoccurred after cortical cultures were treated with combined $\mathrm{E} 2 / \mathrm{LiCl}$ for $48 \mathrm{~h}$. The $48 \mathrm{~h}$ decrease was noted when combined $\mathrm{E} 2 / \mathrm{LiCl}$ was compared with E2 and Control (figure 2A). Cortical cultures treated after $24 \mathrm{~h}$ did not alter NR1 mRNA expression. In hippocampal cultures, combined E2/LiCl treatment significantly reduced NR1 expression. Combined E2/LiCl treatment when compared with Control and E2 significantly reduced $(p<0.05)$ NR1 expression after a $48 \mathrm{~h}$ treatment period (figure 2B). No significant differences were noted for combined $\mathrm{E} 2 / \mathrm{LiCl}$ treated hippocampal cultures after a 12 and $24 \mathrm{~h}$ treatment, though.

These results demonstrated that combined $\mathrm{E} 2 / \mathrm{LiCl}$ treatment decreased NR1 gene expression for both culture types, specifically after a $48 \mathrm{~h}$ treatment period. Cortical cultures showed significantly decreased NR1 gene expression after 12 and $48 \mathrm{~h}$ treatment periods and hippocampal cultures showed significantly decreased expression only after a $48 \mathrm{~h}$ treatment period. Additionally, NR1 gene expression in LiCl-treated hippocampal cultures decreased after a 24 and $48 \mathrm{~h}$ when compared with $12 \mathrm{~h}$ treatment period. Cultures treated with E2 did not affect NR1 mRNA expression across all experimental parameters. 


\subsubsection{Combined $\mathrm{E} 2 / \mathrm{LiCl}$ and $\mathrm{E} 2$ failed to reduce excitotoxicity}

Glia are extremely tolerant to excitotoxicity [see 35] and since my primary cultures express high glial mRNA (see figures 1A-D) a high dosage of glutamate $(100 \mu \mathrm{M})$ was necessary. In my experiment, primary cell cultures were pretreated for 48 h, subjected to excitotoxicity with glutamate, and assessed for cell viability using fluorescein diacetate/propidium iodide assay (FDA/PI). Figure 3A displays captured images of primary cultures after experimental procedures. Live cells were labeled green (FDA) and dead cells were labeled red (PI). These primary cultures maintained a tolerance for glutamate toxicity without treatment (Control) when compared with Initial Viability (i.e., assayed prior to any experimental procedure). Additionally, Control cortical cultures compared with Initial Viability showed an increase in FDA labeling (figure 3A). Increased Control FDA labeling did not occur for hippocampal cultures, though (figure 3A). Pretreatment with E2 and combined E2/LiCl decreased viability for both cortical or hippocampal cultures, as indicated by the intense PI labeling; however, LiCl-treated cortical cultures showed increased cell viability which did not occur for hippocampal (figure 3A). These images were then processed using ImageJ cell counter [49] and data generated were statistically analyzed using ANOVA. 
$3 \mathrm{~A}$.

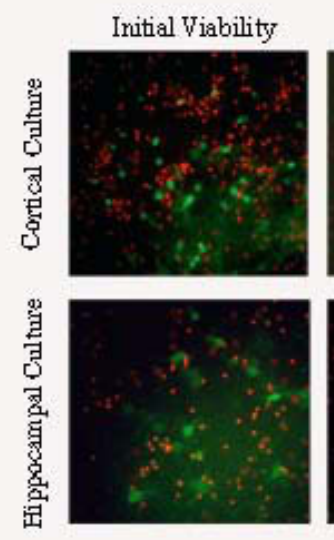

Control
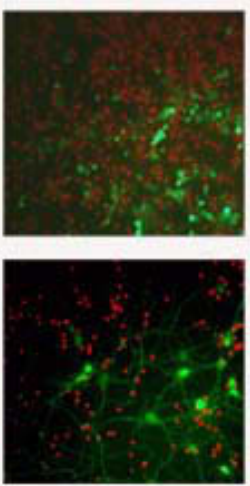

E2
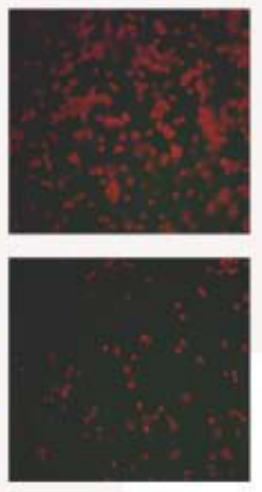

$\mathrm{LiCl}$
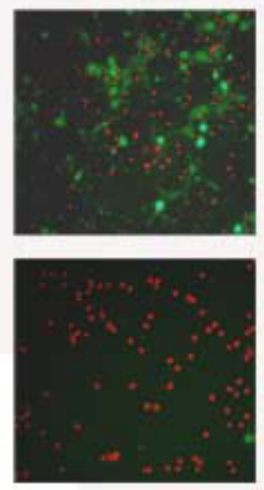

$\mathrm{E} 2 / \mathrm{LiCl}$
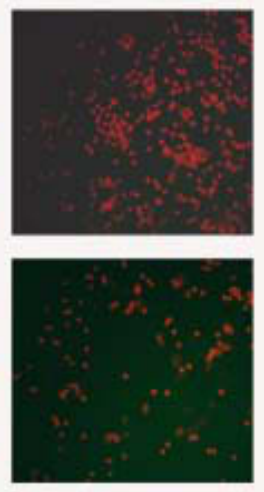

$3 B$.

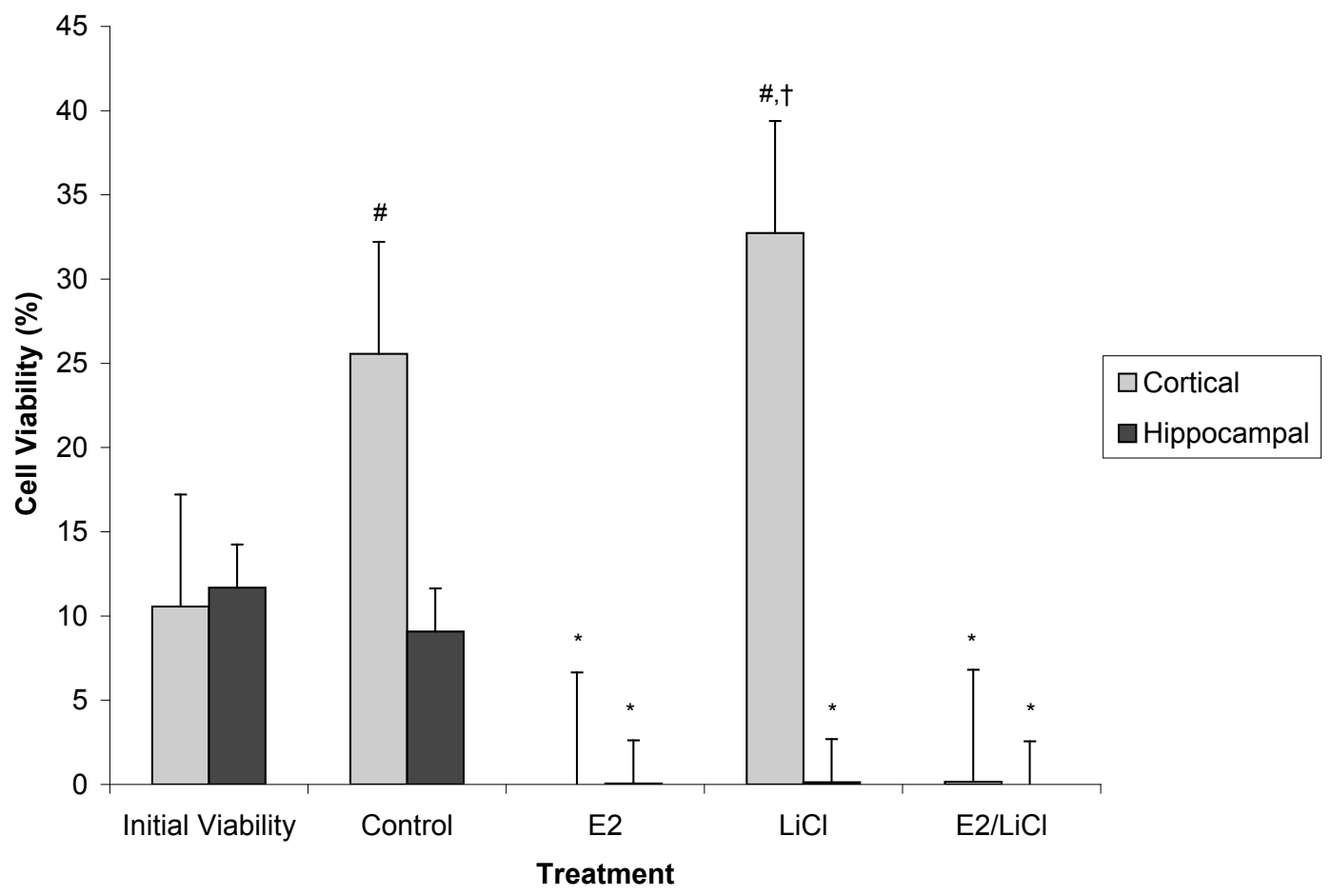


Figure 3A-3B: Mean viability for glutamate excitotoxicity from $48 \mathrm{~h}$ treated cortical (grey bars) and hippocampal (black bars) primary cell cultures. A pre-treatment measurement (Initial viability) was assayed to note any changes caused by the treatment and glutamate excitotoxicity. Images were captured (green labeling, fluorescein diacetate (FDA; live cells) and red labeling, propidium iodide (PI; dead cells)) and viability $(\mathrm{FDA} /(\mathrm{FDA}+\mathrm{PI}))$ was assessed using ImageJ Cell Counter for both cortical and hippocampal primary cultures. *, significantly reduced cell viability compared with Initial Viability and Control ( $p$-value $<.05)$; \#, significantly increased cell viability when compared with Initial Viability ( $\mathrm{p}$-value $<.05)$; $\uparrow$, significantly increased cell viability when compared with other treatments $(p$-value $<.05)$.

Viability was not reduced for Control cortical and hippocampal cultures when compared with Initial Viability after glutamate excitotoxicity (figure 3B); specifically in Control cortical cultures where viability significantly increased $(\mathrm{p}<.05)$ (figure $3 \mathrm{~B})$. Figure 3B indicated cortical cultures pretreated with E2 and combined E2/LiCl significantly failed to rescue cells from glutamate excitotoxicity when compared with Control and Initial Viability. Cortical cultures treated with $\mathrm{LiCl}$, however, exhibited increased cell viability when compared with other treatment types and Initial Viability (figure 3B). Figure 3B also depicts that all pretreated hippocampal cultures failed to rescue cells from glutamate excitotoxicity when compared with Control and Initial Viability. Hippocampal cultures also did not display increased cell viability because of glutamate (e.g. Control) as did cortical cultures. 


\subsection{Discussion}

Several cell signaling transduction pathways are affected by $\mathrm{E} 2$ and $\mathrm{LiCl}$, but few studies concentrate on any neurobiological effects the two combined may present. Additionally, investigations are wanting on how combined $\mathrm{E} 2$ and $\mathrm{LiCl}$ affect glia. In the mammalian brain glia are ten times more numerous than neurons and such would be expected to play a role in the progression of neurodegenerative diseases [see 57]. In this study, densitometric results showed high levels of GFAP mRNA expression among cortical and hippocampal cultures (see figures 1A \& C) compared with NF-H (see figures 1B \& D), suggesting a predominance of glia. I chose to use GFAP and NF-H since these are standard markers in identifying brain cell type (glia or neuron, respectively). Cultures used in this study were harvested at a late embryonic age (E18.5) when most neurons have differentiated. As expected, neurons harvested at E18.5 would have a greater propensity for cell death during mechanical trituration, hence the low NF-H expression (see figures 1B \& D). Primarily, B27/Neurobasal medium is used for culturing cortical and hippocampal neurons and this medium generates a $90 \%$ neuronal population compared with a $10 \%$ glial population as described by immunocytochemistry [3]. Glia population percentage coincides with my FDA/PI assay of Initial Viability (e.g. viability assayed prior to any experimental procedures; see figures 3B) for both cortical and hippocampal cultures since B27/Neurobasal media maintained a neuronal population while suppressing glia proliferation. This allowed me to maintain cultures that sustained neurons (see figures 1B \& D), suppressed glia proliferation, but still with a predominance of glial cells (see figures 1A \& C). Densitometric data (figures 1A-D) indicated that cortical cultures increased and were higher in GFAP mRNA expression across treatment 
periods (see figure 1A) compared with hippocampal cultures (see figure 1C). Glia are constantly proliferating and this gradual increase and higher GFAP expression in cortical cultures could be explained since cortical cultures were plated at a higher density than hippocampal cultures (see Experimental Procedures). Hippocampal cultures expressed higher levels of NF-H mRNA (see figure 1D) compared with cortical cultures (see figure 1B), but still, with higher GFAP levels than NF-H (see figure 1C \& D). Rocha et al. (1994) indicated that GFAP protein expression increased in the caudate nucleus and hippocampus of 4 week lithium-treated rats [50] and though I noted GFAP mRNA increased in cortical cultures (specifically at 24 and $48 \mathrm{~h}$; see figure 1A) this was not apparent in hippocampal cultures. This may be a result of my treatment being an acute (up to $48 \mathrm{~h}$ ) rather than a chronic one (4 weeks).

Glia, like neurons, are also known to express functional NMDA receptor and nonNMDA receptor $[12,30]$. Glia NMDA receptor expression increases susceptibility to excitotoxicity and facilitates glutamate transport [see 35]. Glial susceptibility to excitotoxicity, however, is less severe than neuronal. This is of specific interest since NMDA receptor subunit expression and excitotoxicity of glia are rarely studied. The critical subunit of NMDA receptor is NR1 and without it there is no functional receptor. In studying glial NR1 gene expression within my experimental parameters I can postulate transcriptional activities affected (e.g., estrogen receptor- $\alpha /$ GSK-3 $\beta$-mediated pathways or CREB). Among both culture types, hippocampal cultures expressed higher levels of NR1 mRNA (see figure 2B) compared with cortical cultures; this difference is worth discussing even with $p$-value $=.058$ (see figure 2A). Both cultures expressed high levels 
of GFAP but hippocampal cultures also expressed higher levels of NF-H (see figure 1D) compared with cortical cultures (see figure 1B). The higher levels of NR1 mRNA expression in hippocampal cultures is that glia express functional NMDA receptor at a lower level than neurons [see 11]. Additionally, autoradiography using NMDA receptorspecific ligands depict higher density of NMDA receptor in hippocampal regions than cortical [41]. My study showed no effect of E2 treatment on NR1 mRNA expression for both culture types (see figures 2A \& B). My E2 results on NR1 mRNA contradicts Jelks et al. (2007) findings where E2 treatment increased NR1 in neuronal cultures [24], but my cultures did express higher levels of GFAP mRNA (see figures 1A \& C). Few studies investigate how E2 (or lithium) influence glia but I suggest my glia cultures reached a saturation point since glia also produce estrogen - as noted in astrocytic culture media [23]. The E2-estrogen receptor complex have a $K_{d}$ of 150pM [53], therefore, doses of $.04 \mu \mathrm{M}$ E2 may have been negligible in altering NR1 mRNA expression. Expression of NR1 mRNA did not change in LiCl-treated cortical cultures (see figures 2A) across treatment periods which coincides with Hashimoto et al. (2002) who showed that lithium does not influence NR1 protein expression in neuronal cultures [19]. Treatment of LiCl, however, did reduce NR1 mRNA expression in hippocampal cultures after a 24 and $48 \mathrm{~h}$ treatment period compared with $12 \mathrm{~h} \mathrm{LiCl-treatment} \mathrm{(see} \mathrm{figures} 2 \mathrm{~B}$ ). Lithium diffuses into a cell via sodium channel but also through glutamate receptors [27]. I clearly show that hippocampal cultures express higher levels of NR1 mRNA (see figure 2B) than cortical cultures (see figure 2A) and this may be indicative of functionally expressed NMDA receptor. Hippocampal NR1 mRNA down-regulation by $\mathrm{LiCl}$ may be caused by the influx rate of $\mathrm{LiCl}$. This rate will change NR1 expression since estrogen 
receptor- $\alpha$ is involved in facilitating NMDA receptor subunit expression [see 58] that is mediated by GSK-3 $\beta$ [see 37]; and lithium is known as a selective inhibitor of GSK-3 $\beta$ [26].

The purpose of this study was to note the combined affect of E2 and LiCl on NR1 mRNA expression and excitotoxicity. After a $12 \mathrm{~h}$ treatment, NR1 expression for cortical cultures was not altered with individual treatment of $\mathrm{E} 2$ or $\mathrm{LiCl}$; however, when $\mathrm{LiCl}$ was combined with E2, NR1 expression decreased after $12 \mathrm{~h}$ (see figure $2 \mathrm{~A}$ ). Hippocampal cultures did not display this reduction at $12 \mathrm{~h}$, though (see figure 2B). Studies show that in rat cerebral cortex hormone and dopamine-stimulated adenyl cyclase activity is hindered by lithium [43]. Adenyl cyclase produces cAMP, a main constituent in CREB signaling pathway. Activated CREB is highly involved in facilitating NMDA receptor subunit expression [48] and reduced NR1 at $12 \mathrm{~h}$ may be caused by $\mathrm{LiCl}$ inhibiting cortical adenyl cyclase activity triggered by E2. Combined E2/LiCl did not alter NR1 expression in cortical and hippocampal cultures after $24 \mathrm{~h}$ treatment (see figure 2A \& B). Therefore, the $12 \mathrm{~h}$ decrease in cortical NR1 mRNA may be caused by the fast action of extracellular $\mathrm{LiCl}$ concentration inhibiting adenyl cyclase activity [6] as opposed to intracellular concentration since reduced cortical NR1 mRNA reoccurred at $48 \mathrm{~h}$ treatment period for both culture types. The decrease in NR1 after $48 \mathrm{~h}$ was significant compared with Control and E2 treated cortical and hippocampal cultures (see figures $2 \mathrm{~A} \& \mathrm{~B}$ ). Reduced $\mathrm{NR} 1$ at $48 \mathrm{~h}$ with combined $\mathrm{E} 2 / \mathrm{LiCl}$ occurred for both cultures indicating a similar pathway involved, possibly through the intracellular estrogen receptor- $\alpha /$ GSK-3 $\beta$-mediated pathway [37]. Down-regulation of NR1 mRNA could be 
explained since estrogen receptor- $\alpha$, when bound by its ligand E2, facilitates NMDA receptor subunit gene expression by recognizing palindromic DNA sequences [58]; thus, E2 has a direct genomic role in NMDA receptor subunit expression. Additionally, response element binding of estrogen receptor- $\alpha$ relies on GSK-3 $\beta$ phosphorylation and this phosphorylation is inhibited by lithium [37] since lithium is a selective inhibitor of GSK-3 $\beta$ [26]. I chose such high concentrations for $\mathrm{E} 2$ and $\mathrm{LiCl}$ based on the literature, since $10 \mathrm{mM} \mathrm{LiCl}$ inhibits $\sim 70 \%$ GSK-3 $\beta$ protein activity [52], and a $0.04 \mu \mathrm{M}$ concentration of E2 significantly increases bcl-2 expression - an anti-apoptotic protein via calcium influx in cell cultures [59]. Medunjanin et al. [37] used MELN cells treated for $48 \mathrm{~h}$ with $30 \mathrm{mM} \mathrm{LiCl}$ which decreased estrogen receptor- $\alpha$ response element binding and this decrease was the result of GSK-3 $\beta$ inhibition. The aforementioned references provide insight into my results since $\mathrm{LiCl}$ significantly decreased NR1 mRNA expression in E2-treated cortical (see figure 2A) and hippocampal cultures (see figure 2B) after $48 \mathrm{~h}$ treatment period. Since NR1 mRNA in E2-treated cells did not change, I deduce this reduction is the result of $\mathrm{LiCl}$ (potentially via inhibition of GSK-3 $\beta$ activity). Whether or not $\mathrm{LiCl}$ influences estrogen receptor- $\alpha / \mathrm{GSK}-3 \beta$-mediated pathway within my experimental parameters still remains to be elucidated. I am currently working on experiments to test these effects. Studies on NR1 protein level should be conducted under my experimental and treatment conditions. Present results are represented in mRNA expression and post-transcription and/or post-translational influences may render differences at the protein level when compared. Both estrogen and lithium alter the phosphorylation state of NMDA receptor subunits reducing NMDA receptor-mediated 
excitotoxicity $[13,19,34]$. It will be interesting to note the phosphorylated state of NMDARs within my experimental parameters; however, within the scope of this project, I provide substantial evidence on that combined $\mathrm{E} 2 / \mathrm{LiCl}$ alter excitotoxicity and $\mathrm{NR} 1$ mRNA expression.

Excitotoxicity mediated by NMDA receptor characterizes many neurological diseases [see 33]. The E2 concentration I chose for my experimental procedures $(0.04 \mu \mathrm{M})$ also provides neuroprotection for hippocampal cultures [9], and as mentioned, increases bcl-2 expression [59]. A concentration of $0.04 \mu \mathrm{M}$ E2 should provide neuroprotection against excitotoxicity, however, glia may respond differently to this treatment. After pre-treating primary cultures for $48 \mathrm{~h}$ with $\mathrm{E} 2 \mathrm{and} / \mathrm{or} \mathrm{LiCl} \mathrm{I}$ exposed these glial cultures to a toxic level of glutamate for $1 \mathrm{~h}$. Cortical cultures displayed higher viability with $\mathrm{LiCl}$ treatment compared with hippocampal cultures (see figures 3B \& C). NR1 (see figure 2B) and NF-H mRNA expression (see figure 1D) were higher in hippocampal cultures than cortical cultures (see figure 1B \& 2A). These observations could explain the extremely low viability in treated hippocampal cultures (see figure 3B) since excitotoxicity is mediated via NMDA receptor signaling. The literature indicates that E2 and lithium affect NMDA receptor, but with opposing actions. On the one hand, estrogen facilitates NMDA receptor-regulated calcium influx [59], but studies show estrogen's neuroprotective qualities against glutamate insult are through calciumindependent pathways [47]. On the other hand, lithium reduces calcium influx and NMDA receptor-mediated glutamate excitotoxicity [10, 18]. Normally, inducing excitotoxicity reduces viability among neuronal cultures, but glia are more tolerant to this 
insult [see 35]. My cortical cultures exhibited high glia-associated GFAP mRNA expression (figures 1A). Although hippocampal cultures showed this as well (see figures 1C), hippocampal cultures also expressed higher levels of neuron-associated NF-H mRNA expression compared with cortical cultures (see figures 1B \& D). Results from FDA/PI assay (figures 3A-C) strengthen densitometric data since cortical and hippocampal cultures tolerated excitotoxicity as observed with Control, which was not significantly affected by such a high dosage of glutamate (see figures 3A-C). Cortical cultures expressing higher levels GFAP mRNA (see figure 1A) also explain increased cell viability in Control and LiCl-treated cortical cultures (see figure 3B). Treated hippocampal cultures (figure 3B) did not display this protective quality since hippocampal cultures also expressed higher levels of NF-H mRNA (see figure 1D).

Previous literature specifies that both estrogen and lithium act as neuroprotective agents and may be used as a palliative treatment for neurodegeneration $[10,15,51]$. My study is the first to show that combined E2 and $\mathrm{LiCl}$ affect NR1 mRNA expression and excitotoxicity in cortical and hippocampal primary mixed brain cell cultures. Studies of this caliber are wanting since little is known about how E2 and LiCl influence molecular processes of the brain. Analysis of NMDA receptor subunit mRNA and protein expression using post-mortem Alzheimer's disease (AD) brains show a decrease in NR1 and NR2B in the hippocampal formation with advancement of the disease [38]. In a study using ovariectomized rats, estrogen-replacement did not affect NMDA receptor subunit mRNA expression; although, duration of ovariectomy did affect this expression [1]. In recent years, post-menopausal women are diagnosed with AD more often than 
men and this statistic is related to estrogen deficiency [14]. Estrogen replacement therapy (ERT) proves to be beneficial to post-menopausal women in reducing the risk of developing AD [see 14]. Studies demonstrate that the dominant form of estrogen, estradiol, plays an important role in neuroprotection and enhancement of learning and memory [20]. The use of ERT is a subject of debate due to the risk of developing breast cancer. This is marked by an increased incidence of lobular carcinoma in postmenopausal women under ERT [42] and women suffering from depression during periand post-menopause are often prescribed lithium [4, 29]. Estrogen and lithium also affects the dopamine pathway, a pathway implicated in many clinical disorders and neurodegenerative diseases $[40,54]$. An increase in dopaminergic pathways is a characteristic of bipolar disorder (manic-depression) and lithium is readily prescribed as a prophylactic for this disorder [54]. Studies show that combined E2/LiCl alter serotonin and dopamine metabolites. Ovariectomized rats treated with E2 show no change in frontal cortices levels of serotonin, dopamine or dopamine metabolites. When E2 is combined with $\mathrm{LiCl}$, though, dopamine is greatly decreased but show higher levels of serotonin and dopamine metabolites [39]. Additionally, NMDA agonist increase dopamine release modulated by hormones [5]. It will be worth studying the involvement of combined $\mathrm{E} 2$ and $\mathrm{LiCl}$ in the dopamine pathway and how these two agents affect NMDA receptor expression and function. An understanding of underlying molecular mechanism in regards to how $\mathrm{E} 2$ and $\mathrm{LiCl}$ interact is lacking. The present study introduces and advances perspectives for additional studies directed towards developing palliative therapies for neurodegeneration and postmenopausal-related cognitive decline. 


\section{REFERENCES}

[1] M.M. Adams, T. Oung, J.H. Morrison, A.C. Gore, Length of Postovariectomy Interval and Age, but Not Estrogen Replacement, Regulate N-Methyl-D-Aspartate Receptor mRNA Levels in the Hippocampus of Female Rats, Exp. Neurol. 170 (2001) 345-356.

[2] F. Angelucci, L. Aloe, P. Jiménez-Vasquez, A.A. Mathé, Lithium treatment alters brain concentrations of nerve growth factor, brain-derived neurotrophic factor and glial cell line-derived neurotrophic factor in a rat model of depression, Int. J. Neuropsychopharmacol. 6 (2003) 225-231.

[3] G.J. Brewer, Serum-free B27/neurobasal medium supports differentiated growth of neurons from the striatum, substantia nigra, septum, cerebral cortex, cerebellum, and dentate gyrus, J. Neurosci. Res. 42 (1995) 674-683.

[4] V.K. Burt, N. Rasgon, Special considerations in treating bipolar disorder in women, Bipolar Disord. 6 (2004) 2-13.

[5] R.J. Cabrera, C. Bregonzio, M. Laconi, A. Mampel, Allopregnanolone Increase in Striatal N-Methyl-D-aspartic Acid Evoked [ $\left.{ }^{3} \mathrm{H}\right]$ Dopamine Release Is Estrogen and Progesterone Dependent, Cell. Mol. Neurobiol. 22 (2002) 445-454.

[6] A.K. Campbell, K. Siddle, Effect of replacement of extracellular sodium ions and of D-600 on the activation by adrenalin of adenylate cyclase in intact pigeon erythrocytes, Mol. Cell. Endocrinol. 11 (1978) 79-89.

[7] P. Cardona-Gomez, M. Perez, J. Avila, L.M. Garcia-Segura, F. Wandosell, Estradiol inhibits GSK3 and regulates interaction of estrogen receptors, GSK3, and beta-catenin in the hippocampus, Mol. Cell. Neurosci. 25 (2004) 363-373.

[8] P. Chen, Z. Gu, W. Liu, Z. Yan, Glycogen Synthase Kinase 3 Regulates NMethyl-D-aspartate Receptor Channel Trafficking and Function in Cortical Neurons, Mol. Pharmacol. 72 (2007) 40-51.

[9] S. Chen, J. Nilsen, R.D. Brinton, Dose and Temporal Pattern of Estrogen Exposure Determines Neuroprotective Outcome in Hippocampal Neurons: Therapeutic Implications, 147 (2006) 5303-5313.

[10] D.-M. Chuang, R.-W. Chen, E. Chalecka-Franaszek, M. Ren, R. Hashimoto, V. Senatorov, H. Kanai, C. Hough, T. Hiroi, P. Leeds, Neuroprotective effects of lithium in cultured cells and animal models of diseases, Bipolar Disord. 4 (2002) 129-136. 
[11] F. Conti, P. Barbaresi, M. Melone, A. Ducati, Neuronal and Glial Localization of NR1 and NR2A/B Subunits of the NMDA Receptor in the Human Cerebral Cortex, Cereb. Cortex 9 (1999) 110-120.

[12] F. Conti, S. DeBiasi, A. Minelli, M. Melone, Expression of NR1 and NR2A/B subunits of the NMDA receptor in cortical astrocytes, Glia 17 (1996) 254-258.

[13] R. Dominguez, R. Liu, M. Baudry, 17 $\beta$-Estradiol-mediated activation of extracellular-signal regulated kinase, phosphatidylinositol 3-kinase/protein kinase B-Akt and N-methyl-D-aspartate receptor phosphorylation in cortical synaptoneurosomes, Jounal of Neurochemistry 101 (2007) 232-240.

[14] L.M. Garcia-Segura, I. Azcoitia, L.L. DonCarlos, Neuroprotection by estradiol, Prog. Neurobiol. 63 (2001) 29-60.

[15] S. Goodenough, M. Schafer, C. Behl, Estrogen-induced cell signalling in a cellular model of Alzheimer's disease, J. Steroid Biochem. Mol. Biol. 84 (2003) 301-305.

[16] S. Goodenough, D. Schleusner, C. Pietrzik, T. Skutella, C. Behl, Glycogen synthase kinase $3 \beta$ links neuroprotection by $17 \beta$-estradiol to key Alzheimer processes, Neuroscience 132 (2005) 581-589.

[17] C.A. Grimes, R.S. Jope, CREB DNA binding activity is inhibited by glycogen synthase kinase-3 $\beta$ and facilitated by lithium, J. Neurochem. 78 (2001) 12191232.

[18] R. Hashimoto, K. Fujimaki, M.R. Jeong, L. Christ, D.-M. Chuang, Lithiuminduced inhibition of Src tyrosine kinase in rat cerebral cortical neurons: a role in neuroprotection against N-methyl-D-aspartate receptor-mediated excitotoxicity, FEBS Lett. 538 (2003) 145-148.

[19] R. Hashimoto, C. Hough, T. Nakazawa, T. Yamamoto, D.-M. Chuang, Lithium protection against glutamate excitotoxicity in rat cerebral cortical neurons: involvement of NMDA receptor inhibition possibly by decreasing NR2B tyrosine phosphorylation, J. Neurochem. 80 (2002) 589-597.

[20] V.W. Henderson, A. Paganini-Hill, C.K. Emanuel, M.E. Dunn, J.G. Buckwalter, Estrogen replacement therapy in older women. Comparisons between Alzheimer's disease cases and nondemented control subjects, Arch. Neurol. 51 (1994) 896900 .

[21] K. Honda, S. Shimohama, H. Sawada, T. Kihara, T. Nakamizo, H. Shibasaki, A. Akaike, Nongenomic antiapoptotic signal transduction by estrogen in cultured cortical neurons, J. Neurosci. Res. 64 (2001) 466-475. 
[22] V. Hongisto, N. Smeds, S. Brecht, T. Herdegen, M.J. Courtney, E.T. Coffey, Lithium Blocks the c-Jun Stress Response and Protects Neurons via Its Action on Glycogen Synthase Kinase 3, Mol. Cell. Biol. 23 (2003) 6027-6036.

[23] R. Hu, W.Q. Cai, X.G. Wu, Z. Yang, Astrocyte-derived estrogen enhances synapse formation and synaptic transmission between cultured neonatal rat cortical neurons, Neuroscience 144 (2007) 1229-1240.

[24] K.B. Jelks, R. Wylie, C.L. Floyd, A.K. McAllister, P. Wise, Estradiol Targets Synaptic Proteins to Induce Glutamatergic Synapse Formation in Cultured Hippocampal Neurons: Critical Role of Estrogen Receptor- $\alpha$, J. Neurosci. 27 (2007) 6903-6913.

[25] K.H. Jones, J.A. Senft, An improved method to determine cell viability by simultaneous staining with fluorescein diacetate-propidium iodide, J. Histochem. Cytochem. 33 (1985) 77-79.

[26] R.S. Jope, Lithium and GSK-3: one inhibitor, two inhibitory actions, multiple outcomes, Trends Pharmacol. Sci. 24 (2003) 441-443.

[27] A.Y. Kabakov, N.B. Karkanias, R.H. Lenox, R.L. Papke, Synapse-specific accumulation of lithium in intracellular microdomains: A model for uncoupling coincidence detection in the brain, Synapse 28 (1998) 271-279.

[28] P.S. Klein, D.A. Melton, A molecular mechanism for the effect of lithium on development, PNAS 93 (1996) 8455-8459.

[29] A. Kukopulos, G. Minnai, B. Muller-Oerlinghausen, The influence of mania and depression on the pharmacokinetics of lithium: A longitudinal single-case study, J. Affect. Disord. 8 (1985) 159-166.

[30] U. Lalo, Y. Pankratov, F. Kirchhoff, R.A. North, A. Verkhratsky, NMDA Receptors Mediate Neuron-to-Glia Signaling in Mouse Cortical Astrocytes, 26 (2006) 2673-2683.

[31] C. Leranth, M. Shanabrough, D.E. Redmond Jr., Gonadal hormones are responsible for maintaining the integrity of spine synapses in the CA1 hippocampal subfield of female nonhuman primates, The Journal of Comparative Neurology 447 (2002) 34-42.

[32] D.K. Lewis, A.B. Johnson, S. Stohlgren, A. Harms, F. Sohrabji, Effects of estrogen receptor agonists on regulation of the inflammatory response in astrocytes from young adult and middle-aged female rats, J. Neuroimmunol. 195 (2008) 47-59. 
[33] S.A. Lipton, The Molecular Basis of Memantine Action in Alzheimer's Disease and Other Neurologic Disorders: Low-affinity, Uncompetitive Antagonism, Curr. Alzheimer Res. 2 (2005) 155-165.

[34] J. Ma, G.-Y. Zhang, Y. Liu, J.-Z. Yan, Z.-B. Hao, Lithium suppressed Tyr-402 phosphorylation of proline-rich tyrosine kinase (Pyk2) and interactions of Pyk2 and PSD-95 with NR2A in rat hippocampus following cerebral ischemia, Neurosci. Res. 49 (2004) 357-362.

[35] C. Matute, E. Alberdi, G. Ibarretxe, M.V. Sánchez-Gómez, Excitotoxicity in glial cells, Eur. J. Pharmacol. 447 (2002) 239-246.

[36] B.S. McEwen, Genome and Hormones: Gender Differences in Physiology: Invited Review: Estrogens effects on the brain: multiple sites and molecular mechanisms, J. Appl. Physiol. 91 (2001) 2785-2801.

[37] S. Medunjanin, A. Hermani, B. De Servi, J. Grisouard, G. Rincke, D. Mayer, Glycogen Synthase Kinase-3 Interacts with and Phosphorylates Estrogen Receptor $\alpha$ and Is Involved in the Regulation of Receptor Activity, J. Biol. Chem. 280 (2005) 33006-33014.

[38] A.J. Mishizen-Eberz, R.A. Rissman, T.L. Carter, M.D. Ikonomovic, B.B. Wolfe, D.M. Armstrong, Biochemical and molecular studies of NMDA receptor subunits NR1/2A/2B in hippocampal subregions throughout progression of Alzheimer's disease pathology, Neurobiol. Dis. 15 (2004) 80-92.

[39] M. Morissette, T. Di Paolo, Acute effect of 17ß-estradiol and lithium on ovariectomized rat brain biogenic amines metabolism, J. Psychiatr. Res. 30 (1996) 95-107.

[40] M. Morissette, M. Le Saux, M. D'Astous, S. Jourdain, S. Al Sweidi, N. Morin, E. Estrada-Camarena, P. Mendez, L.M. Garcia-Segura, T. Di Paolo, Contribution of estrogen receptors alpha and beta to the effects of estradiol in the brain, J. Steroid Biochem. Mol. Biol. 108 (2008) 327-338.

[41] M. Mugnaini, F. van Amsterdam, E. Ratti, D. Trist, N. Bowery, Regionally different N-methyl-D-aspartate receptors distinguished by ligand binding and quantitative autoradiography of [3H]-CGP 39653 in rat brain., Br. J. Pharmacol. 119 (1996) 819-828.

[42] L.M. Newcomer, P.A. Newcomb, J.D. Potter, Y. Yasui, A. Trentham-Dietz, B.E. Storer, M.P. Longnecker, J.A. Baron, J.R. Daling, Postmenopausal hormone therapy and risk of breast cancer by histologic type United States, Cancer Causes \& Control 14 (2003) 225-233. 
[43] M.E. Newman, R.H. Belmaker, Effects of lithium in vitro and ex vivo on components of the adenylate cyclase system in membranes from the cerebral cortex of the rat, Neuropharmacology 26 (1987) 211-217.

[44] S. Nonaka, C.J. Hough, D.-M. Chuang, Chronic lithium treatment robustly protects neurons in the central nervous system against excitotoxicity by inhibiting N-methyl-D-aspartate receptor-mediated calcium influx, PNAS 95 (1998) 26422647.

[45] N. Ozaki, D.-M. Chuang, Lithium Increases Transcription Factor Binding to AP-1 and Cyclic AMP-Responsive Element in Cultured Neurons and Rat Brain, J. Neurochem. 69 (1997) 2336-2344.

[46] S. Peineau, C. Taghibiglou, C. Bradley, T.P. Wong, L. Liu, J. Lu, E. Lo, D. Wu, E. Saule, T. Bouschet, P. Matthews, J.T.R. Isaac, Z.A. Bortolotto, Y.T. Wang, G.L. Collingridge, LTP Inhibits LTD in the Hippocampus via Regulation of GSK3 $\beta$, Neuron 53 (2007) 703-717.

[47] J. Perrella, B. Bhavnani, Protection of cortical cells by equine estrogens against glutamate-induced excitotoxicity is mediated through a calcium independent mechanism., BMC Neurosci. 6 (2005) 34-51.

[48] M. Qiang, M.K. Ticku, Role of AP-1 in ethanol-induced N-methyl-d-aspartate receptor $2 \mathrm{~B}$ subunit gene up-regulation in mouse cortical neurons, J. Neurochem. 95 (2005) 1332-1341.

[49] W.S. Rasband, ImageJ. U. S. National Institutes of Health, Bethesda, 1997-2007.

[50] E. Rocha, R. Rodnight, Chronic Administration of Lithium Chloride Increases Immunodetectable Glial Fibrillary Acidic Protein in the Rat Hippocampus, J. Neurochem. 63 (1994) 1582-1584.

[51] M.K. Rowe, D. Chuang, Lithium neuroprotection: molecular mechanisms and clinical implications, Expert Rev. Mol. Med. 6 (2004) 1-18.

[52] W.J. Ryves, A.J. Harwood, Lithium Inhibits Glycogen Synthase Kinase-3 by Competition for Magnesium, Biochem. Biophys. Res. Commun. 280 (2001) 720725.

[53] S. Sasson, A.C. Notides, Estriol and Estrone Interaction with the Estrogen Receptor: Temperature-induced modulation of the cooperative binding of $\left[{ }^{3} \mathrm{H}\right]$ estriol and $\left[{ }^{3} \mathrm{H}\right]$ estrone to the estrogen receptor The Journal of Biological Chemistry 258 (1983) 8113-8117.

[54] T. Silverstone, Dopamine in manic depressive illness : A pharmacological synthesis, J. Affect. Disord. 8 (1985) 225-231. 
[55] D.T. Solum, R.J. Handa, Estrogen Regulates the Development of Brain-Derived Neurotrophic Factor mRNA and Protein in the Rat Hippocampus, J. Neurosci. 22 (2002) 2650-2659.

[56] F.A. Stephenson, Subunit Characterization of NMDA Receptors, Curr. Drug Targets 2 (2001) 233-239.

[57] L.J. Van Eldik, W.L. Thompson, H.R. Ranaivo, H.A. Behanna, D. Martin Watterson, Glia Proinflammatory Cytokine Upregulation as a Therapeutic Target for Neurodegenerative Diseases: Function-Based and Target-Based Discovery Approaches, Int. Rev. Neurobiol. 82 (2007) 277-296.

[58] T. Watanabe, S. Inoue, H. Hiroi, A. Orimo, M. Muramatsu, NMDA receptor type 2D gene as target for estrogen receptor in the brain, Mol. Brain Res. 63 (1999) 375-379.

[59] T.W. Wu, J.M. Wang, S. Chen, R.D. Brinton, $17 \beta$-estradiol induced $\mathrm{Ca}^{2+}$ influx via L-type calcium channels activates the Src/ERK/cyclic-AMP response element binding protein signal pathway and BCL-2 expression in rat hippocampal neurons: A potential initiation mechanism for estrogen-induced neuroprotection, Neuroscience 135 (2005) 59-72. 


\title{
CHAPTER II
}

Combined Estradiol and Lithium Chloride Specifically Alter Factors Involved in Learning, Memory, but not Neuroprotection in Primary Cultures

\begin{abstract}
Estrogen replacement therapy (ERT) is commonly prescribed during menopause. Postmenopausal women also tend to suffer from depression and as a result are prescribed antidepressants - in addition to ERT. Glia are the dominant brain cell type but little is known about how the combination of hormones and antidepressants affect glia. Investigations show that both hormones and antidepressants facilitate gene expression. The paucity of data on how combined hormones and antidepressants interact in regulating gene expression led me to hypothesize that in primary cultures of mixed brain cells predominated by glia, combined $17 \beta$-estradiol (E2) and lithium chloride ( $\mathrm{LiCl})(\mathrm{E} 2 / \mathrm{LiCl})$ will alter mRNA expression of markers involved in synaptic plasticity and neuroprotection. I recently published that $48 \mathrm{~h}$ treatment of $\mathrm{E} 2 / \mathrm{LiCl}$ reduces glutamate receptor subunit mRNA expression and increases excitotoxicity in primary cultures of mixed hippocampal and cortical cells predominated by glia. In the present study, I quantified mRNA expression of BDNF, Bcl-2 and ER- $\alpha$ using the cDNA of treated primary cultures of mixed brain cells from the previous chapter. Results indicate that a $48 \mathrm{~h}$ treatment period with combined E2/LiCl significantly increases BDNF and ER- $\alpha$ mRNA expression compared with Control and E2 treatment alone. Increased ER- $\alpha$ mRNA expression, however, was culture specific - e.g. an increase in hippocampal but not cortical cultures. No significant differences were noted for Bcl-2 mRNA expression,
\end{abstract}


though. These results add to the literature that combined hormones (E2) and antidepressants $(\mathrm{LiCl})$ alter gene transcription of factors involved in learning and memory.

\subsection{Introduction}

Estrogen replacement therapy (ERT) is a common prescription for menopause, specifically during post-menopausal stages. Depression is common during menopause and as a result, women are prescribed antidepressants in combination with ERT [5, 27]. It is unfortunate that few studies focus on the interacting properties of hormones and antidepressants since both influence a myriad of cell signaling pathways [23, 31]. Estrogen is the main constituent diminished during menopause [2] and this depletion not only affects women physiologically but also has neurological implications [12]. Studies show that estrogen depletion influences astrocytosis, cell proliferation and differentiation of neurons [41]. A plethora of protein signaling cascades are facilitated by estrogen and these interactions result in gene expression of markers involved in cell survival, learning and memory among glia and neurons [31]. The two receptors for estrogen are estrogen receptor $\alpha$ and $\beta$ (ER- $\alpha$ and ER- $\beta$ ) and these receptors play a role in facilitating estrogenmediated glial [9] and neuronal [31] protein signaling cascades. Studies also show the co-expression of brain derived neurotrophic factor (BDNF) and ER- $\alpha$ among pyramidal cells of rat hippocampus [45], but BDNF drastically decreases in people suffering from neurodegenerative disorders [44]. Although BDNF expression is noted primarily among neurons [19], BDNF is also shown to be co-expressed among glia in rat cortical and hippocampal areas [39] and in mouse primary glia cultures [21]. Estrogen, via ER- $\alpha$, 
increases BDNF expression and facilitates BDNF-tyrosine kinase receptor signaling in both glia and neurons [44]. Anti-apoptotic factors are also affected by ER- $\alpha$. Astrocytic co-expression of B-cell lymphoma/leukemia-2 (Bcl-2) and ER- $\alpha$ in the hippocampus of post-mortem brains of Alzheimer's disease (AD) patients indicates a potential mechanism for ER- $\alpha$ neuroprotection [9, 29]. Additionally, ER- $\alpha$ expression increases in AD patients compared with controls [29].

Lithium is commonly used to treat bipolar disorder, and it is now over a decade since lithium was identified as a specific inhibitor of glycogen synthase kinase-3beta (GSK-3 $\beta$ ) [25], and molecular implications for lithium continue to be explored. Similar to estrogen, lithium facilitates gene expression responsible for anti-apoptosis, learning and memory [30]. Lithium indirectly facilitates gene expression by interacting with GSK-3 $\beta$, an enzyme highly involved in development, gene expression, and cell signaling regulation as reviewed by Grimes and Jope [15]. Among neurons, lithium-GSK$3 \beta$ inhibition is associated with reducing apoptosis [20], increasing neurotrophic factors [1], and facilitating DNA binding of transcription factors [14, 37]. Lithium also affects astrocytic $\mathrm{pH}$ levels that stimulate myo-inositol transport systems, ultimately affecting protein signaling pathways in astrocytes [46]. Inositol signaling is known to be regulated by proline-, glutamic acid-, and leucine-rich protein-1 (PELP1), a co-regulator of ER- $\alpha$ signaling [35]. 
There is a paucity of studies on how various treatments interact with one another (through physiological and/or molecular processes). I recently published a study focusing on combined effects of estradiol (17ß-estradiol; E2) and lithium chloride ( $\mathrm{LiCl})$ (E2/LiCl) on glial NMDAR subunit NR1 gene expression and glutamate excitotoxicity. I showed that a $48 \mathrm{~h} \mathrm{E} 2 / \mathrm{LiCl}$ treatment reduced NR1 gene expression and increased glutamate excitotoxicity in mouse hippocampal and cortical primary cultures of mixed brain cells predominated by glia [48]. In the present study, I use the same cDNA from treated primary cultures of mixed brain cells from previous chapter to further investigate how combined $\mathrm{E} 2 / \mathrm{LiCl}$ influence gene expression. Both estrogen and lithium directly and/or indirectly influence gene expression of factors involved in learning, memory and neuroprotection $[23,31]$, which led me to hypothesize that combined $\mathrm{E} 2 / \mathrm{LiCl}$ will alter BDNF, Bcl-2, and ER- $\alpha$ mRNA expression in these cultures. My results indicate that a $48 \mathrm{~h} \mathrm{E} 2 / \mathrm{LiCl}$ treatment increases BDNF, ER- $\alpha$ mRNA, but not Bcl-2 mRNA expression in mouse primary mixed cultures. I also note that these results differed according to culture type (hippocampal versus cortical cultures). My data does present developmental differences since results are generated from embryonic brain cell cultures. Still, I believe my results will help elucidate interactions of hormones and antidepressants and how they affect gene expression of proteins involved in learning, memory and neuroprotection. 


\subsection{Experimental Procedures}

\subsubsection{Primary Mixed Brain Cell Cultures, Chemicals and Treatment}

For a detailed description of experimental procedures, refer to the previous chapter. Briefly, primary mixed hippocampal and cortical cultures were harvested from E18.5 C57BL/6J mice. Disassociated cells were randomly plated $\left(6 \times 10^{6}\right.$ for cortical cultures and $3 \times 10^{6}$ for hippocampal cultures) on poly-D-lysine $(100 \mu \mathrm{g} / \mathrm{mL}$; SigmaAldrich, Missouri) coated 12-well plates containing B27/Neurobasal medium (Invitrogen, California) with $0.5 \mathrm{mM} \mathrm{L}$-glutamine and $4 \mu \mathrm{g} / \mathrm{mL}$ gentamicin. Cells were maintained in a humidified, $5 \% \mathrm{CO}_{2}$ atmosphere incubator with a set temperature of $37^{\circ} \mathrm{C}$. Additional 12-well plates, with poly-D-lysine $(100 \mu \mathrm{g} / \mathrm{mL})$ coated coverslips were set aside for immunocytochemical purposes. After 4 days in culture, the media was removed entirely and replaced with fresh media; half of the media was changed every 4 days, thereafter,

until E2 and/or $\mathrm{LiCl}$ treatment. After twelve days in culture, the media was removed entirely and replaced with media treated with $10 \mathrm{mM} \mathrm{LiCl}$ (Sigma-Aldrich, Missouri), $0.04 \mu \mathrm{M}$ E2 (Sigma-Aldrich, Missouri), or combined E2/LiCl and duration of treatment for each group was $48 \mathrm{~h}$.

\subsection{Experimental Techniques}

\subsubsection{Immunocytochemistry}

Primary mixed cultures were immunolabeled using neurofilament-H (NFH) (Upstate, Virginia) and glia fibrillary acidic protein (GFAP) (Sigma-Aldrich, Missouri) antibodies. Cells were fixed for 15 minutes at $4{ }^{\circ} \mathrm{C}$ with ice-cold $4 \%$ paraformaldehyde/4\% Sucrose/DPBS and permeabilized for 30min at room 
temperature with $0.25 \%$ DPBST (DPBS with $0 . .25 \%$ [v/v] Triton X-100). Nonspecific binding sites blocked with 10\% normal goat serum/DPBS overnight at $4^{\circ} \mathrm{C}$. Primary antibodies were then incubated at room temperature with mouse NF-H or GFAP antibodies and visualized using fluorescent-conjugated secondary antibodies (directed against the host of the $1^{\circ}$ antibody). Cells were counterstained with Hoechst to reveal nuclei, coverslips were mounted on glass slides, and sealed with clear nail polish. Images were captured using a Leica Leitz DM RB fluorescent microscope with a Leica DM 500 camera (Leica, Bannockburn, IL, USA).

\subsubsection{Total RNA Isolation and cDNA Synthesis}

Total RNA was isolated from cultures after treatment with TRIzol reagent (GIBCO, California), according to manufacturer's protocol. Briefly, cultures were rinsed with ice-cold DPBS, TRIzol Reagent $(600 \mu \mathrm{L}-1 \mathrm{~mL})$ was added directly into each well, and then homogenized. Homogenized cells were then transferred to a fresh tube, and incubated at room temperature. Chloroform was added and centrifuged at $6,700 \mathrm{xg}$ at $4^{\circ} \mathrm{C}$. Total RNA (aqueous phase) was transferred to a sterile tube and allowed to precipitate with isopropanol and glycogen overnight at $-20^{\circ} \mathrm{C}$. The RNA was pelleted via centrifugation at $6,700 \mathrm{xg}$ at $4^{\circ} \mathrm{C}$, supernatant decanted and RNA pellet was washed twice with $75 \%$ ethanol. Pellets were then air dried and resuspended with DEPC-treated water. The DNA contaminants were removed with the RQ1 DNase kit (Promega, Wisconsin). Total RNA was then reverse transcribed (RT) using SUPERSCRIPT ${ }^{\mathrm{TM}}$ II RNase $\mathrm{H}$-free reverse transcriptase (Invitrogen, California), according to the 
manufacturer's protocol. Briefly, 500ng of total RNA was reverse transcribed with $0.05 \mu \mathrm{g} / \mu \mathrm{l}$ of Oligo $(\mathrm{dT})_{12-18}$ at $65^{\circ} \mathrm{C}$ for 5 minutes. First strand cDNA was synthesized with $5 \mathrm{mM} \mathrm{MgCl}, 10 \mathrm{mM}$ DTT, and 2.5 units Superscript II and incubated at $42^{\circ} \mathrm{C}$ for 50 minutes; reaction was terminated at $70^{\circ} \mathrm{C}$ for 15 minutes. RNase $\mathrm{H}$ (Invitrogen, California) was added once the first strand was synthesized to remove any remaining RNA by incubated at $37^{\circ} \mathrm{C}$ for 20 minutes.

\subsubsection{Quantitative Real Time RT-PCR}

First strand cDNA was amplified via real time PCR using SYBR Green PCR master mix (ABgene, New York), 200-300nM of forward and reverse primers using AB 7300 qPCR apparatus. Cycling parameters were set at: $95^{\circ} \mathrm{C} 15 \mathrm{~s}, 57^{\circ} \mathrm{C}$ or $63^{\circ} \mathrm{C} 30 \mathrm{~s}$, and extension at $72^{\circ} \mathrm{C}$ for $30 \mathrm{~s}$, for a total of 40 cycles, followed by a final extension at $72^{\circ} \mathrm{C}$ for 10 minutes. The specific primer pairs were: BDNF: forward primer, 5'ATCCAAATATGGCACAGCAA-3; reverse TTCTGCCTGAGTTTTGATGC-3'; Bcl-2: forward primer, 5'AGGAGCAGGTGCCTACAAGA-3; reverse primer, 5'-GCATTTTCCCA CCACTGTCT-3'; ER- $\alpha$ : forward primer, 5'-AAGGGCAGTCACAATGAACC-3; reverse primer, 5'-GCCAGGTCATTCTCCACATT-3'; HPRT: forward primer, 5'GGAGCGGTAGCACCTCCT-3'; reverse primer, 5'-AATCCAGCAGGTCAGCAAAG3'. All samples were compared with a standard curve comprised of pDNA of HPRT, BDNF, Bcl-2, and ER- $\alpha$ generated using TOPO TA Cloning® Kit (Invitrogen, California). Readings were normalized by dividing mRNA starting quantity (SQ) of 
BDNF, Bcl-2, or ER- $\alpha$ by the house-keeping gene HPRT mRNA SQ; output are in picograms (pg) of mRNA.

\subsubsection{Statistical Analysis}

Data are presented as the mean \pm S.E.M and statistical significances were determined by ANOVA followed by Fisher's least significant difference post-hoc testing. Significant differences have a p-value $<.05$. All results were obtained from two separate experimental procedures with factors and levels randomly determined.

\subsection{Results}

2.4.1 Combined $\mathrm{E} 2 / \mathrm{LiCl}$ increases factors involved in learning and memory

I chose to analyze mRNA expression since both estrogen and lithium indirectly and/or directly affect genomic responses [23, 31]. Real time RT-PCR results indicate that BDNF, ER- $\alpha$ and Bcl-2 mRNA expression significantly differs depending on the brain region $(\mathrm{p}<0.001)$ - hippocampal cultures express higher levels of mRNA compared with cortical cultures (figures 1A-1C). I also noted that combined E2/LiCl significantly increases $(\mathrm{p}<0.05)$ BDNF and ER- $\alpha$ mRNA expression (figure $1 \mathrm{~A}$ and 1C). Chronic lithium does not affect Bcl-2 expression in glia [8], but I specifically wanted to see if a short-term treatment with $\mathrm{LiCl}(48 \mathrm{~h})$ will alter Bcl-2 gene expression in my primary mixed culture predominated by glia. Expression of Bcl-2 mRNA, however, showed no significant differences $(\mathrm{p}>0.4)$ across treatment parameters (figure 1B). 
After a $48 \mathrm{~h}$ treatment period E2 alone did not affect BDNF mRNA expression for either hippocampal or cortical cultures (figure 1A). The $\mathrm{LiCl}$ and $\mathrm{E} 2 / \mathrm{LiCl}$ treatment, however, significantly increased hippocampal and cortical BDNF mRNA expression. In cortical cultures, $\mathrm{LiCl}$ significantly increased $(\mathrm{p}<0.05)$ BDNF mRNA expression compared with Control, but combined E2/LiCl treatment significantly increased ( $\mathrm{p}<$ 0.05) BDNF mRNA expression compared with both Control and E2 treated cortical cultures (figure 1A). Hippocampal cultures also displayed this trend, except that $\mathrm{LiCl}$ also increased BDNF mRNA expression compared with E2 treatment as well (figure 1A). There were no significant differences in ER- $\alpha$ mRNA expression for cortical cultures across treatments $(\mathrm{p}<0.05)$ (figure $1 \mathrm{C})$. The E2 treatment did not significantly alter hippocampal ER- $\alpha$ mRNA expression when compared with control and, although $\mathrm{LiCl}$ seemed to increase ER- $\alpha$ mRNA expression this was not a significant increase (figure 1C). Combined $\mathrm{E} 2 / \mathrm{LiCl}$ treatment, however, significantly increased $(\mathrm{p}<0.05)$ hippocampal ER- $\alpha$ mRNA expression after a $48 \mathrm{~h}$ treatment period compared with Control and E2 treated hippocampal cultures (figure 1C). These results demonstrate that my treatment parameters do not alter Bcl-2 gene expression and that combined $\mathrm{E} 2 / \mathrm{LiCl}$ treatment increases BDNF and ER- $\alpha$ gene expression but this increase is region-specific for ER- $\alpha$ (e.g. increase seen in hippocampal cultures but not cortical cultures). This increased gene expression is significant when compared with Control and E2 treated cultures. Additionally, $\mathrm{LiCl}$ treatment only affects BDNF gene expression. No significant differences in gene expression for any markers were detected with E2-treated cultures. 
$1 \mathrm{~A}$.

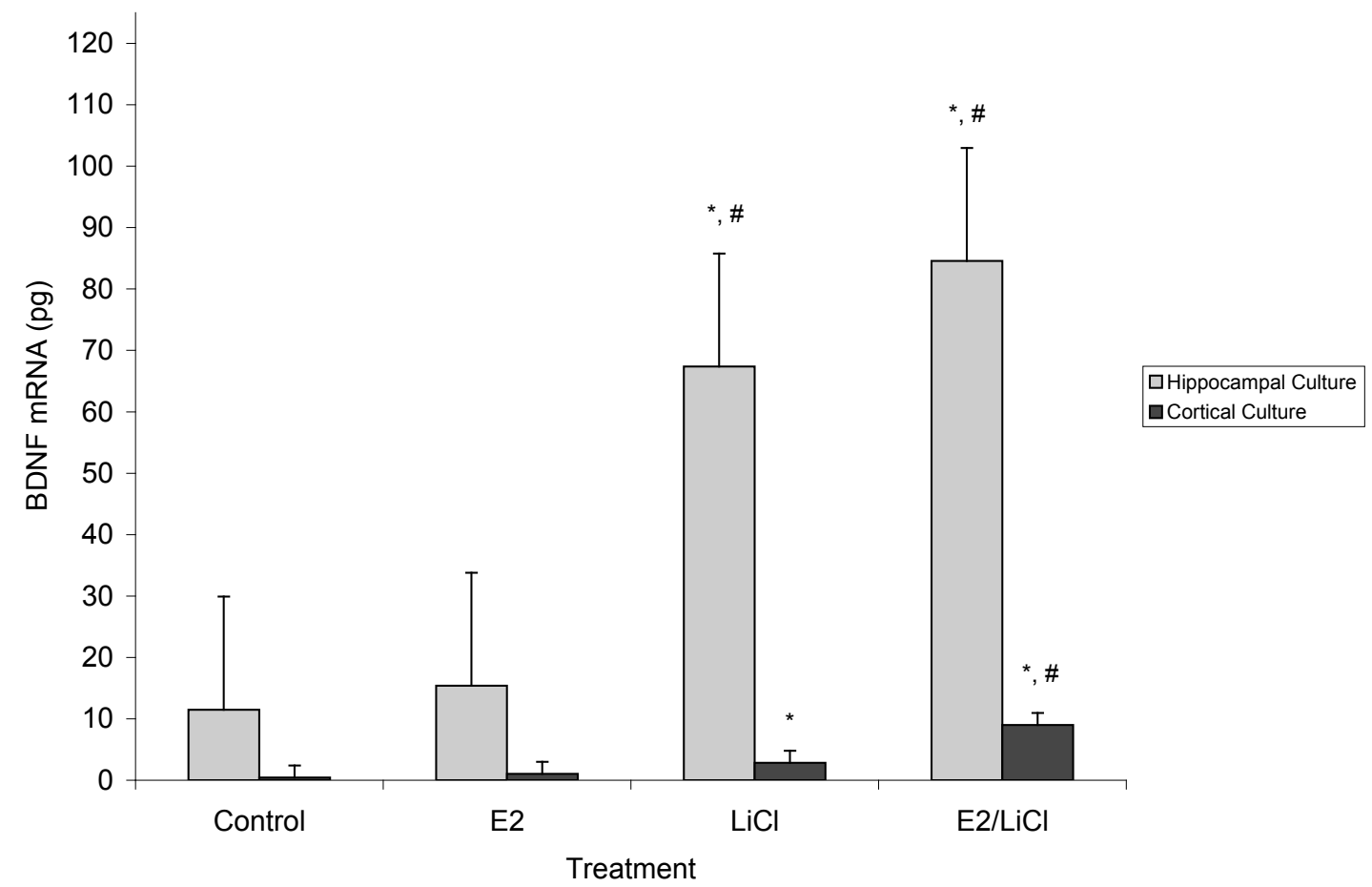

$1 B$.

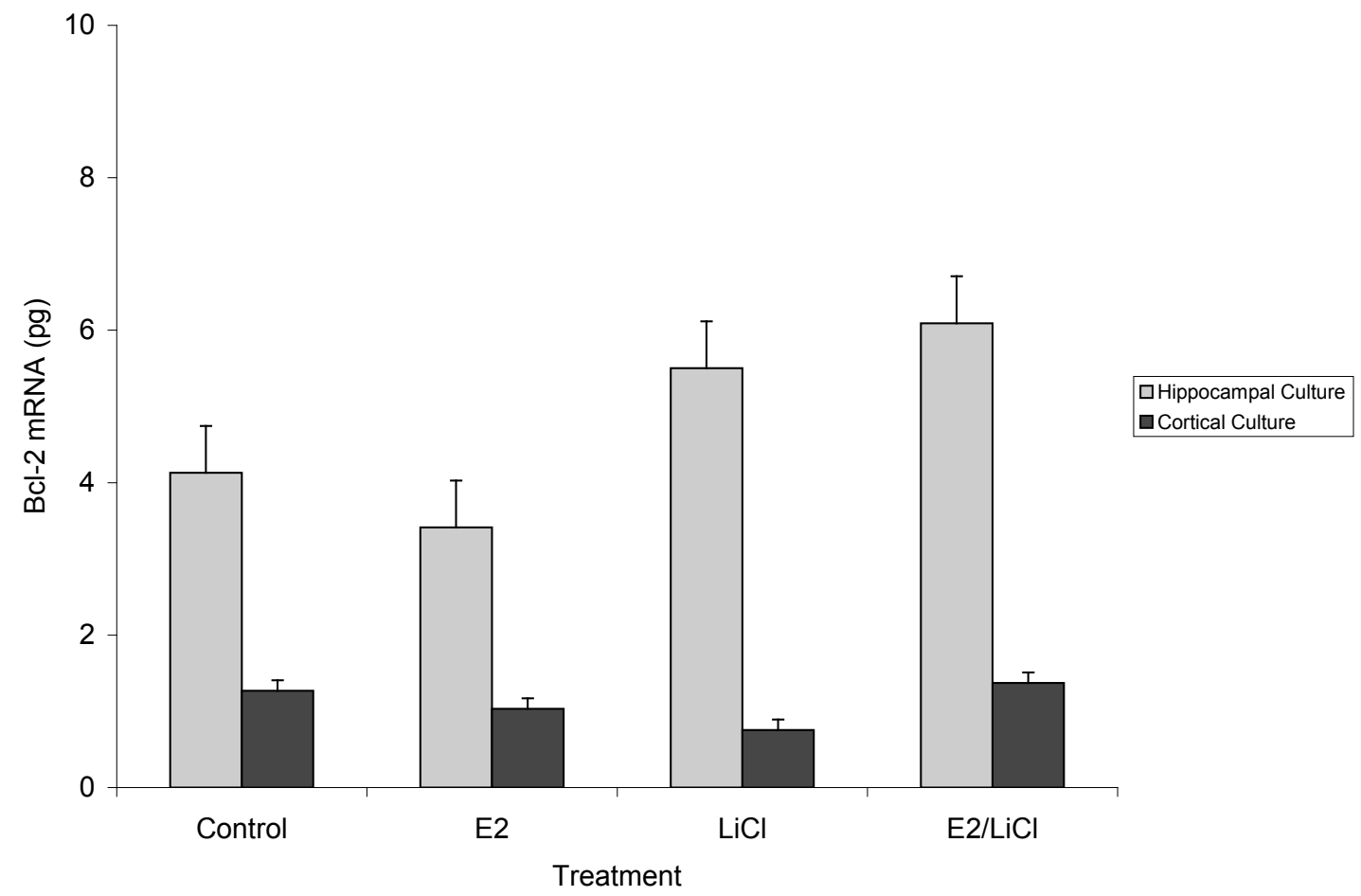




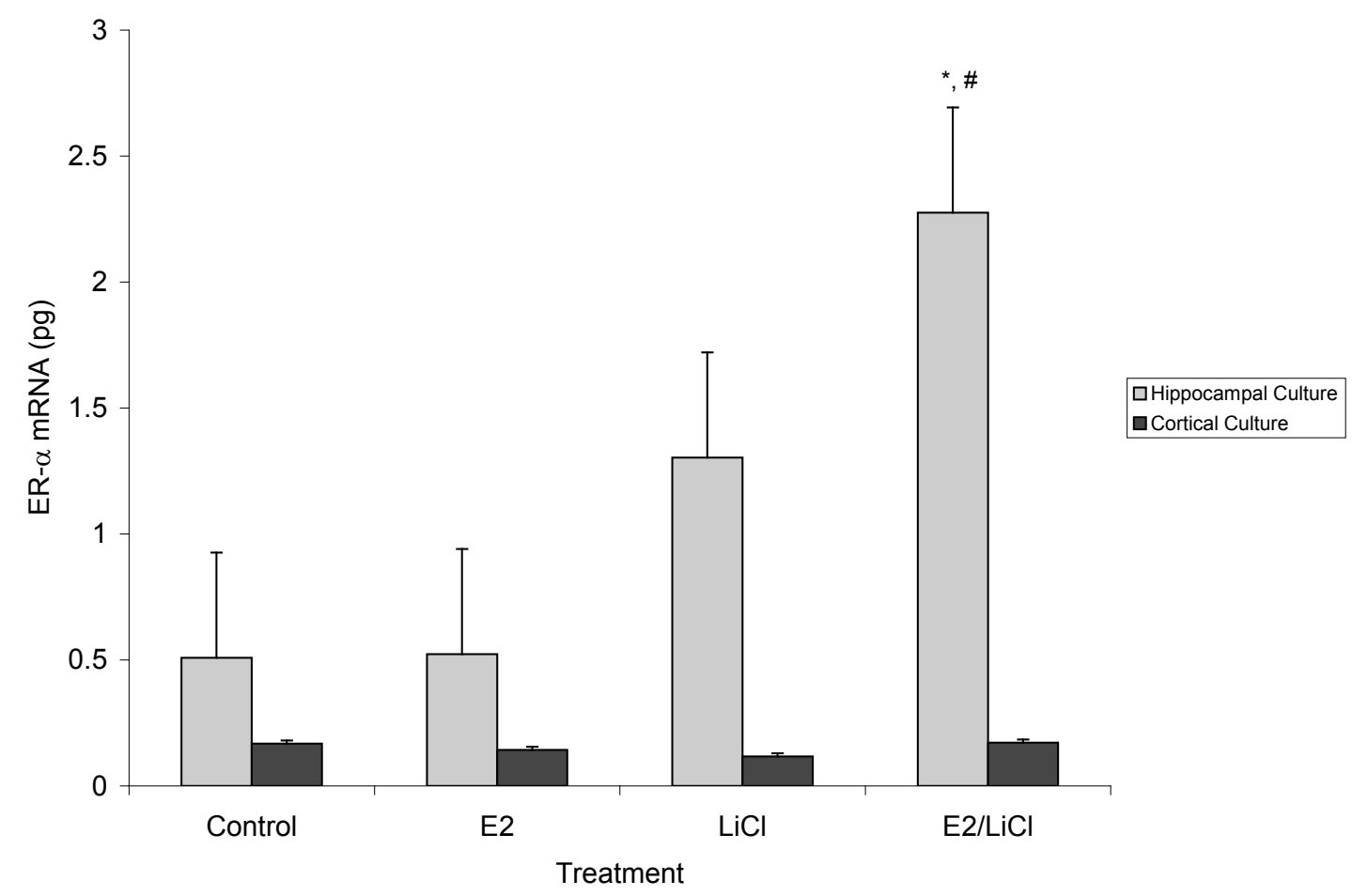

Figures 1A-C: Real time RT-PCR of BDNF (A), Bcl-2 (B), and ER- $\alpha$ (C) mRNA expression. E18.5 hippocampal (grey bars) and cortical (black bars) primary cell cultures were treated for $48 \mathrm{~h}$ with $0.04 \mu \mathrm{M} \mathrm{E} 2,10 \mathrm{mM} \mathrm{LiCl}$, combined $\mathrm{E} 2 / \mathrm{LiCl}$, or Control (no treatment). After treatment total RNA was isolated and reverse transcribed. Expression for each gene was normalized using the house-keeping gene HPRT. The figure denotes normalized mRNA expression in picograms (y-axis) and treatment type (x-axis). *, pvalue $<.05$ compared with control; \#, p-value $<.05$ compared with E2.

\subsection{Discussion}

The immunocytochemical images in figure 2A clearly depict high GFAP expression in hippocampal cultures, but still with low NF-H labeling - as noted by the 
unlabeled surrounding nuclei (figure 2B). This coincides with findings from the previous chapter that these primary mixed brain cell cultures express high levels of glia-specific mRNA, but with consistently low levels of neuron-specific mRNA [48]. Also, it is noteworthy that harvesting brain cells at E18.5 rather than at E14-E15, along with the process of mechanical trituration, promotes viable primary cultures with a predominance of glia. Glia predominate the brain and investigations on how estrogen and lithium affect glial molecular mechanisms are essential for developing and providing palliative treatment regimes for post-menopausal women. Glia are known to express similar markers as neurons do, such as BDNF, Bcl-2, and ER- $\alpha$ and expression level of these markers vary according to neuroanatomical region and developmental stage. Both BDNF [51] and Bcl-2 [7] are highly expressed in hippocampal and cortical regions; however, mRNA distribution of ER- $\alpha$ is also expressed in these brain regions but is difficult to determine due to low expression level in these brain regions [42]. My data concurs with the literature indicating that BDNF, Bcl-2, and ER- $\alpha$ mRNA are expressed in these hippocampal cultures and cortical cultures, but higher expression is noted in hippocampal cultures (figures 1A-1C). 
2A.

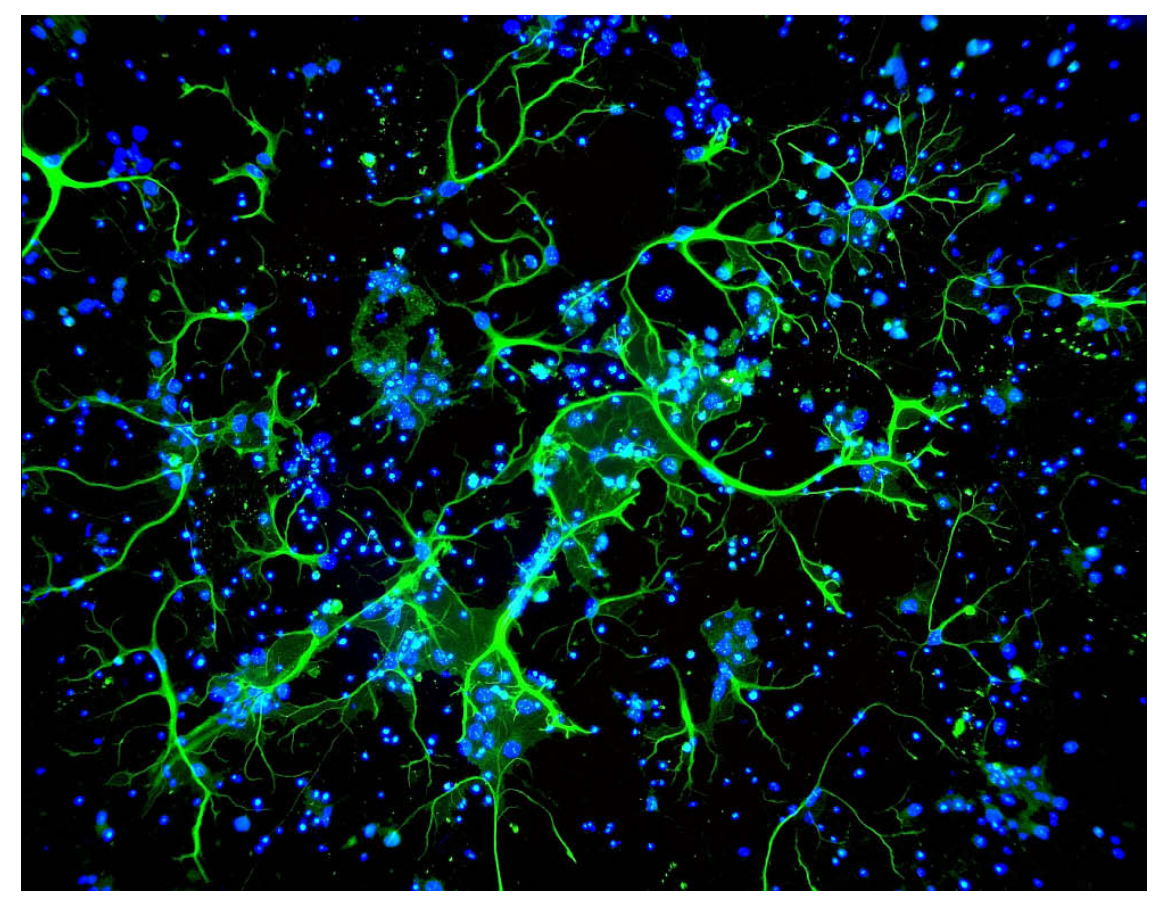

2B.

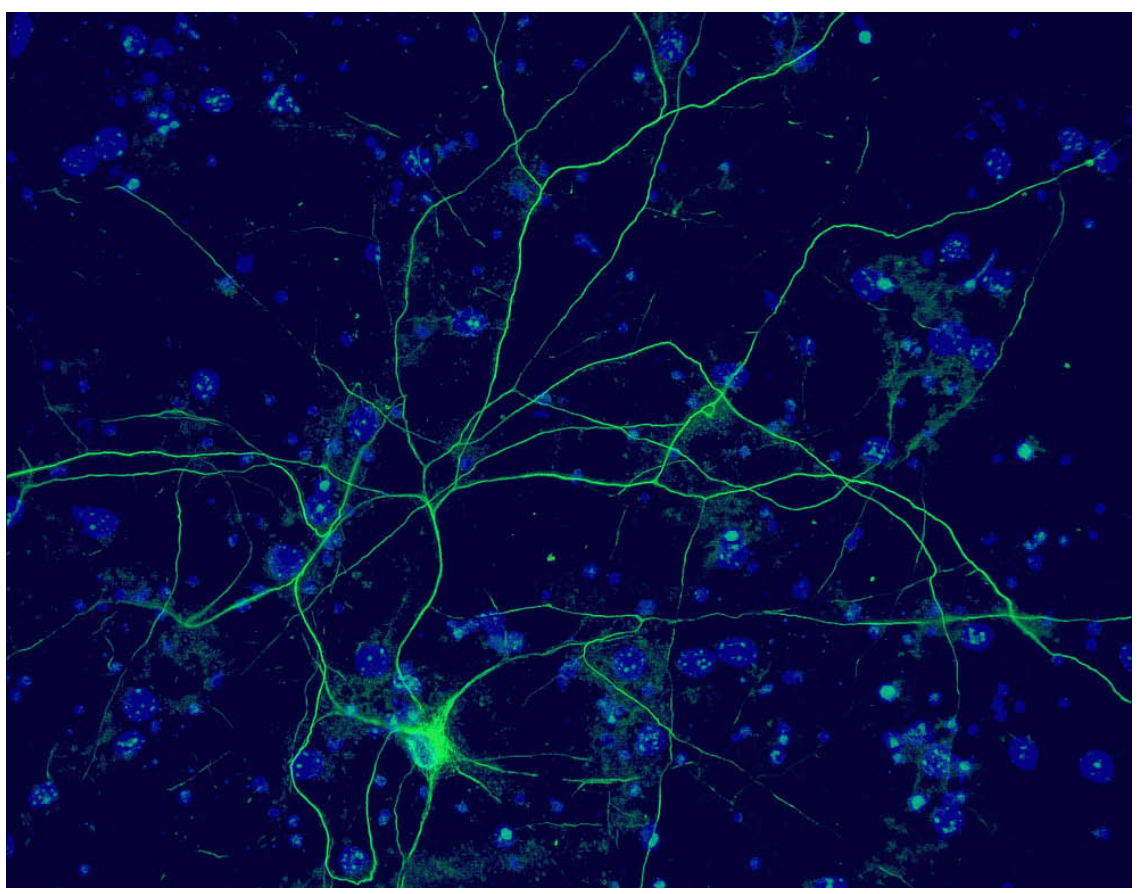


Figures 2A-2B: Immunocytochemical images of hippocampal cultures labeled with GFAP (A; 200X) and; NF-H (B; 400X) antibodies (green). All nuclei are labeled with Hoechst stain (blue). Image color quality and gamma adjustments were made using Adobe Photoshop CS.

I note no significant differences in Bcl-2 gene expression across cultures and all treatment types (figure 1B). This absence coincides with results obtained from chronic lithium treated neuronal and glial cell lines [8]. Studies do indicate that E2 increases Bcl2 expression in primary neuronal cultures from prenatal rat hippocampus, specifically with the concentration and treatment period used in my study [50]. Since I used cultures expressing high GFAP levels (figure 2A), the E2 concentration $\mathrm{Wu}$ et al. [50] used must not affect glia Bcl-2 expression - solely at the transcriptional level and under my experimental parameters, though (figure 1B). Wu et al. [50] explains that the molecular mechanisms that underlie E2 up-regulating Bcl-2 is mediated through ER- $\alpha$ interactions within the Akt pathway. One potential explanation for my results is the ER- $\alpha$ /Akt pathway is highly dependent on PELP1 [4] and PELP1 is expressed at lower levels in glia [24]; there are caveats of molecular processes that may be at play, though.

In the previous chapter, I note that in E2-treated cultures LiCl reduces NMDA subunit NR1 mRNA expression [48]. In the present study, E2 has an additive effect in LiCl-treated cultures on BDNF and ER- $\alpha$ mRNA expression, however, E2 alone does not significantly alter BDNF or ER- $\alpha$ expression (figure 1A and 1C). Lack of altering mRNA BDNF or ER- $\alpha$ expression may be explained by the plasticity of estrogen- 
mediated signaling pathways. Direct genomic effects are classically mediated by estrogen bound ERs, one specific target is NMDA subunit promoter regions [49] and transcriptional properties of ERs are facilitated by GSK-3 $\beta$ - a pathway attenuated by lithium [32]. Attenuation by lithium could explain findings from the previous chapter, but some other mechanism must be at play to explain my present findings. Estrogen mediates indirect genomic effects by binding to ERs and non-ERs such as G-protein coupled receptor, GPR30 [31, 38], which is shown to be expressed in rat brain [3] and activate adenylyl cyclase resulting in cAMP production [38]. Production of cAMP ultimately leads to the activation of the transcription factor cAMP response element binding protein (CREB) [22]. Lithium is a well known facilitator of CREB DNA binding properties by selectively inhibiting GSK-3 $\beta$, a CREB attenuator [14], and BDNF gene expression is mediated by CREB $[17,26]$. These indirect genomic effects mediated by estrogen may be facilitated by lithium, thereby increasing BDNF mRNA expression (figure 1A); however, further investigation is needed to elucidate the upstream molecular pathways involved using my experimental parameters.

The literature is dichotomous on whether lithium increases BDNF levels in the hippocampus or not. Studies show that rats chronically treated with lithium for 2 and 4 weeks increase BDNF expression in their hippocampus [11], but Hammonds and Shim [17] demonstrate that a 4 week lithium treatment does not alter BDNF levels specifically in rat CA1 region of the hippocampus. There may be some developmental differences, since Fukumoto et al. [11] used younger rats compared with Hammonds and Shim [17]. Additionally, Hammonds and Shim [17] showed BDNF expression is specific to 
neuroanatomical regions, since they reported that lithium did increase BDNF expression in the dentate gyrus. In my study, $\mathrm{LiCl}$ increased BDNF gene expression for both culture types (hippocampal and cortical), specifically compared with Control (figure 1A), but the literature states that astrocytic BDNF expression is not affected by lithium [16]. Guo et al. [16] used neonatal rat primary cortical astrocytic cultures showing no effect by lithium on BDNF expression, but lithium does increase BDNF among rat cortical neurons [18] and my results on ER- $\alpha$ and BDNF mRNA expression may be influenced by the low neuronal population in my primary mixed cultures (figure 2B; [48]). Additionally, Guo et al. [16] treated their cultures for only $20 \mathrm{~h}$ which might indicate a temporal difference in lithium treatment and BDNF expression. But the interesting note is that in the Guo et al. study, these lithium-treated primary astrocytic cultures also expressed increased GSK$3 \beta$ inhibition [16].

Results indicate that although $\mathrm{E} 2$ or $\mathrm{LiCl}$ treatment does not significantly alter ER- $\alpha$ mRNA levels, I note a significant additive effect by E2 in LiCl-treated hippocampal cultures (figure 1C) that express high GFAP immunoreactivity (figure 2A). Under conditions of neuronal damage, ER- $\alpha$ expression increases among neonate rat cortical astrocytes, mediated by E2, and this increase aids neuronal damage [6]. Cortical ER- $\alpha$ mRNA expression was not affected by my treatment parameters, though (figure 1C). Cortical cultures did express higher glia-specific mRNA than hippocampal [48] and I report in the present study that primary hippocampal cultures show NF-H perikaryon accumulation (figure 2B), which is indicative of neuronal apoptosis [28]. 
Recent studies using neuronal cell lines show that ER- $\alpha$ gene expression has an E2 dose dependency - reducing ER- $\alpha$ gene expression within $16 \mathrm{~h}$ treatment of $0.1 \mu \mathrm{M}$ E2 [36]. Other studies indicate that ER- $\alpha$ increases in neonatal rat hippocampus with E2 treatment [40]. ER- $\alpha$ also raises developmental considerations since ER- $\alpha$ expression in rat brain is high during prenatal day 9 , declines then increases at neonate stage and then declines again with age [47]; this occurs in both the hippocampus and cortex [13]. Cultures used in this study are from embryonic mouse brain (E18.5) and this developmental factor may account for differences noted in other publications, but I show no significant differences in ER- $\alpha$ mRNA expression with $\mathrm{E} 2$ or $\mathrm{LiCl}$ individual treatment (figure 1C).

Studies show that combined estrogen and lithium affect the dopamine pathway, a pathway associated with many neurodegenerative diseases [34, 43]. Stereotypedbehavior is increased with apomorphine, a dopaminergic agonist, in ovariectomized rats after discontinuing chronic treatment of estrogen; but this increase in stereotypedbehavior is diminished with lithium [10]. Additionally, ovariectomized rats treated with combined E2 and LiCl show greatly decreased dopamine levels, but show higher levels of serotonin and dopamine metabolites in the brain [33]. Results presented in this chapter are generated and interpreted at the transcriptional level but these results indicate that some molecular mechanism is being altered as a result of my treatment paradigm. Many brain cell signaling pathways are facilitated by both estrogen and lithium and both seem to affect similar pathways. One common element that both estrogen and lithium 
possess is an interaction with GSK-3 $\beta$ since lithium affects estrogen receptor-mediated cell signaling via GSK-3 $\beta$ inhibition [32]. Evidence showing that combined estrogen and lithium affect GSK-3 $\beta$ and dopamine pathways postulate some underlying interaction between estrogen and lithium that affect brain cell signaling pathways. Knowledge on how estrogen and lithium interact at the molecular level will contribute to providing proper treatment regiments for women undergoing ERT while displaying symptoms of depression. 


\section{REFERENCES}

[1] F. Angelucci, L. Aloe, P. Jiménez-Vasquez, A.A. Mathé, Lithium treatment alters brain concentrations of nerve growth factor, brain-derived neurotrophic factor and glial cell line-derived neurotrophic factor in a rat model of depression, Int. J. Neuropsychopharmacol. 6 (2003) 225-231.

[2] J. Blake, Menopause: evidence-based practice, Best Practice \& Research Clinical Obstetrics \& Gynaecology 20 (2006) 799-839.

[3] E. Brailoiu, S.L. Dun, G.C. Brailoiu, K. Mizuo, L.A. Sklar, T.I. Oprea, E.R. Prossnitz, N.J. Dun, Distribution and characterization of estrogen receptor G protein-coupled receptor 30 in the rat central nervous system, J. Endocrinol. 193 (2007) 311-321.

[4] D.W. Brann, Q.-G. Zhang, R.-M. Wang, V.B. Mahesh, R.K. Vadlamudi, PELP1 A novel estrogen receptor-interacting protein, Mol. Cell. Endocrinol. 290 (2008) $2-7$.

[5] V.K. Burt, N. Rasgon, Special considerations in treating bipolar disorder in women, Bipolar Disord. 6 (2004) 2-13.

[6] V. Carbonaro, F. Caraci, M.L. Giuffrida, S. Merlo, P.L. Canonico, F. Drago, A. Copani, M.A. Sortino, Enhanced expression of ER $\alpha$ in astrocytes modifies the response of cortical neurons to $\beta$-amyloid toxicity, Neurobiol. Dis. 33 (2009) 415421.

[7] E. Castre'n, Y. Ohga, M.P. Berzaghi, G. Tzimagiorgis, H. Thoenen, D. Lindholm, bcl-2 Messenger RNA is localized in neurons of the developing and adult rat brain, Neuroscience 61 (1994) 165-177.

[8] T.W. Corson, K.K. Woo, P.P. Li, J.J. Warsh, Cell-type specific regulation of calreticulin and Bcl-2 expression by mood stabilizer drugs, Eur. Neuropsychopharmacol. 14 (2004) 143-150.

[9] K.M. Dhandapani, D.W. Brann, Role of astrocytes in estrogen-mediated neuroprotection, Exp. Gerontol. 42 (2007) 70-75.

[10] V.A.C. Dorce, J. Palermo-Neto, Lithium effects on estrogen-induced dopaminergic supersensitivity in rats, Brain Res. Bull. 29 (1992) 239-241.

[11] T. Fukumoto, S. Morinobu, Y. Okamoto, A. Kagaya, S. Yamawaki, Chronic lithium treatment increases the expression of brain-derived neurotrophic factor in the rat brain, Psychopharmacology 158 (2001) 100-106. 
[12] S. Gandy, Estrogen and Neurodegeneration, Neurochem. Res. 28 (2003) 10031008 .

[13] M. González, A. Cabrera-Socorro, C.G. Pérez-García, J.D. Fraser, F.J. López, R. Alonso, G. Meyer, Distribution patterns of estrogen receptor alpha and beta in the human cortex and hippocampus during development and adulthood, J. Comp. Neurol. 503 (2007) 790-802.

[14] C.A. Grimes, R.S. Jope, CREB DNA binding activity is inhibited by glycogen synthase kinase-3 $\beta$ and facilitated by lithium, J. Neurochem. 78 (2001) 12191232.

[15] C.A. Grimes, R.S. Jope, The multifaceted roles of glycogen synthase kinase $3 \beta$ in cellular signaling, Prog. Neurobiol. 65 (2001) 391-426.

[16] S. Guo, K. Arai, M.F. Stins, D.-M. Chuang, E.H. Lo, Lithium Upregulates Vascular Endothelial Growth Factor in Brain Endothelial Cells and Astrocytes, Stroke 40 (2009) 652-655.

[17] M. Hammonds, S.S. Shim, Effects of 4-week Treatment with Lithium and Olanzapine on Levels of Brain-derived Neurotrophic Factor, B-Cell CLL/Lymphoma 2 and Phosphorylated Cyclic Adenosine Monophosphate Response Element-binding Protein in the Sub-regions of the Hippocampus, Basic Clin. Pharm. Toxicol. 9999 (2009).

[18] R. Hashimoto, N. Takei, K. Shimazu, L. Christ, B. Lu, D.-M. Chuang, Lithium induces brain-derived neurotrophic factor and activates TrkB in rodent cortical neurons: An essential step for neuroprotection against glutamate excitotoxicity, Neuropharmacology 43 (2002) 1173.

[19] M. Hofer, S.R. Pagliusi, A. Hohn, J. Leibrock, Y.A. Barde, Regional distribution of brain-derived neurotrophic factor mRNA in the adult mouse brain., European Molecular Biology Organization Journal 9 (1990) 2459-2464.

[20] V. Hongisto, N. Smeds, S. Brecht, T. Herdegen, M.J. Courtney, E.T. Coffey, Lithium Blocks the c-Jun Stress Response and Protects Neurons via Its Action on Glycogen Synthase Kinase 3, Mol. Cell. Biol. 23 (2003) 6027-6036.

[21] T. Ivanova, C. Beyer, Pre- and postnatal expression of brain-derived neurotrophic factor $\mathrm{mRNA} /$ protein and tyrosine protein kinase receptor B mRNA in the mouse hippocampus, Neurosci. Lett. 307 (2001) 21-24.

[22] M. Johannessen, M.P. Delghandi, U. Moens, What turns CREB on?, Cell. Signal. 16 (2004) 1211-1227. 
[23] R.S. Jope, Lithium and GSK-3: one inhibitor, two inhibitory actions, multiple outcomes, Trends Pharmacol. Sci. 24 (2003) 441-443.

[24] M.M. Khan, M. Hadman, C. Wakade, L.M. De Sevilla, K.M. Dhandapani, V.B. Mahesh, R.K. Vadlamudi, D.W. Brann, Cloning, Expression, and Localization of MNAR/PELP1 in Rodent Brain: Colocalization in Estrogen Receptor- $\alpha$ But Not in Gonadotropin-Releasing Hormone-Positive Neurons, Endocrinology 146 (2005) 5215-5227.

[25] P.S. Klein, D.A. Melton, A molecular mechanism for the effect of lithium on development, PNAS 93 (1996) 8455-8459.

[26] Y. Koyama, K. Tsujikawa, T. Matsuda, A. Baba, Endothelin increases expression of exon III- and exon IV-containing brain-derived neurotrophic factor transcripts in cultured astrocytes and rat brain, J. Neurosci. Res. 80 (2005) 809-816.

[27] A. Kukopulos, G. Minnai, B. Muller-Oerlinghausen, The influence of mania and depression on the pharmacokinetics of lithium: A longitudinal single-case study, J. Affect. Disord. 8 (1985) 159-166.

[28] J.M. Lee, K. Adeel, C.P. Ann, Motor neuron degeneration after sciatic nerve avulsion in adult rat evolves with oxidative stress and is apoptosis, J. Neurobiol. 40 (1999) 185-201.

[29] Y.-P. Lu, M. Zeng, X.-Y. Hu, H. Xu, D.F. Swaab, R. Ravid, J.-N. Zhou, Estrogen receptor $\alpha$-immunoreactive astrocytes are increased in the hippocampus in Alzheimer's disease, Exp. Neurol. 183 (2003) 482-488.

[30] H.K. Manji, G.J. Moore, G. Chen, Lithium at 50: have the neuroprotective effects of this unique cation been overlooked?, Biol. Psychiatry 46 (1999) 929-940.

[31] B.S. McEwen, Genome and Hormones: Gender Differences in Physiology: Invited Review: Estrogens effects on the brain: multiple sites and molecular mechanisms, J. Appl. Physiol. 91 (2001) 2785-2801.

[32] S. Medunjanin, A. Hermani, B. De Servi, J. Grisouard, G. Rincke, D. Mayer, Glycogen Synthase Kinase-3 Interacts with and Phosphorylates Estrogen Receptor $\alpha$ and Is Involved in the Regulation of Receptor Activity, J. Biol. Chem. 280 (2005) 33006-33014.

[33] M. Morissette, T. Di Paolo, Acute effect of $17 \beta$-estradiol and lithium on ovariectomized rat brain biogenic amines metabolism, J. Psychiatr. Res. 30 (1996) 95-107. 
[34] M. Morissette, M. Le Saux, M. D'Astous, S. Jourdain, S. Al Sweidi, N. Morin, E. Estrada-Camarena, P. Mendez, L.M. Garcia-Segura, T. Di Paolo, Contribution of estrogen receptors alpha and beta to the effects of estradiol in the brain, J. Steroid Biochem. Mol. Biol. 108 (2008) 327-338.

[35] S. Nair, R.K. Vadlamudi, Emerging significance of ER-coregulator PELP1/MNAR in cancer, Histol. Histopathol. 22 (2007) 91-96.

[36] Y. Ng, A. Wolfe, H.J. Novaira, S. Radovick, Estrogen regulation of gene expression in GnRH neurons, Mol. Cell. Endocrinol. 303 (2009) 25-33.

[37] N. Ozaki, D.-M. Chuang, Lithium Increases Transcription Factor Binding to AP-1 and Cyclic AMP-Responsive Element in Cultured Neurons and Rat Brain, J. Neurochem. 69 (1997) 2336-2344.

[38] E.R. Prossnitz, J.B. Arterburn, H.O. Smith, T.I. Oprea, L.A. Sklar, H.J. Hathaway, Estrogen Signaling through the Transmembrane G Protein-Coupled Receptor GPR30, Annu. Rev. Physiol. 70 (2008) 165-190.

[39] C. Riley, T. Cope, C. Buck, CNS neurotrophins are biologically active and expressed by multiple cell types, J. Mol. Hist. 35 (2004) 771-783.

[40] G.M. Rune, U. Wehrenberg, J. Prange-Kiel, L. Zhou, G. Adelmann, M. Frotscher, Estrogen up-regulates estrogen receptor [alpha] and synaptophysin in slice cultures of rat hippocampus, Neuroscience 113 (2002) 167-175.

[41] F. Saravia, J. Beauquis, L. Pietranera, A.F. De Nicola, Neuroprotective effects of estradiol in hippocampal neurons and glia of middle age mice, Psychoneuroendocrinology 32 (2007) 480-492.

[42] P.J. Shughrue, M.V. Lane, I. Merchenthaler, Comparative distribution of estrogen receptor- $\alpha$ and $-\beta$ mRNA in the rat central nervous system, J. Comp. Neurol. 388 (1997) 507-525.

[43] T. Silverstone, Dopamine in manic depressive illness : A pharmacological synthesis, J. Affect. Disord. 8 (1985) 225-231.

[44] F. Sohrabji, D.K. Lewis, Estrogen-BDNF interactions: Implications for neurodegenerative diseases, Front. Neuroendocrinol. 27 (2006) 404-414.

[45] D.T. Solum, R.J. Handa, Estrogen Regulates the Development of Brain-Derived Neurotrophic Factor mRNA and Protein in the Rat Hippocampus, J. Neurosci. 22 (2002) 2650-2659. 
[46] D. Song, T. Du, B. Li, L. Cai, L. Gu, H. Li, Y. Chen, L. Hertz, L. Peng, Astrocytic alkalinization by therapeutically relevant lithium concentrations: implications for myo-inositol depletion, Psychopharmacology 200 (2008) 187195.

[47] J.-D. Su, J. Qiu, Y.-P. Zhong, X.-Y. Li, J.-W. Wang, Y.-Z. Chen, Expression of estrogen receptor (ER)-alpha and -beta immunoreactivity in hippocampal cell cultures with special attention to GABAergic neurons, J. Neurosci. Res. 65 (2001) 396-402.

[48] J.J. Valdés, O.I. Weeks, Estradiol and lithium chloride specifically alter NMDA receptor subunit NR1 mRNA and excitotoxicity in primary cultures, Brain Res. 1268 (2009) 1-12.

[49] T. Watanabe, S. Inoue, H. Hiroi, A. Orimo, M. Muramatsu, NMDA receptor type 2D gene as target for estrogen receptor in the brain, Mol. Brain Res. 63 (1999) 375-379.

[50] T.W. Wu, J.M. Wang, S. Chen, R.D. Brinton, $17 \beta$-estradiol induced $\mathrm{Ca}^{2+}$ influx via L-type calcium channels activates the Src/ERK/cyclic-AMP response element binding protein signal pathway and BCL-2 expression in rat hippocampal neurons: A potential initiation mechanism for estrogen-induced neuroprotection, Neuroscience 135 (2005) 59-72.

[51] H.-T. Zhang, L.-Y. Li, X.-L. Zou, X.-B. Song, Y.-L. Hu, Z.-T. Feng, T.T.-H. Wang, Immunohistochemical Distribution of NGF, BDNF, NT-3, and NT-4 in Adult Rhesus Monkey Brains, J. Histochem. Cytochem. 55 (2007) 1-19. 


\section{CHAPTER III}

Lithium Enhances Episodic Memory and the Expression of Factors Involved in Learning, Memory and Anti-Apoptosis in Estrogen-Deficient Mice

\section{Abstract}

The hippocampus and cortex are areas of the mammalian brain that are involved in learning and long-term memory, respectively. Also, there is a tendency for learning and memory to decline in adult women during peri- and post-menopausal periods. Both estrogen and lithium affect learning and memory processes and both of these agents may be prescribed to post-menopausal women; however, the literature shows that hormone therapy is correlated with an increased incidence of breast cancer. I hypothesized that in estrogen-deficient mice lithium alone will enhance behavioral task performance, and in the brain, increase expression of factors involved in learning and memory. My study used bilaterally ovariectomized (bOVX) C57BL/6J mice treated for one month with 14.2mM lithium chloride $(\mathrm{LiCl})$ in their drinking water. Results indicated that LiCltreated bOVX mice enhanced their performance in an object recognition task (ORT) compared with non-treated bOVX. Enhanced performance in ORT led me to examine in the hippocampus and cortex, expression of mRNA and related proteins involved in learning, memory and neuroprotection. Gene expression of these factors are increased in the cortex of LiCl-treated bOVX mice, but not in the hippocampus, compared with nontreated bOVX mice. A glutamate receptor subunit and neurotrophic factor protein expression increased in the hippocampus of LiCl-treated bOVX mice compared with non-treated bOVX mice. Additionally, increased protein and mRNA expression 
coincided with increased inhibition of a kinase involved in attenuating expression of markers relevant to learning, memory and neuroprotection. I believe my study may be useful in developing palliative therapies that use lithium as a treatment for cognitive decline associated with estrogen-deficiency (e.g. post-menopause).

\subsection{Introduction}

A lack of circulating estrogen during peri-menopause is correlated with cognitive decline [29]. Hormone therapy is usually prescribed during peri- and post-menopause, but increased breast cancer incidences are reported for women undergoing hormone therapy [31]. Scientific investigations do indicate that estrogen-mediated neuromechanisms enhance synaptic plasticity [25], reduce apoptotic activity in cortical neurons [21], regulate brain derived neurotrophic factor (BDNF) [40], and facilitate transcription factor activation such as cyclic adenosine monophosphate (cAMP) responsive element binding protein (CREB) [27]. Estrogen stimulates molecular processes involved in learning and memory; however, hormone therapy does not improve cognitive decline during menopause, specifically episodic memory [20]. Ovariectomized (OVX) and estrogen receptor- $\alpha$ (ER- $\alpha)$ knockout mice perform poorly on hippocampaldependent behavioral tasks indicating that normal circulating estrogen and ER- $\alpha$ expression influence cognitive-behavioral performance levels [11]. Co-localization of ER- $\alpha$ and BDNF are noted in pyramidal cells of the hippocampus, and estrogen influences BDNF expression [40]. Ligand binding of BDNF to tyrosine receptors initiates a signaling cascade that results in activating CREB [3], increasing synaptic 
plasticity [43], and facilitating CREB-mediated gene expression via $N$-methyl-D-aspartate receptor (NMDAR) signaling pathways [47].

Lithium is commonly prescribed for bipolar disorder and schizophrenia [10], but lithium also affects several molecular pathways via glycogen synthase kinase-3beta (GSK-3 $\beta$ ) inhibition [24]. Inhibition of GSK-3 $\beta$ reduces apoptotic activity [22], increases neurotrophic factors [2], and facilitates CREB's response element binding [15, 33]. Though the mechanism remains elusive, the literature states that lithium inhibits GSK-3 $\beta$ through indirect and direct mechanisms. Indirectly, lithium promotes protein kinases that inhibit and may simultaneously inhibit phosphatases that activate GSK-3 $\beta$ [24]. Lithium directly inhibits GSK-3 $\beta$ by acting as a competitive inhibitor of magnesium, magnesium being co-factor for ATP in GSK-3 $\beta$ activation [36]. Aside from lithium's inhibitory action on GSK-3 $\beta$, lithium acts as neuroprotectant by indirectly influencing NMDAR signaling. Lithium decreases NMDAR-mediated excitotoxicity by reducing phosphorylation/activation of Src tyrosine kinases thus inhibiting NMDAR subunit signaling pathways [18]. The neuroprotective properties of lithium are also marked by increased levels of the anti-apoptotic agent B-cell lymphoma/leukemia-2 (Bcl2) and BDNF [5]. Estrogen also facilitates Bcl-2 expression by the CREB activation pathway and by indirectly interacting with NMDAR [50].

Estrogen and lithium influence similar signaling transduction pathways; specifically facilitating molecular signaling pathways involved in learning and memory 
$[15,27]$. Chapter one experimental data showed that combined estrogen and lithium chloride $(\mathrm{LiCl})$ treatment reduces mRNA expression of NR1, a critical subunit of NMDAR, in primary mixed brain cell cultures, predominated by glia [42], indicating interaction between estrogen and lithium in genetic expression. A former master's degree graduate from the laboratory of my advisor, Dr. Ophelia I. Weeks, showed that 14.2 $\mathrm{mM} \mathrm{LiCl}$ in drinking water maintains a sub-therapeutic plasma level of lithium at about $0.2 \mathrm{mM}$ and facilitates enhanced performance in spatial and non-spatial memory tasks (unpublished data). In the present study I hypothesized that LiCl-treated estrogendeficient mice will perform better in an object recognition task (ORT) by altering mRNA/protein expression of factors involved in learning, memory and neuroprotection in the hippocampus and cortex. To test my hypothesis I treated bilaterally OVX (bOVX) C57BL/6J mice with $14.2 \mathrm{mM} \mathrm{LiCl}$ for 1 month. Results presented in this chapter indicate that $\mathrm{LiCl}$ treatment enhances ORT performance in bOVX mice and this enhancement coincides with an increase in factors involved in learning, memory and neuroprotection.

Typically, women undergo natural menopause by their late 40 s to early 50 s and estrogen replacement therapy (ERT) is commonly prescribed peri- and post-menopause. Post-menopausal women on ERT may be at risk, since there is increased incidences of lobular carcinoma in women undergoing ERT [31]. Selective estrogen receptor modulators (SERMs) provide an alternative to ERT but studies show that SERMs do not improve cognitive functioning [30, 34]. Therefore, an alternative therapy for peri- and post-menopausal women is wanting. The present study will contribute data to the 
literature on lithium's potential as a therapeutic agent for enhancing cognitive function during a period of estrogen-deficiency.

\subsection{Experimental Procedures}

\subsubsection{Subjects, Surgery and Treatment}

C57BL/6J female mice $(n=20)$ were purchased from Jackson Laboratories. Animals were kept in an environment of $20-22^{\circ} \mathrm{C}$ temperature, $60 \%$ humidity, within polycarbonate transparent cages $(26.7 \mathrm{~cm} \mathrm{X} 20.6 \mathrm{~cm} \mathrm{X} 14 \mathrm{~cm})$ on a 12-hour day-night cycle with free access to water and food. The Institutional Animal Care and Use Committee approved all experiments (08-017).

At 4.5 months of age mice were anesthetized with ether, weighed, and both ovaries were removed surgically. Mice were positioned dorsal side up and for each surgical procedure, parallel to the long axis of the animal's body, an incision $3 / 4 \mathrm{~cm}$ in length was made $1 / 2 \mathrm{~cm}$ from the hip area. The fallopian tube was located bilaterally and both ovaries were removed. Treatment with $14.2 \mathrm{mM} \mathrm{LiCl}+0.9 \%$ Saline in their drinking water began at 5 months of age for 1 month; $\mathrm{LiCl}$ at $14.2 \mathrm{mM}$ maintains lithium blood content at a sub-therapeutic range $(<0.5 \mathrm{mM})$ [37]. The control group received only $0.9 \%$ Saline in their drinking water. All animals were divided into four groups (lithium-treated bOVX and Sham; saline-treated bOVX and Sham). Mice were handled for 15-30 s weekly and weighed weekly. After a one-month treatment period, mice were subjected to a cognitive-behavioral task (e.g., ORT). 


\subsubsection{Object Recognition Task (ORT), Thigmotaxis and Velocity}

Studies using ORT indicate that animals habituate to an object and when subsequently introduced to a different, novel object these animals will spend greater lengths of time with the novel object [32]. In addition, ORT is known to be highly dependent upon the hippocampus $[44,48]$ and is a form of episodic memory. The ORT were performed in an arena measuring $121 \mathrm{~cm}$ in diameter, with a depth of $22 \mathrm{~cm}$. The arena was painted white and the flooring covered with bedding material. Two strips of Velcro, $60 \mathrm{~cm}$ apart were placed on the bottom of the arena to secure each object. There were three objects in total: two oval/egg-shaped objects (Old) and one pyramid object (New). All objects were of the same color and size, made of the same material, by the same manufacturer (Playskool $\left.{ }^{\circledR}\right)$. All objects were wiped with 95\% ethanol between trials. Twenty-four hours $(24 \mathrm{~h})$ prior to each treatment regime, 3-5 experimental mice were allowed to run freely in the empty arena (no objects) for 30 min to introduce olfactory cues to the testing arena. After olfactory habituation, each mouse was individually exposed to two identical objects (egg shaped), for ten minutes (priming). After priming, the subject was rested for thirty minutes and then tested on novel object recognition for ten minutes. During this portion of the test, one of the two old objects was replaced with a new pyramid object (positioning of objects was randomized). These last ten minutes were videotaped using a Panasonic digital camera and analyzed with the tracking system EthoVision XT (version 5.0 Noldus Information Technology, Leesburg, VA) to measure ORT, thigmotaxis to measure anxiety and velocity to measure speed. Parameters for ORT were measured when the subject came within $5 \mathrm{~cm}$ of the new object, and/or investigated the new object. Measurements were calculated and presented as a 
percentage, based on the following calculation, the novel object/(novel object + old object). Thigmotaxis measures anxiety displayed by the experimental mice. Anxiety was characterized as time spent $5 \mathrm{~cm}$ from the edge of the arena, defined as the thigmotactic zone, distinguishable from the ORT zone, the inner area with a diameter of $116 \mathrm{~cm}$ (the total diameter being $121 \mathrm{~cm})$. Velocity was measured as the average speed $(\mathrm{cm} / \mathrm{sec})$ of experimental mice. A baseline measurement for each parameter (ORT, thigmotaxis and velocity) was taken using non-experimental mice $(\mathrm{n}=3)$.

\subsubsection{Uterine and Bone Weight}

All mice were anesthetized under ether and were then cervically dislocated. Brains, uteri, femora and humeri were removed from each experimental mouse. Each uterus was weighed and inspected to assure complete removal of ovaries during bOVX surgery. Bones were dried at $70^{\circ} \mathrm{C}$ for $24 \mathrm{~h}$ and then weighed.

\subsubsection{Total RNA Isolation and Reverse Transcription (RT)}

After ORT, total RNA was isolated from brain tissue using TRIzol reagent (GIBCO, California), according to manufacturer's protocol. Briefly, brains were removed from each subject, the cortex and hippocampus of each hemisphere were isolated under a dissecting microscope, weighed, and rinsed with Dulbecco's Phosphate Buffer Saline (DPBS). A 1:10 weight TRIzol reagent was added then homogenized with an IKA homogenizer (speed 5 for $10 \mathrm{~s}$ ). Chloroform was added and centrifuged at $12,000 \times \mathrm{g}$ for $15 \mathrm{~min}$ at $4^{\circ} \mathrm{C}$. After phase separation total RNA (aqueous phase) was collected and the protein (phenol phase) was stored at $-80^{\circ} \mathrm{C}$ for further processing (see 
Protein isolation and Western Blot section). Total RNA was then precipitated with isopropanol and RNA was pelleted via centrifugation. Total RNA pellet was washed with $75 \%$ ethanol and then resuspended in DEPC-treated water. To remove any DNA containments RQ1 DNase kit (Promega, Wisconsin) was used. Aliquots of samples were used for concentration and purity quantification using absorptions at $260 \mathrm{~nm}$ and $280 \mathrm{~nm}$.

First strand cDNA synthesis was performed using SUPERSCRIPT ${ }^{\mathrm{TM}}$ III RNase H-free reverse transcriptase (Invitrogen, California), according to manufacturer's protocol. Briefly, $3 \mu \mathrm{g}$ of total RNA was reverse transcribed with $0.05 \mu \mathrm{g} / \mu \mathrm{l}$ of Oligo $(\mathrm{dT})_{20}$ at $65^{\circ} \mathrm{C}$ for 5 min. First strand cDNA was synthesized with Superscript III/RNase OUT Enzyme mix and incubated at $50^{\circ} \mathrm{C}$ for $50 \mathrm{~min}$; reaction was terminated at $85^{\circ} \mathrm{C}$ for 5 min. RNase H (Invitrogen, California) was added once first strand was synthesized to remove any remaining RNA. RNase $\mathrm{H}$ was incubated at $37^{\circ} \mathrm{C}$ for $20 \mathrm{~min}$. Samples were stored at $-20^{\circ} \mathrm{C}$ until further processed.

\subsubsection{Quantitative Real Time RT-PCR}

First strand cDNA was amplified via real time PCR using SYBR Green PCR master mix (ABgene, New York), 200-300nM of forward and reverse primers using AB 7300 Real Time PCR system. Cycling parameters were set at $95^{\circ} \mathrm{C}$ for $30 \mathrm{~s}, 57^{\circ} \mathrm{C}-63^{\circ} \mathrm{C}$ for $30 \mathrm{~s}$, and extension at $72^{\circ} \mathrm{C}$ for $30 \mathrm{~s}$, for a total of 40 cycles, followed by a final extension at $72^{\circ} \mathrm{C}$ for $10 \mathrm{~min}$. The specific primer pairs were: ER- $\alpha$ : forward primer, $5^{\prime}-$ AAGGGCAGTCACAATGAACC-3; reverse 5' GCCAGGTCATTCTCCACATT-3'; NMDAR subunit NR1: forward primer, 5'- 
ACTCCCAACGACCACTTCAC-3;

reverse

primer,

5

GTAGACGCGCATCATCTCAA-3'; Bcl-2: forward primer, 5'AGGAGCAGGTGCCTACAAGA-3; reverse primer, 5'-GCATTTTCCCA CCACTGTCT-3'; BDNF: forward primer, 5'-ATCCAAATATGGCACAGCAA-3; reverse primer, 5'-TTCTGCCTGAGTTTTGATGC-3'. The endogenous control was HPRT: forward primer, 5'-GGAGCGGTAGCACCTCCT-3'; reverse primer, 5'AATCCAGCAGGTCAGCAAAG-3'. All samples were compared with a standard curve comprised of pDNA generated using TOPO TA Cloning® Kit (Invitrogen, California). Readings were normalized by dividing interest gene number of copies by the housekeeping gene (HPRT) number of copies; output is the ratio mRNA number of copies (described in the previous chapters as starting quantity).

\subsubsection{Protein Isolation and Western Blot}

Protein isolation from TRIzol after DNA precipitation was performed according to manufacturer's protocol. Briefly, protein was precipitated with isopropanol, centrifuged at $10000 \mathrm{x}$ g for $10 \mathrm{~min}$, and pellet washed several times with $0.3 \mathrm{M}$ guanidine hydrochloride $/ 95 \%$ ethanol. Pellet was resuspended in $1 \%$ SDS and stored at $-20^{\circ} \mathrm{C}$ until further processing. A Bradford assay was used to determine protein concentration of cortical and hippocampal lysates and calculated for $20 \mu \mathrm{g} / \mathrm{lane}$. Samples were diluted in non-reducing sample buffer (0.3 M Tris- $\mathrm{HCl}$ [pH 6.8]; $2 \% \mathrm{SDS} ; 10 \%$ Glycerol; $0.01 \%$ bromophenol blue) and boiled at $100^{\circ} \mathrm{C}$ for 5 min. Protein samples were separated by molecular weight with an $8 \%-16 \%$ SDS polyacrilamide gel and transferred onto a nitrocellulose membrane using XCell II Blot Module (Invitrogen, California). Non- 
specific binding sites were blocked overnight at $4^{\circ} \mathrm{C}$ with $5 \%$ non-fat dry milk in TBST (TBS with $0.1 \%[\mathrm{v} / \mathrm{v}]$ Tween-20) and immunolabeled at room temperature for $1.5 \mathrm{~h}$ using antibodies against: BDNF (Santa Cruz Biotechnology, California) and; NMDAR subunit NR1, Phospho-CREB (serine 133), and Phospho-GSK-3 $\beta$ (serine 9) (Cell Signaling, Massachusetts). Membrane was then incubated at room temperature for $1 \mathrm{~h}$ with secondary horseradish peroxidase-conjugated antibodies (directed against the host of the $1^{\circ}$ antibody); signal enhanced with LumiGLO (Cell Signaling, Massachusetts) and developed/visualized using x-ray film. Membranes were stripped with 0.2 M Glycine $(\mathrm{pH} 2.5)$ and $0.1 \%(\mathrm{v} / \mathrm{v})$ Tween-20 and labeled with anti-actin (Sigma-Aldrich, MO) used as a loading control. Images of x-ray films were scanned using a CanoScan Lide 30 scanner (Canon).

\subsubsection{Statistical Analysis}

The data are presented as mean \pm S.E.M and statistical significance is determined by ANOVA followed by LSD post-hoc procedure. Significant differences have p-values $<0.05$.

\subsection{Results}

\subsubsection{Removal of ovaries from mice resulted in weight gain}

During pre-bOVX all mice weighed on average $22.0 \mathrm{~g}$. Throughout post-bOVX and treatment period, mice were handled and weighed weekly prior to ORT. The average weekly weight showed that both Sham groups (non-treated and LiCl-treated Sham) roughly weighed the same $(23.6 \mathrm{~g})$; however, LiCl-treated bOVX $(25.5 \mathrm{~g})$ weighed less 
than non-treated bOVX (27.0g). Statistical analyses on weekly weight indicated that non-treated bOVX significantly weighed more $(p<0.05)$ than non-treated Sham and LiCl-treated Sham during week 1, 2, 4, and 5 - week 3 the significant difference lies solely compared with non-treated Sham (figure 1). Weight gain for LiCl-treated bOVX mice fluctuated since weight gain was not apparent during week 3 and 5 in LiCl-treated bOVX compared with both Sham groups - there was also no difference during week 1 when LiCl-treated bOVX were compared with LiCl-treated Sham (figure 1). I also monitored the daily volume intake of the treatment (or control) that indicates the average intake of LiCl-treated water $(21.7 \mathrm{~mL} /$ day/mouse) was slightly less than saline treated water $(24.4 \mathrm{~mL} /$ day/mouse $)$, but this difference was not significant $(\mathrm{p}>0.05)$.

\subsubsection{An increase of episodic memory by $\mathrm{LiCl}$ in estrogen-deficient mice}

Cognitive decline is a common characteristic of estrogen-deficiency as measured by behavioral tasks [11]. Figure 2A shows that non-treated bOVX animals showed decreased performance in ORT compared with the baseline group and the other three experimental groups. Statistical analysis of ORT indicated that LiCl-treated bOVX mice showed a significant increase $(\mathrm{p}<0.05)$ in novel object recognition performance when compared with non-treated bOVX (figure 2A). The LiCl-treated Sham group showed a $13 \%$ increase in novel object recognition compared with non-treated bOVX, but this proved to be non-significant $(\mathrm{p}>0.05)$. I also measured thigmotactic behavior and velocity showing that experimental mice displayed less anxiety (figure $2 \mathrm{~B}$ ) and speed (figure 2C), respectively, compared with baseline. These parameters, however, showed no significant changes across treatment groups. 


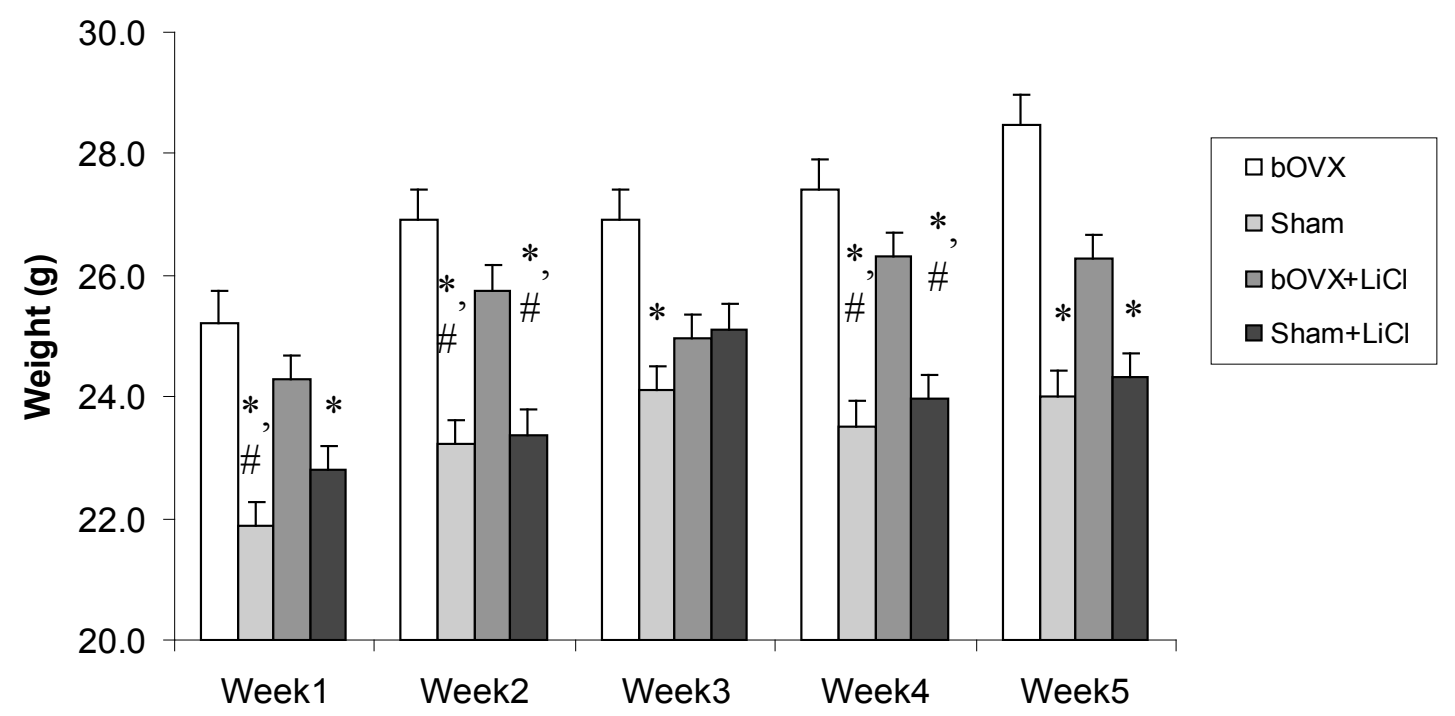

Figure 1. Weekly weight of experimental mice. *, significant increase compared to bOVX; \#, significant increase compared to bOVX + LiCl.

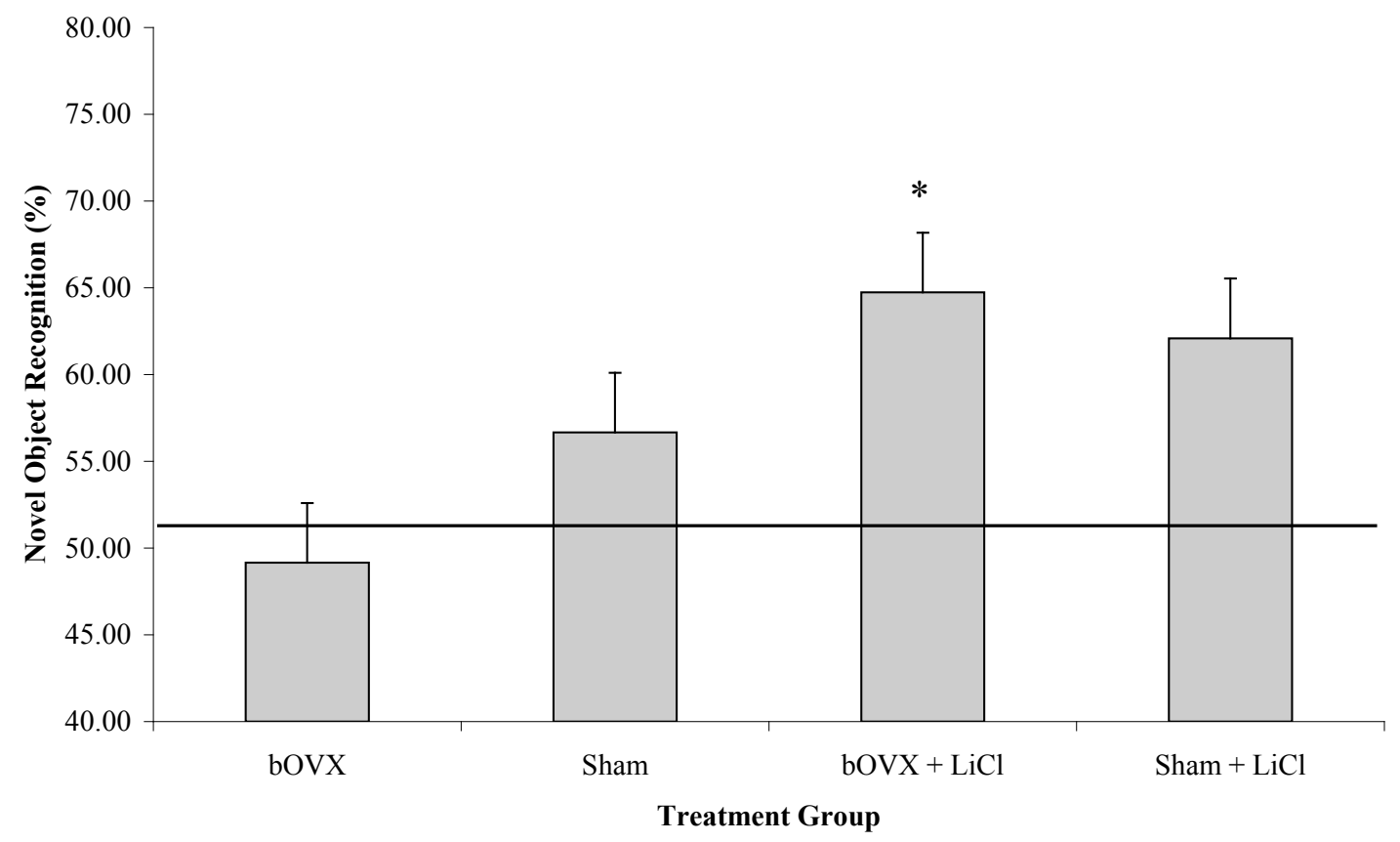


2B.

Thigmotaxis

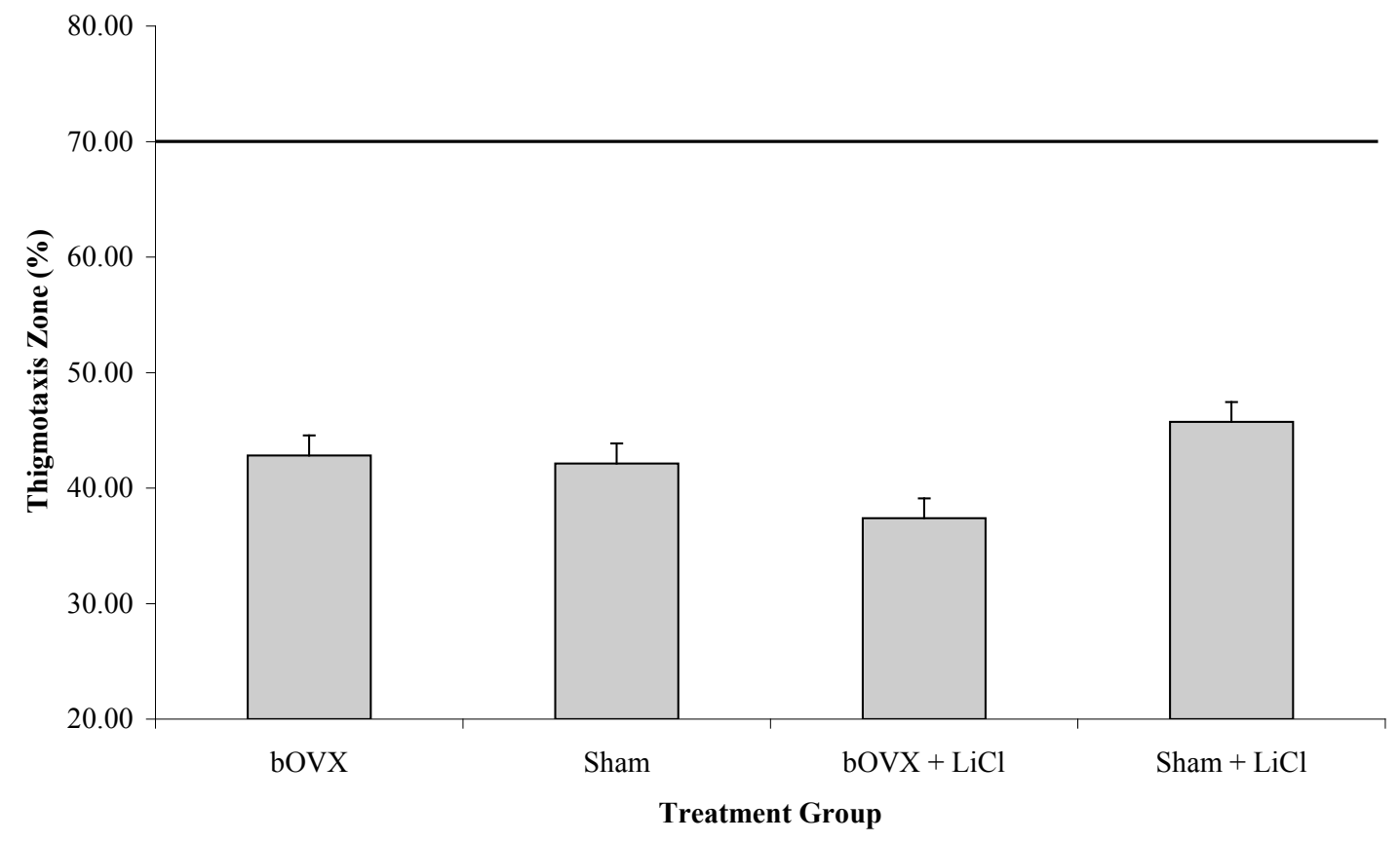

2C.

Velocity

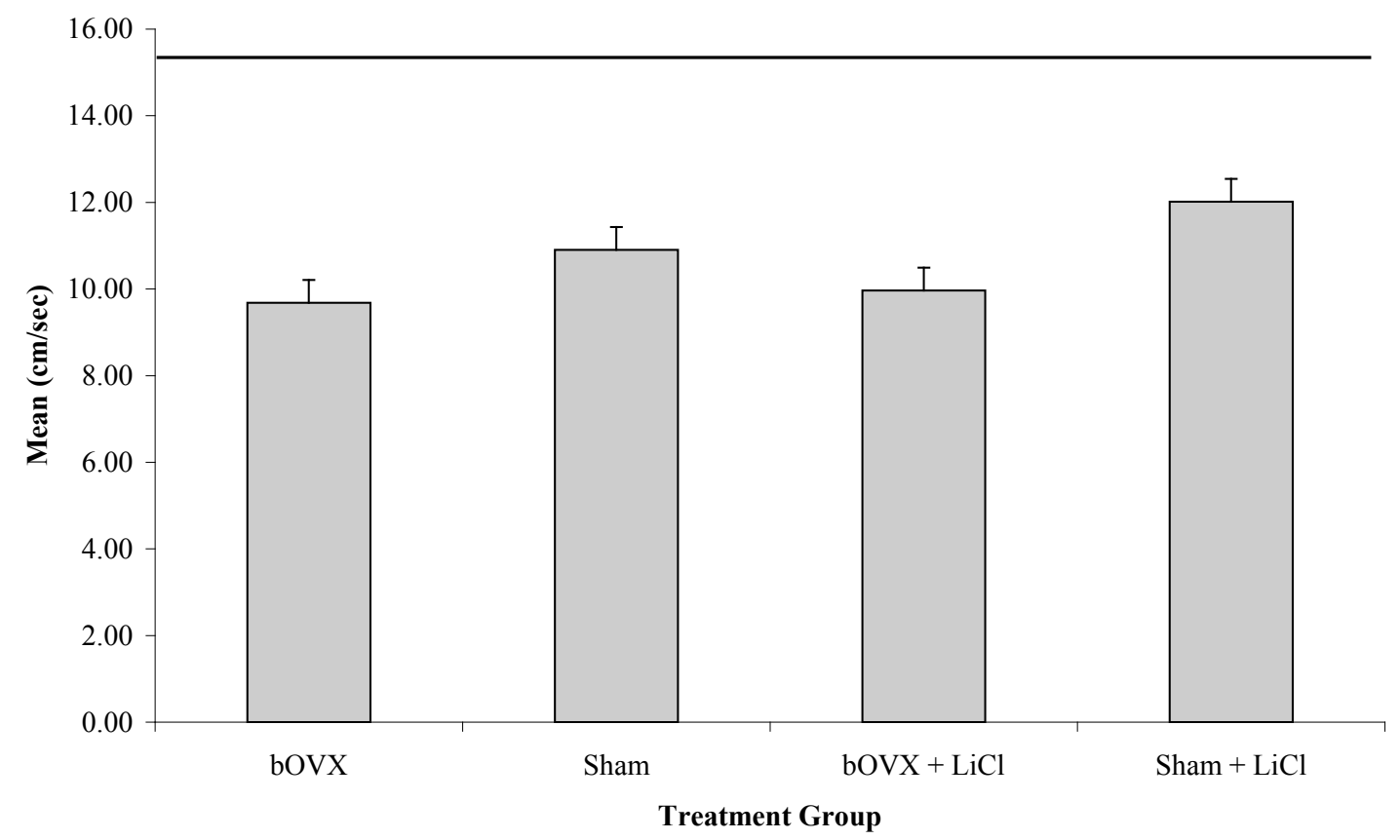


Figures 2A-2C. Performance level on ORT (A), thigmotaxis (B) and velocity (C) using EthoVison XT (see Experimental Procedures section). Baseline performance is indicated by the black line across the graphs. *, significant increase performance compared with non-treated bOVX.

\subsubsection{Bones and Uteri}

Osteoporosis and uterine atrophy are pathological characteristics of estrogendeficiency [13]. I analyzed dry bone weight from experimental mice and noted no significant differences between non-treated and LiCl-treated groups or between bOVX and Sham (figures 3A). Uterine weight was significantly less in bOVX (non-treated and treated) compared with Sham (non-treated and treated), but no significant differences between treatment groups were noted (figures 3B). 
$3 \mathrm{~A}$.

\section{Dry Bone}

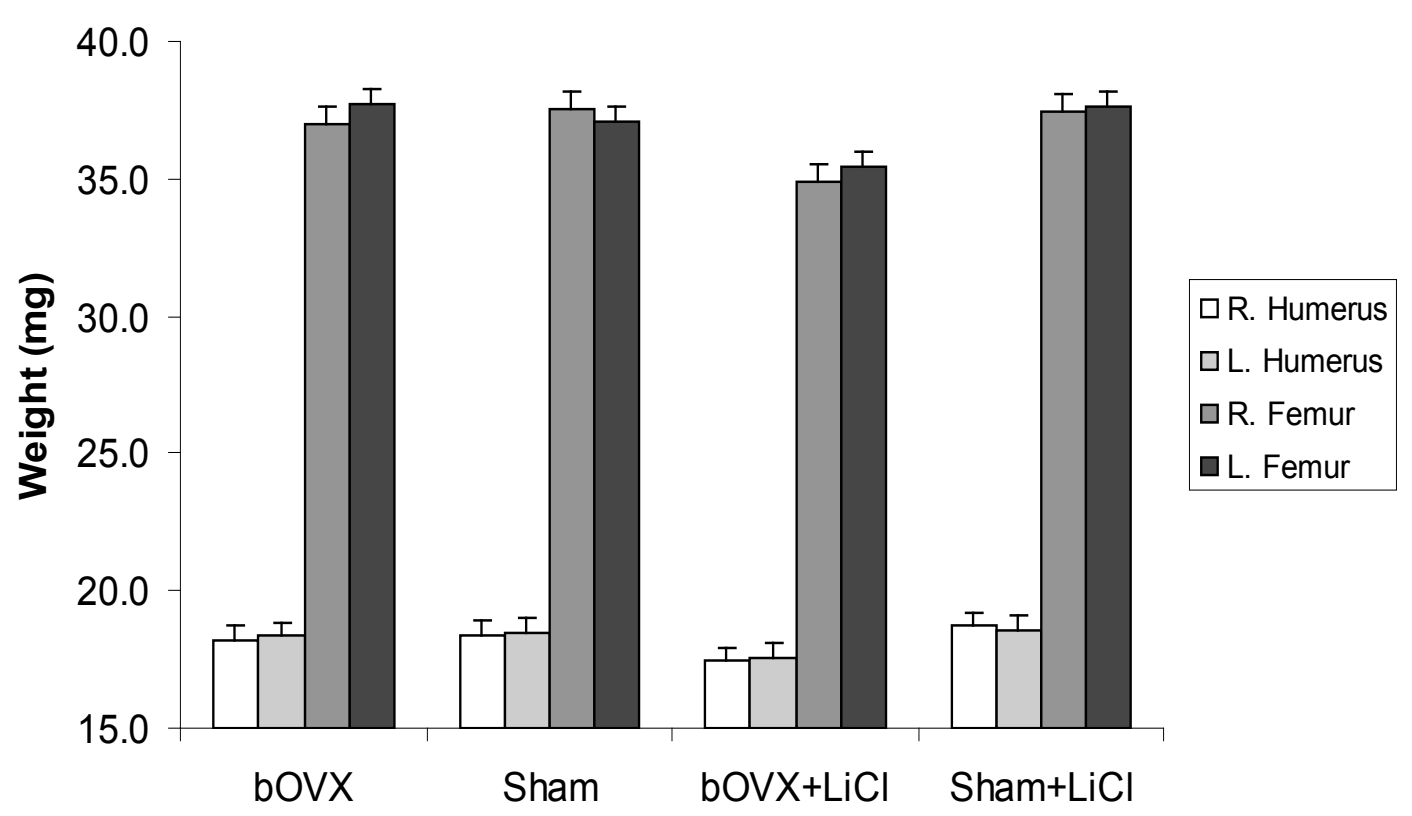

3B.

\section{Uterus}

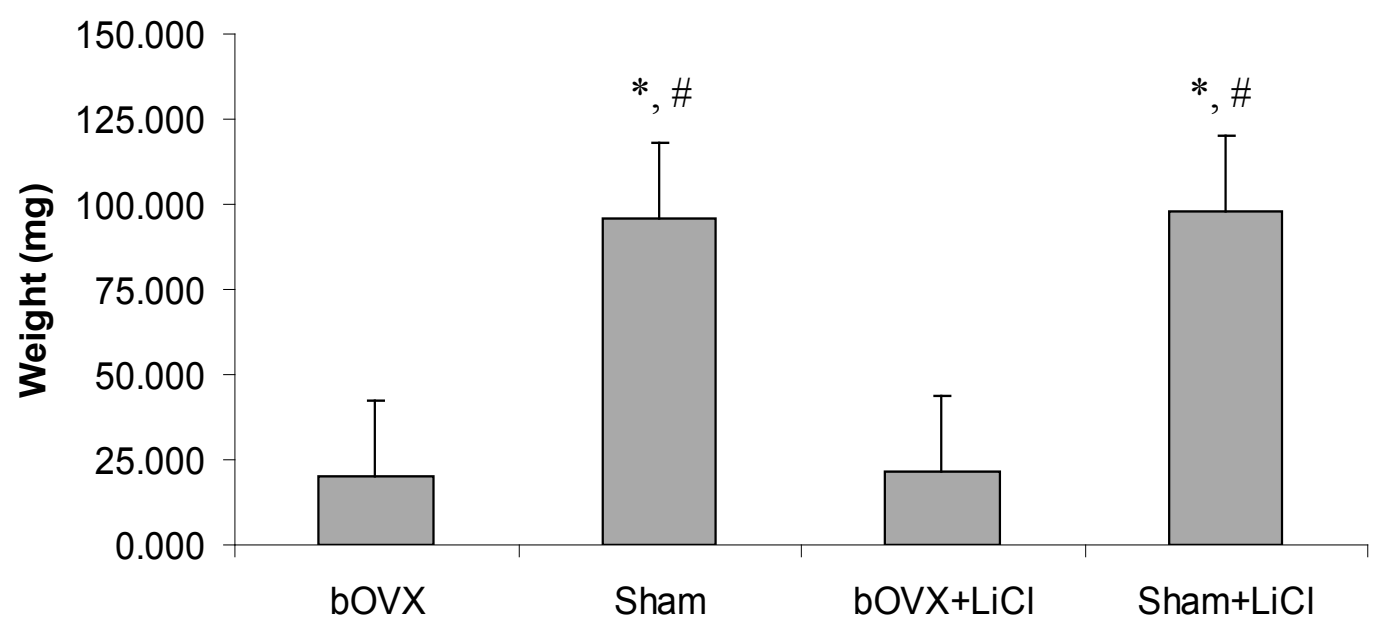

Figures 3A-3B. Bone (A) and Uterine weight (B). *, significant increase compared to bOVX; \#, significant increase compared to bOVX $+\mathrm{LiCl}$. 
3.3.4 Altered levels of Bcl-2, BDNF, ER- $\alpha$ and NR1 by LiCl in estrogen-deficient mice

Since LiCl increased episodic memory in bOVX mice according to ORT analysis (figure 2A), I hypothesized this enhanced performance was caused by increased expression of mRNA and proteins involved in learning, memory, and anti-apoptotic activity in the brain. Figures 4A-4D shows that overall mRNA expression of ER- $\alpha, N R 1$, Bcl-2 and BDNF differed between the hippocampus and cortex - ER- $\alpha$ and NR1 expressed higher in the cortex, and Bcl-2 and BDNF expressed higher in the hippocampus. Statistical analysis suggest LiCl-treated bOVX mice show significant increases $(p<0.05)$ in cortical mRNA expression of these genes, but with no significant differences in hippocampal mRNA expression across treatment groups (figures 4A-4D).

Once bound by estrogen, ER- $\alpha$ facilitates NMDAR subunit expression via response element binding [46] and ER- $\alpha$ response element binding is attenuated by lithium [28]. LiCl-treated bOVX mice show significantly enhanced $(\mathrm{p}<.05)$ cortical ER- $\alpha$ mRNA compared with non-treated bOVX and Sham (figure 4A). Cortical NR1 mRNA of LiCl-treated bOVX significantly increased $(\mathrm{p}<.05)$ compared with Sham and LiCl-treated Sham, but not in non-treated bOVX (figure 4B). Lithium influences Bcl-2 activity through BDNF signaling cascade [38], a signaling pathway that is also affected by estrogen [27]. Figures $4 \mathrm{C}$ and $4 \mathrm{D}$ show that $\mathrm{LiCl}$ treatment significantly elevates $\mathrm{Bcl}$ 2 and BDNF cortical mRNA levels $(\mathrm{p}<.05)$ in bOVX mice compared with non-treated bOVX, Sham and LiCl-treated Sham. Cortical BDNF mRNA levels are also significantly 
higher $(\mathrm{p}<0.05)$ in Sham and LiCl-treated Sham compared with non-treated bOVX (figure 4D).

Although the hippocampus showed no increase in genetic expression I wanted to see if protein levels were altered. I used TRIzol reagent to obtain total RNA and protein from each case study to avoid any discrepancies that might occur if RNA and protein were isolated from different subjects (see Experimental procedures). I analyzed NR1and BDNF expression and noted that in the hippocampus of LiCl-treated bOVX mice NR1 and BDNF protein expression increased compared to non-treated bOVX mice (figures 5A and 5B). An increase in NR1 was also noted in LiCl-treated bOVX mice compared with both Sham groups (figure 5A) - this increase was not noted for BDNF, though (figure $5 B)$.

\subsubsection{Phosphorylated GSK-3 $\beta$ levels are altered by $\mathrm{LiCl}$}

Lithium facilitates CREB transcriptional properties by inhibiting GSK-3 $\beta$ activity [15]. I hypothesized that LiCl-treated bOVX mice will express in their hippocampus higher levels of phosphorylated CREB (pCREB) at serine 133 (CREB's activation

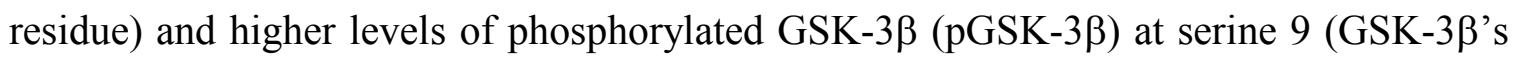
inhibitory residue). I found that in LiCl-treated bOVX mice pGSK- $3 \beta$ increased compared to non-treated bOVX mice (figure 6B), but this increase was not apparent for pCREB (figure 6A). No differences were found in levels of pGSK-3 $\beta$ in LiCl-treated bOVX mice compared with both Sham groups, though (figure 5B). 
4A.

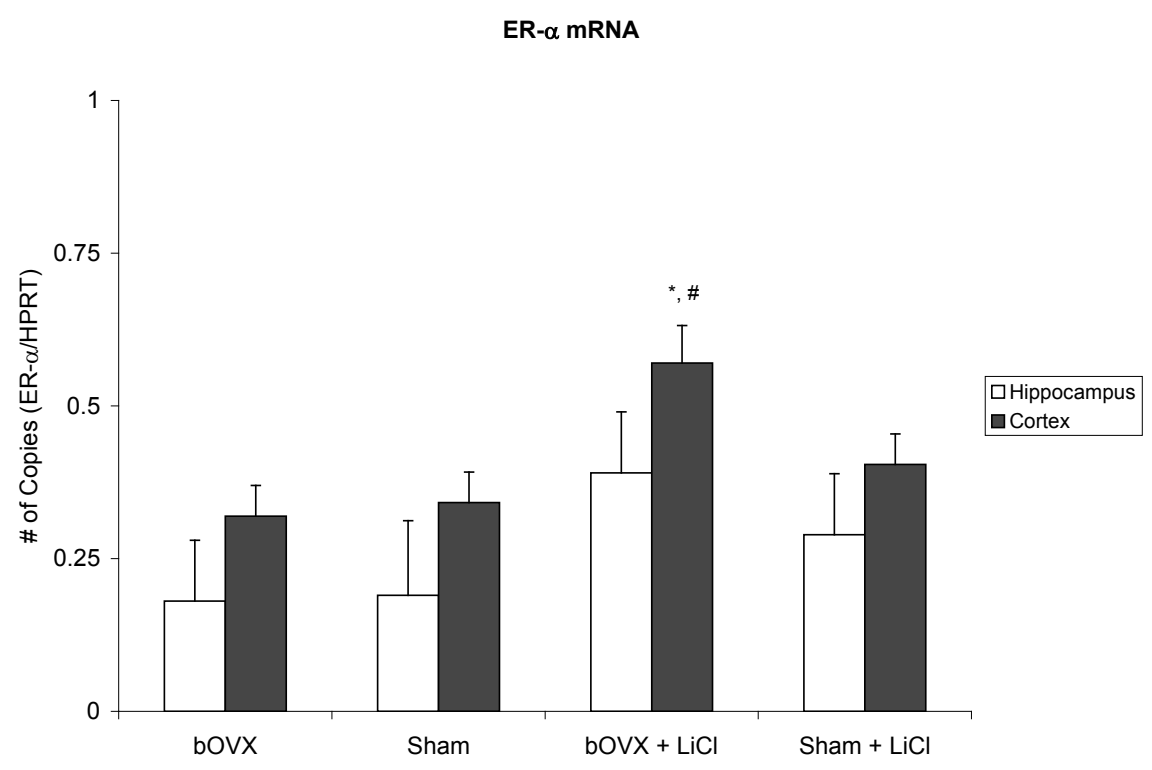

4B.

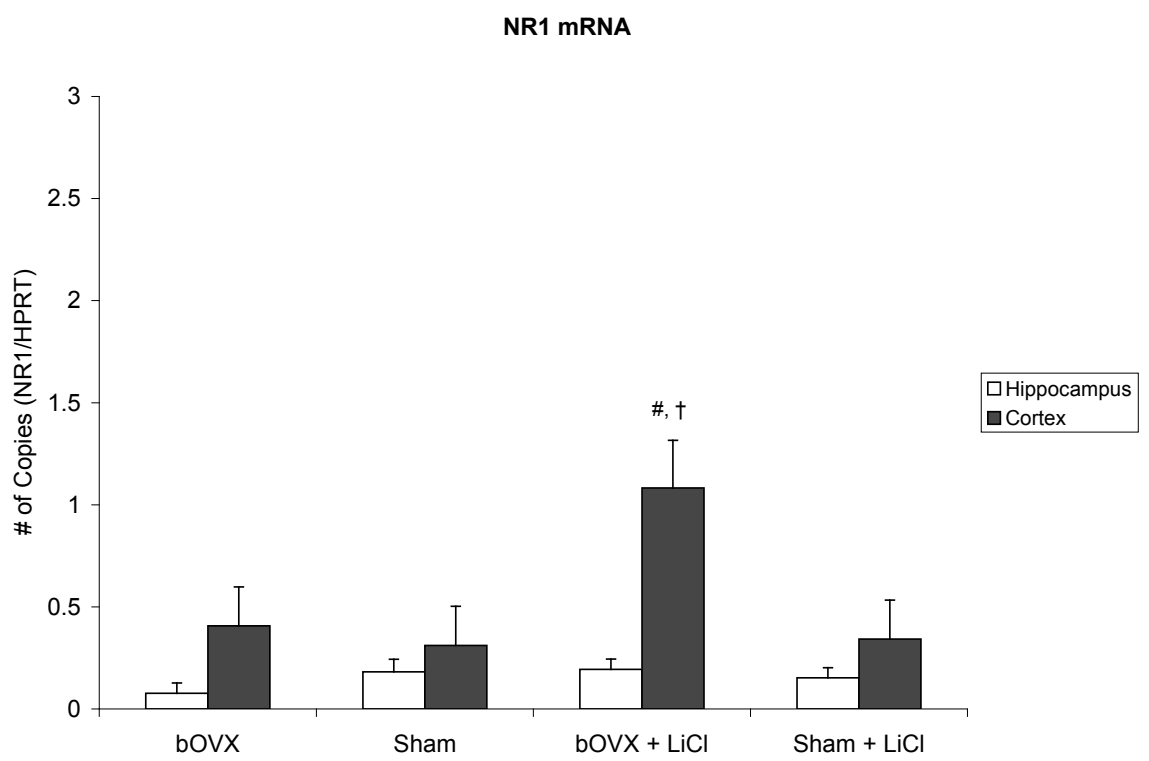


$4 \mathrm{C}$.

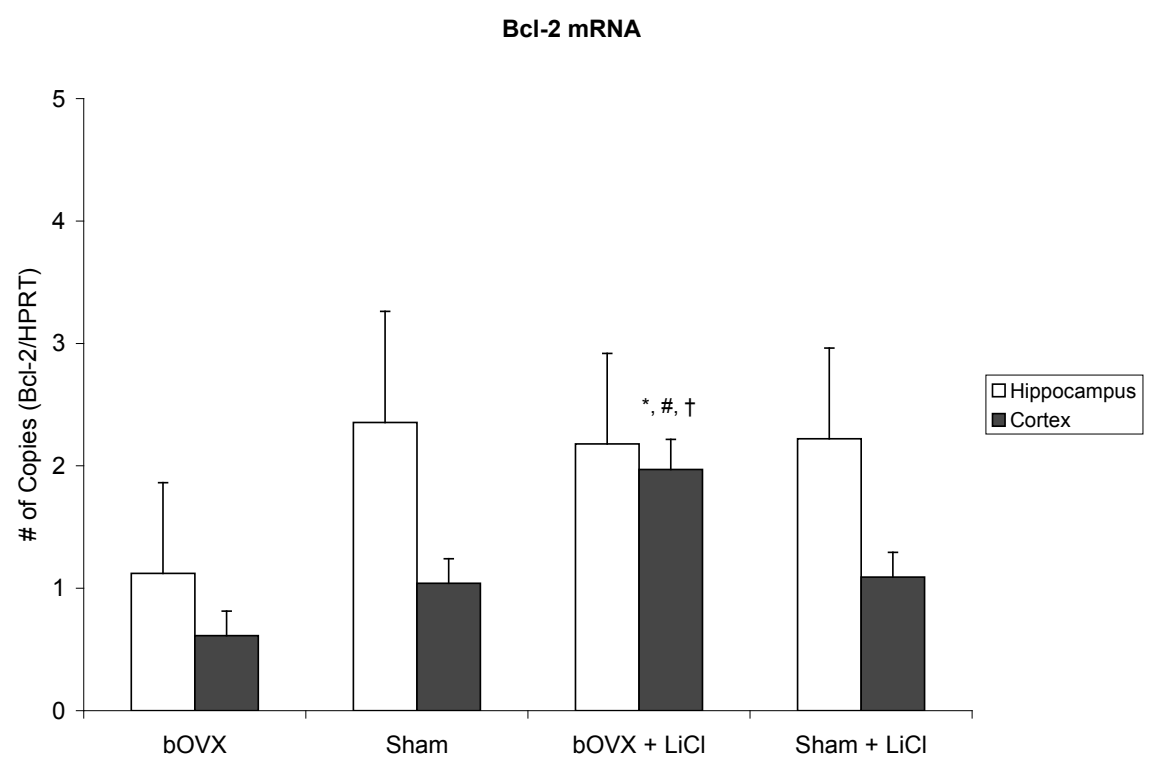

4D.

BDNF mRNA

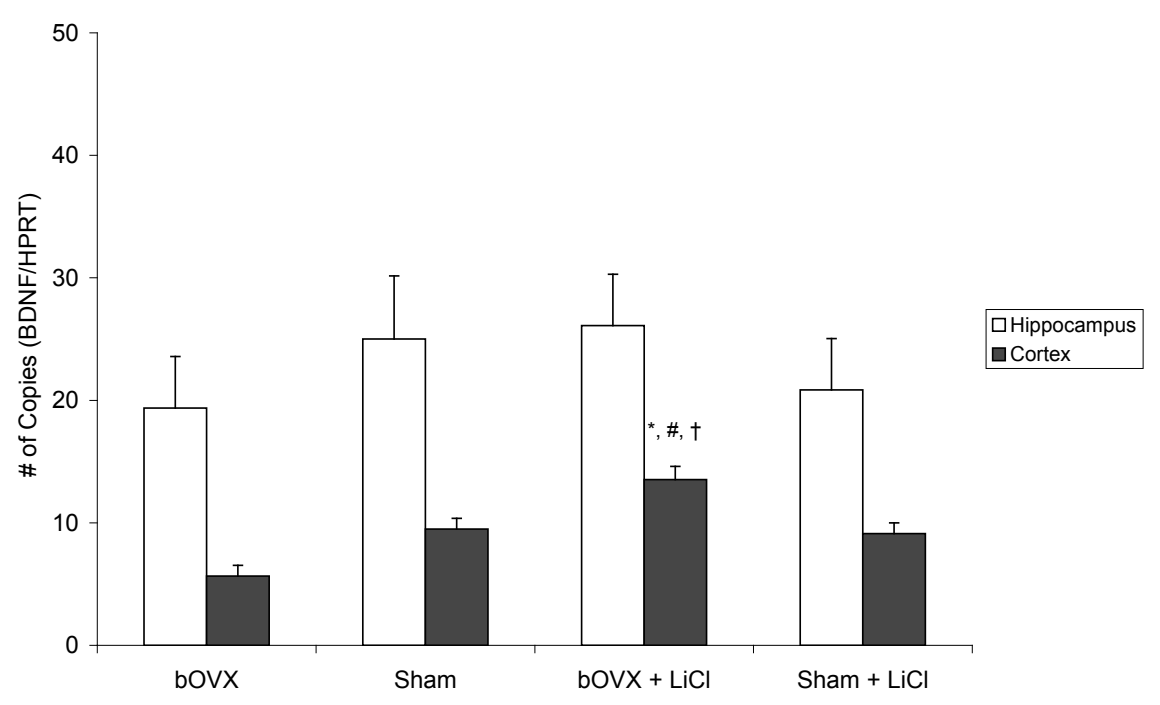

Figures 4A-4D. Hippocampal and cortical mRNA expression for ER- $\alpha$ (A), NR1 (B), Bcl-2 (C), and BDNF (D) using quantitative RT-PCR. *, significant increase compared to non-treated bOVX; \#, significant increase compared to non-treated Sham; $\dagger$, significant increase compared to LiCl-treated Sham. 
5A.

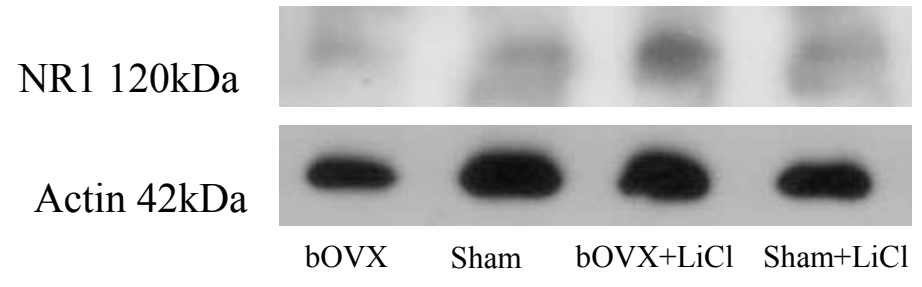

$5 B$.

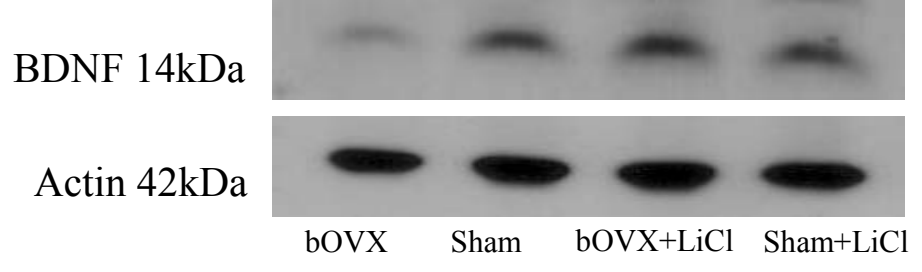

Figures 5A-5B. Hippocampal protein expression of NR1 (A) and BDNF (B).

$6 \mathrm{~A}$.

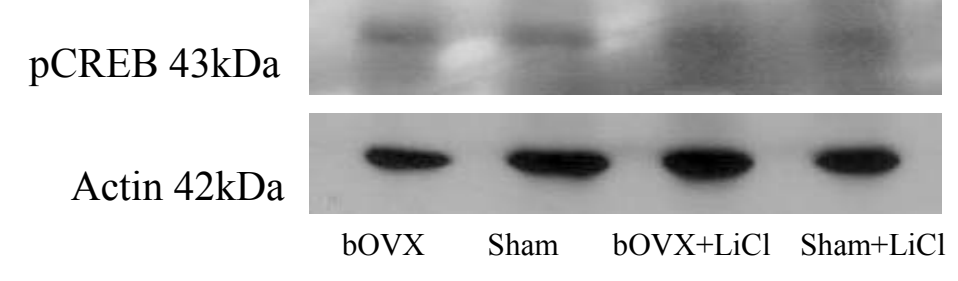

$6 \mathrm{~B}$.

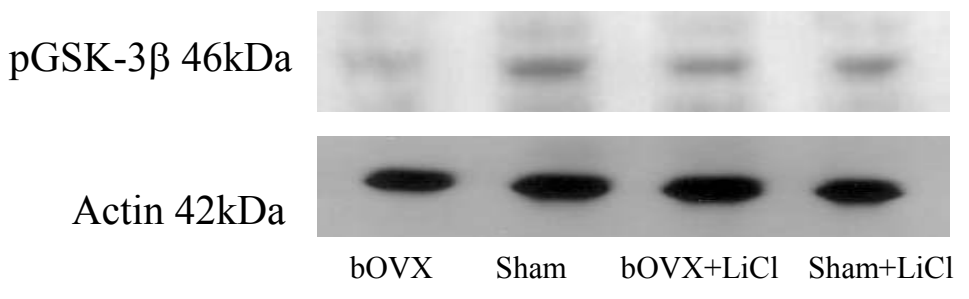

Figures 6A-6B. Hippocampal phosphorylated protein expression of pCREB at serine 133 (A) and pGSK-3 $\beta$ at serine 9 (B). 


\subsection{Discussion}

In the laboratory of Dr. Ophelia I. Weeks, my advisor, a former graduate student performed a study treating male $\mathrm{C} 57 \mathrm{BL} / 6 \mathrm{~J}$ mice using the same $\mathrm{LiCl}$ dosage in the current study $(14.2 \mathrm{mM} \mathrm{LiCl})$. Treating male mice with this $\mathrm{LiCl}$ dosage increased their performance in a Morris Water Maze and ORT over a 5 month period (unpublished data). Atomic absorption spectroscopy analyses of lithium content showed that treating mice with $14.2 \mathrm{mM} \mathrm{LiCl}$ in their drinking water maintained a sub-therapeutic level of about $0.2 \mathrm{mM}$ lithium (figure 7A). A therapeutic range is $0.6-1.5 \mathrm{mM}$ [37]. I later assayed serum samples from these male LiCl-treated mice for the dominant form of estrogen, $17 \beta$-estradiol (E2) and noted that these animals showed elevated E2 plasma-content (figure 7B). That lithium could increase E2 content in these male mice is consistent with other studies that showed a lithium-related E2 increase in female rats [1].

In the present study, I specifically wanted to analyze the affect of $14.2 \mathrm{mM} \mathrm{LiCl}$ on episodic memory in estrogen-deficient mice since this form of memory is compromised in women during post-menopause periods [20]. A lack of circulating estrogen results in uterine atrophy, and I clearly showed that uterine weight of bOVX mice is significantly lower compared with Sham mice (figure 3B). Interestingly, lithium is reported to increase cell proliferation and hyperplasia in murine uteri [16]. Furthermore, lithium treatment increases human [6] and murine [51] bone density. But in the current study, I did not find increases in uterine weight or bone density with lithium treatment (figure 3A \& 3B). Treatment duration and developmental stage of experimental animals may account for these differing results since Clément-Lacroix et al. 
[6] used bipolar patients undergoing chronic lithium treatment and Zamani et al. [51] used up to 12 week old treated mice.

7A.

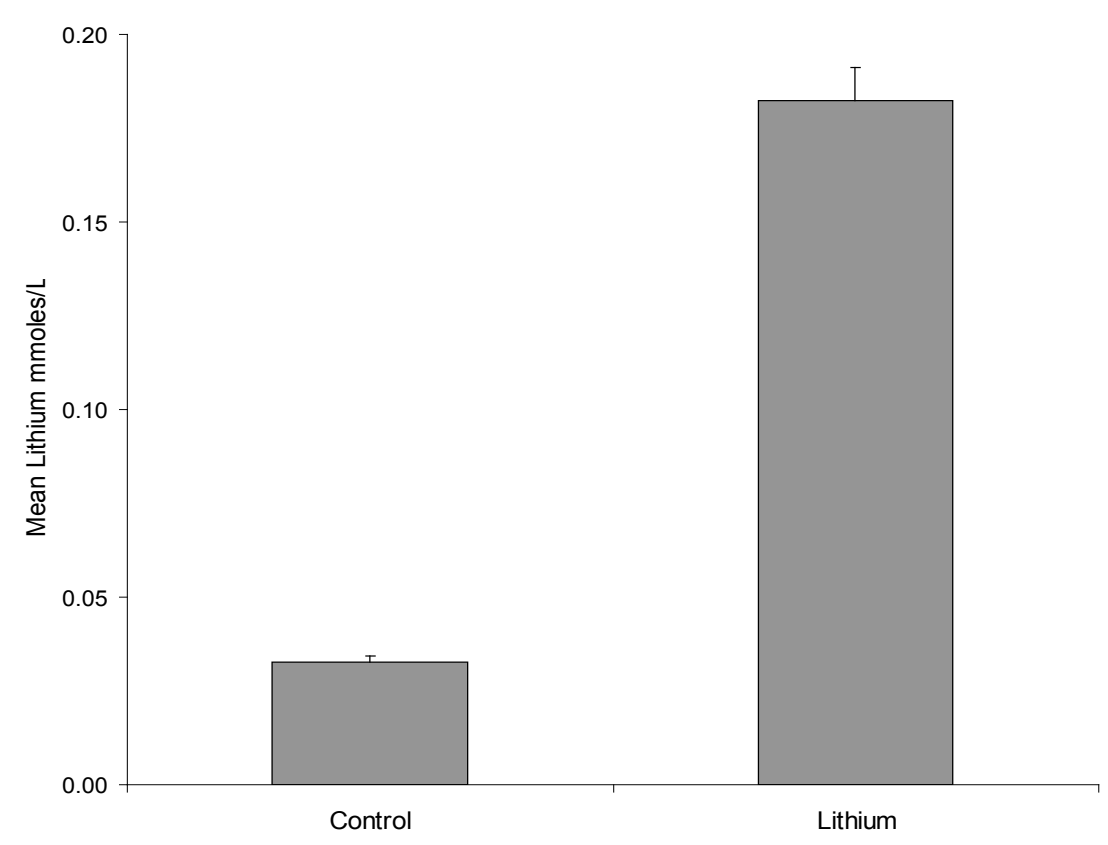

$7 B$.

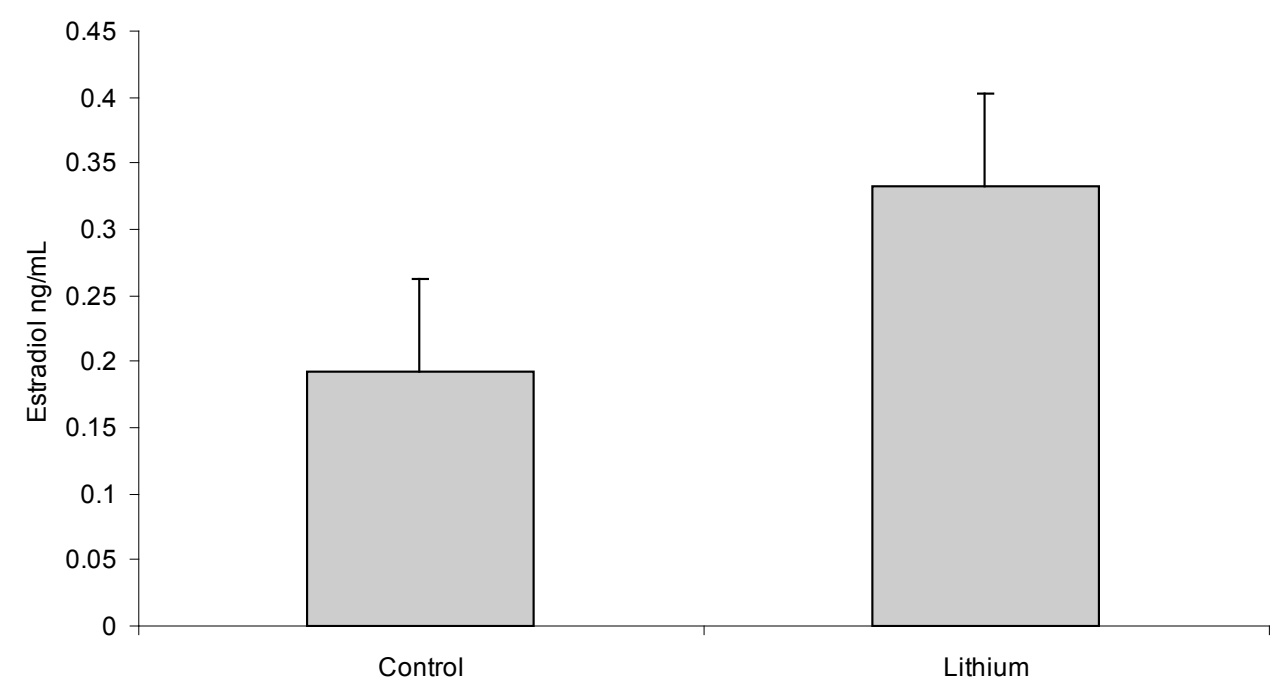


Figure 7A-7B. Lithium and Estradiol blood content of C57BL/6J male mice. Atomic absorption spectroscopy depicting lithium-blood content of (mM) (A), and enzyme linked immunosorbent assay depicting estradiol plasma content (ng/mL) (B).

The ORT performance was not significantly different in LiCl-treated Sham mice compared with non-treated Sham, but when estrogen is diminished (e.g. bOVX) $\mathrm{LiCl}$ significantly compensated for episodic memory loss compared with non-treated bOVX mice (figure 2A). Lithium does improve consolidating fear memories mediated by $\beta$ catenin and processed by the amygdala [26] and studies show that lithium improves spatial memory in rats treated with an inhibitor of spatial memory [39]. Additional studies show that stereotypic behavior induced by apomorphine increased in OVX rats compared with non-bOVX, but no difference occurred in stereotypic behavior when these groups were treated with lithium [45]. Similar studies showed that lithium decreased stereotypic behavior induced by apomorphine in bOVX rats after an abrupt halt of longterm estrogen treatment, but non-estrogen treated bOVX rats did not display this decrease [7]. In my study, lithium may be compensating molecular mechanism by enhancing estrogen-mediated signaling in a system with reduced levels of this hormone (e.g., bOVX). Jope [23] proposes a bimodal model for lithium, indicating that lithium regulates positive and negative cell signaling mechanisms by stabilizing extreme and/or minimized levels of integral factors involved in these cell signaling mechanisms. Lithium's bimodal mechanism may facilitate estrogen-mediated brain cell signaling in an estrogen-deprived system. I show that in bOVX mice $\mathrm{LiCl}$ significantly increases 
episodic memory and that this coincides with an increase in genes and proteins involved in learning, memory and neuroprotection (figures 4A-4D and 5A-5B).

In learning or experiencing novel stimuli, recent information is processed in the hippocampus affecting synaptic connectivity within this brain region. Increased exposure to this novel stimuli causes synaptic connections to form between hippocampal and cortical neurons and further exposure causes cortical neurons to form cortico-cortical neuronal connections [8]. These cortico-cortical neuronal formations are attributed to long-term memory as opposed to the hippocampus that retains recent information [8]. In chapter three, I used an ORT to analyze episodic memory and how lithium may affect this form of memory. Episodic memory is a form of declarative memory, categorized as long-term memory [41]. Studies do show that mice spend more time with a novel object than an older one [32]. In this chapter, an increased exposure to a once novel object e.g. the priming portion of the ORT (see Experimental procedures) - will be retained in the mouse's long-term memory (retention of any stimuli beyond $30 \mathrm{~s}$ is considered longterm memory) causing the mouse to investigate the novel object. My results show that in estrogen deficient mice, $\mathrm{LiCl}$ enhances the ability to distinguish the old object versus the novel one, thereby spending more time investigating the novel object (figure 2A). According to Hebb's theory, hippocampal-cortical and cortico-cortical connections display phase sequences, which are cell assemblies possessing a functional relationship and responsible for organizing behavior [19]. 
Synaptic connectivity is facilitated by BDNF and functional NMDA receptors (heteromeric structures containing the critical subunit NR1) are required for neuronal communication. An increase in cortico-cortical neuronal connections may explain my results since I noted higher levels of mRNA expression in the cortex than in the hippocampus of LiCl-treated bOVX mice (figures 4A-4D), specifically factors involved in learning and memory. Lithium does have a temporal range of action since the literature shows that expression of BDNF and its receptor is dependent on acute rather than chronic lithium treatment [12].

Protein analysis indicate that $\mathrm{LiCl}$ compensated expression of hippocampal NR1 (figure 5A) and BDNF (figure 5B) in a system deprived of estrogen (e.g. bOVX). The increase in hippocampal NR1 and BDNF expression coincided with higher levels of inhibited GSK-3 $\beta$ (figure 6B). Attenuation of CREB's transcriptional properties are caused by GSK-3 $\beta$ [15]. Although I noted no changes in the activated form of CREB (figure 6A), I can postulate that in the hippocampus CREB's transcriptional properties are not attenuated as much in LiCl-treated bOVX mice compared with non-treated bOVX mice - this is also noted by the increased cortical genetic expression as well (figures 4A$4 \mathrm{D}$ and figures $5 \mathrm{~A}-5 \mathrm{~B})$. It is worth noting that CREB does facilitates BDNF, Bcl-2 and NR1 [4, 17, 35]; additionally ER- $\alpha$ mediates CREB activation [27] and ER- $\alpha$ is also responsible for NMDA receptor subunit transcription [46] - and lithium potentiates CREB activity [15]. 
(Protein analysis of cortical samples would augment this study but complications arose when isolating cortical protein from TRIzol. There are a number of factors that fostered these complications including nucleic acid and guanidine contamination which could have formed aggregates that attenuated protein migration during electrophoresis or protein degradation. Efforts to remedy these problems are underway).

In addition to my experimental design, I noted that although experimental mice did not display anxiety, they significantly displayed less anxiety compared to baseline mice (figure 2B). This observation provides a better system for obtaining reliable behavioral data since the experimental mice were handled weekly (see Methods and Approach) and baseline mice were not - indicating that consistent contact with these mice reduces anxiety during behavioral testing. Studies do show that mice perform better on behavioral task in enriched environments [9] and habituating to human contact provides similar improvements since experimental mice used in my study (with the exception of non-treated bOVX) performed better in the ORT (figure 2A). Studies do show that OVX does cause cognitive impairment in mice [11] and may be the reason why non-treated bOVX mice performed lower than baseline.

The benefits of ERT are debatable since studies have shown that ERT reduces the development of neurodegenerative diseases and improves cognitive decline [14, 49]; but these findings have been recently challenged [20]. It seems that the risk of ERT outweigh its benefits, since ERT also increases breast cancer [31]. Estrogen is essential for normal brain function by facilitating factors involved in learning, memory and 
neuroprotection. An alternative therapy that mimics the beneficial aspects of estrogen, without the harmful effects will serve as a better treatment for post-menopausal women. I describe in this chapter that in mice deprived of estrogen (bOVX), lithium enhances episodic memory (figure 2A), increases factors involved in learning memory and neuroprotection (figures 4A-4D and 5A-5B), and increases the inhibitory state of a kinase (figure 6B) that attenuates learning, memory and neuroprotection. This evidence provides great insight into the positive applications of lithium and how it may benefit post-menopausal women. Though extrapolating results obtained from mice to human clinical applications is a giant leap, my study serves as a starting point to further investigate lithium's potential benefits as an estrogen-mediated signaling modulator in a system deprived of this hormone. 


\section{REFERENCES}

[1] M. Allagui, N. Hfaiedh, C. Vincent, F. Guermazi, J. Murat, F. Croute, A. El Feki, Changes in growth rate and thyroid- and sex-hormones blood levels in rats under sub-chronic lithium treatment., Hum. Exp. Toxicol. 25 (2006) 243-250.

[2] F. Angelucci, L. Aloe, P. Jiménez-Vasquez, A.A. Mathé, Lithium treatment alters brain concentrations of nerve growth factor, brain-derived neurotrophic factor and glial cell line-derived neurotrophic factor in a rat model of depression, Int. J. Neuropsychopharmacol. 6 (2003) 225-231.

[3] P.R. Blanquet, J. Mariani, P. Derer, A calcium/calmodulin kinase pathway connects brain-derived neurotrophic factor to the cyclic amp-responsive transcription factor in the rat hippocampus, Neuroscience 118 (2003) 477.

[4] M.J. Chen, A.A. Russo-Neustadt, Running exercise-induced up-regulation of hippocampal brain-derived neurotrophic factor is CREB-dependent, Hippocampus 9999 (2009) NA.

[5] D.-M. Chuang, The Antiapoptotic Actions of Mood Stabilizers, Ann. N. Y. Acad. Sci. 1053 (2005) 195-204.

[6] P. Clement-Lacroix, M. Ai, F. Morvan, S. Roman-Roman, B.a. Vayssĩ̃ “re, C. Belleville, K. Estrera, M.L. Warman, R. Baron, G. Rawadi, Lrp5-independent activation of Wnt signaling by lithium chloride increases bone formation and bone mass in mice, Proceedings of the Academy of Natural Sciences 102 (2005) 17406-17411.

[7] V.A.C. Dorce, J. Palermo-Neto, Lithium effects on estrogen-induced dopaminergic supersensitivity in rats, Brain Res. Bull. 29 (1992) 239-241.

[8] P.W. Frankland, B. Bontempi, The organization of recent and remote memories, Nat. Rev. Neurosci. 6 (2005) 119-130.

[9] K.M. Frick, N.A. Stearns, J.-Y. Pan, J. Berger-Sweeney, Effects of Environmental Enrichment on Spatial Memory and Neurochemistry in Middle-Aged Mice, Learn. Mem. 10 (2003) 187-198.

[10] R.E. Frost, F.S. Messiha, Clinical uses of lithium salts, Brain Res. Bull. 11 (1983) 219-231.

[11] H.N. Fugger, T.C. Foster, J.-A. Gustafsson, E.F. Rissman, Novel effects of estradiol and estrogen receptor $\alpha$ and $\beta$ on cognitive function, Brain Res. 883 (2000) 258-264. 
[12] T. Fukumoto, S. Morinobu, Y. Okamoto, A. Kagaya, S. Yamawaki, Chronic lithium treatment increases the expression of brain-derived neurotrophic factor in the rat brain, Psychopharmacology 158 (2001) 100-106.

[13] R.D. Gambrell, The menopause, Investig. Radiol. 21 (1986) 369-378.

[14] L.M. Garcia-Segura, I. Azcoitia, L.L. DonCarlos, Neuroprotection by estradiol, Prog. Neurobiol. 63 (2001) 29-60.

[15] C.A. Grimes, R.S. Jope, CREB DNA binding activity is inhibited by glycogen synthase kinase-3 $\beta$ and facilitated by lithium, J. Neurochem. 78 (2001) 12191232.

[16] A.G. Gunin, V.U. Emelianov, I.U. Mironkin, M.P. Morozov, A.S. Tolmachev, Lithium treatment enhances estradiol-induced proliferation and hyperplasia formation in the uterus of mice, European Journal of Obstetrics, Gynecology and Reproductive Biology 114 (2004) 83-91.

[17] M. Hammonds, S.S. Shim, Effects of 4-week Treatment with Lithium and Olanzapine on Levels of Brain-derived Neurotrophic Factor, B-Cell CLL/Lymphoma 2 and Phosphorylated Cyclic Adenosine Monophosphate Response Element-binding Protein in the Sub-regions of the Hippocampus, Basic Clin. Pharm. Toxicol. 9999 (2009).

[18] R. Hashimoto, K. Fujimaki, M.R. Jeong, L. Christ, D.-M. Chuang, Lithiuminduced inhibition of Src tyrosine kinase in rat cerebral cortical neurons: a role in neuroprotection against N-methyl-D-aspartate receptor-mediated excitotoxicity, FEBS Lett. 538 (2003) 145-148.

[19] D.O. Hebb, The organization of behavior: a neuropsychological theory, Wiley, New York, 1949.

[20] V.W. Henderson, Menopause, cognitive ageing and dementia: practice implications, Menopause International 15 (2009) 41-44.

[21] K. Honda, S. Shimohama, H. Sawada, T. Kihara, T. Nakamizo, H. Shibasaki, A. Akaike, Nongenomic antiapoptotic signal transduction by estrogen in cultured cortical neurons, J. Neurosci. Res. 64 (2001) 466-475.

[22] V. Hongisto, N. Smeds, S. Brecht, T. Herdegen, M.J. Courtney, E.T. Coffey, Lithium Blocks the c-Jun Stress Response and Protects Neurons via Its Action on Glycogen Synthase Kinase 3, Mol. Cell. Biol. 23 (2003) 6027-6036.

[23] R.S. Jope, A bimodal model of the mechanism of action of lithium, Mol. Psychiatry 4 (1999) 21-25. 
[24] R.S. Jope, Lithium and GSK-3: one inhibitor, two inhibitory actions, multiple outcomes, Trends Pharmacol. Sci. 24 (2003) 441-443.

[25] C. Leranth, M. Shanabrough, D.E. Redmond Jr., Gonadal hormones are responsible for maintaining the integrity of spine synapses in the CA1 hippocampal subfield of female nonhuman primates, The Journal of Comparative Neurology 447 (2002) 34-42.

[26] K.A. Maguschak, K.J. Ressler, [beta]-catenin is required for memory consolidation, Nat. Neurosci. 11 (2008) 1319-1326.

[27] B.S. McEwen, Genome and Hormones: Gender Differences in Physiology: Invited Review: Estrogens effects on the brain: multiple sites and molecular mechanisms, J. Appl. Physiol. 91 (2001) 2785-2801.

[28] S. Medunjanin, A. Hermani, B. De Servi, J. Grisouard, G. Rincke, D. Mayer, Glycogen Synthase Kinase-3 Interacts with and Phosphorylates Estrogen Receptor $\alpha$ and Is Involved in the Regulation of Receptor Activity, J. Biol. Chem. 280 (2005) 33006-33014.

[29] N. Mitsiades, D. Correa, C.P. Gross, A. Hurria, S.F. Slovin, Cognitive Effects of Hormonal Therapy in Older Adults, Semin. Oncol. 35 (2008) 569-581.

[30] V. Natale, P. Albertazzi, N. Missiroli, D. Pedrini, M. Salgarello, Effects of raloxifene on mood, sleep, libido and cognitive function in postmenopausal healthy women: a pilot study, Maturitas 48 (2004) 59-63.

[31] L.M. Newcomer, P.A. Newcomb, J.D. Potter, Y. Yasui, A. Trentham-Dietz, B.E. Storer, M.P. Longnecker, J.A. Baron, J.R. Daling, Postmenopausal hormone therapy and risk of breast cancer by histologic type United States, Cancer Causes \& Control 14 (2003) 225-233.

[32] R.C. O'Reilly, M.H. Johnson, Object Recognition and Sensitive Periods - a Computational Analysis of Visual Imprinting, Neural Comput. 6 (1994) 357-389.

[33] N. Ozaki, D.-M. Chuang, Lithium Increases Transcription Factor Binding to AP-1 and Cyclic AMP-Responsive Element in Cultured Neurons and Rat Brain, J. Neurochem. 69 (1997) 2336-2344.

[34] J. Palmer, T. Trotter, A. Joy, L. Carlson, Cognitive effects of Tamoxifen in premenopausal women with breast cancer compared to healthy controls, Journal of Cancer Survivorship 2 (2008) 275-282.

[35] M. Qiang, M.K. Ticku, Role of AP-1 in ethanol-induced N-methyl-d-aspartate receptor 2B subunit gene up-regulation in mouse cortical neurons, J. Neurochem. 95 (2005) 1332-1341. 
[36] W.J. Ryves, A.J. Harwood, Lithium Inhibits Glycogen Synthase Kinase-3 by Competition for Magnesium, Biochem. Biophys. Res. Commun. 280 (2001) 720725 .

[37] H.R. Sadeghipour-Roudsari, M. Farahani, A. Shokrgozar, H. Farsam, A.R. Dehpour, Decrease in Erythrocyte:Plasma Lithium Ratio by Concurrent Administration of Psychotropic Drugs and Lithium in Mice, Gen. Pharmacol. 31 (1998) 63.

[38] G. Shaltiel, G. Chen, H.K. Manji, Neurotrophic signaling cascades in the pathophysiology and treatment of bipolar disorder, Curr. Opin. Pharmacol. 7 (2007) 22-26.

[39] M. Sharifzadeh, M. Aghsami, S. Gholizadeh, K. Tabrizian, M. Soodi, S. Khalaj, A. Ranjbar, A. Hosseini-Sharifabad, A. Roghani, M.H. Karimfar, Protective Effects of Chronic Lithium Treatment against Spatial Memory Retention Deficits Induced by the Protein Kinase AII Inhibitor H-89 in Rats, Pharmacology 80 (2007) 158-165.

[40] D.T. Solum, R.J. Handa, Estrogen Regulates the Development of Brain-Derived Neurotrophic Factor mRNA and Protein in the Rat Hippocampus, J. Neurosci. 22 (2002) 2650-2659.

[41] E. Tulving, Organization of memory, Academic Press, New York, 1972.

[42] J.J. Valdés, O.I. Weeks, Estradiol and lithium chloride specifically alter NMDA receptor subunit NR1 mRNA and excitotoxicity in primary cultures, Brain Research In Press, Accepted Manuscript.

[43] S. Vaynman, Z. Ying, F. Gomez-Pinilla, Hippocampal BDNF mediates the efficacy of exercise on synaptic plasticity and cognition, Eur. J. Neurosci. 20 (2004) 2580-2590.

[44] S.P. Vecera, R.C. O'Reilly, Figure-Ground Organization and Object Recognition Processes: An Interactive Account, J. Exp. Psychol. Hum. Percept. Perform. 24 (1998) 441.

[45] T. Verimer, S.P. Arnerić, J.P. Long, B.J. Walsh, M.S.A. Zeit-Har, Effects of ovariectomy, castration, and chronic lithium chloride treatment on stereotyped behavior in rats, Psychopharmacology 75 (1981) 273-276.

[46] T. Watanabe, S. Inoue, H. Hiroi, A. Orimo, M. Muramatsu, NMDA receptor type 2D gene as target for estrogen receptor in the brain, Mol. Brain Res. 63 (1999) $375-379$. 
[47] D.G. Wheeler, E. Cooper, Weak synaptic activity induces ongoing signaling to the nucleus that is enhanced by BDNF and suppressed by low-levels of nicotine, Mol. Cell. Neurosci. 26 (2004) 50-62.

[48] C.G. Wible, J.R. Shiber, D.S. Olton, Hippocampus, Fimbria-Fornix, Amygdala, and Memory: Object Discriminations in Rats, Behav. Neurosci. 106 (1992) 751.

[49] P.M. Wise, Estrogens and neuroprotection, Trends Endocrinol. Metab. 13 (2002) 229-230.

[50] T.W. Wu, J.M. Wang, S. Chen, R.D. Brinton, $17 \beta$-estradiol induced $\mathrm{Ca}^{2+}$ influx via L-type calcium channels activates the Src/ERK/cyclic-AMP response element binding protein signal pathway and BCL-2 expression in rat hippocampal neurons: A potential initiation mechanism for estrogen-induced neuroprotection, Neuroscience 135 (2005) 59-72.

[51] A. Zamani, G.R. Omrani, M.M. Nasab, Lithium's effect on bone mineral density, Bone 44 (2009) 331-334. 


\title{
CHAPTER IV
}

Lithium: A Promising Alternative to Estrogen Replacement Therapy

\begin{abstract}
Estrogen replacement therapy (ERT) is a topic that engenders much debate since several studies contradict its efficacy as a palliative therapy for cognitive decline and neurodegenerative diseases. Signaling transduction pathways can alter brain cell activity, survival, and morphology by facilitating transcription factor response element binding and protein production. The steroidal hormone estrogen and the antidepressant drug lithium can interact through these signaling transduction pathways resulting in transcription factor activation. The transcription factor cyclic adenosine monophosphate (cAMP) response element binding protein (CREB) is affected by both estrogen and lithium. Genes involved in learning, memory and neuronal survival are regulated by CREB. Activated of CREB is initiated via phosphorylation at serine 133 by protein kinases and, estrogen and its receptors (ER) facilitate this phosphorylation. Glycogen synthase kinase-3beta (GSK-3 $\beta$ ) attenuates CREB's transcriptional properties via subsequent phosphorylation of its serine 129. Lithium is known as a negative regulator of GSK-3 $\beta$, thus facilitating CREB response element binding; interestingly, ER- $\alpha$ DNAbinding properties are facilitated by GSK-3 $\beta$. In this chapter I include protein modeling depicting estrogen signaling and interactions of CREB/GSK-3 $\beta$ and ER- $\alpha / \mathrm{GSK}-3 \beta$ using I-TASSER and PatchDock web servers. Understanding the molecular pathways of estrogen will assist identifying a palliative therapy for menopause-related dementia, and lithium may act as a selective estrogen-mediated signaling modulator.
\end{abstract}




\subsection{Introduction}

Estrogen and lithium exert neuroprotective properties and may act as palliative treatments for neurodegeneration and cognitive decline [32, 65]. Alzheimer's disease (AD) in post-menopausal women is related to estrogen deficiency, and estrogen replacement therapy (ERT) may benefit post-menopausal women in reducing the risk of developing $\mathrm{AD}[30]$. Other studies, however, contradict these findings and suggest that hormone therapy does not improve cognitive decline during menopause, specifically episodic memory [43]. And, there is a high risk of developing breast cancer, marked by increased incidences of lobular carcinoma, in post-menopausal women undergoing ERT [76]. Furthermore, women suffering from depression during peri- and post-menopause are often prescribed lithium $[13,60]$. Few studies focus on how estrogen and lithium may augment or counteract neuroprotective qualities, and studies demonstrating estrogen and lithium's affect on learning and memory are conflicting. Many underlying mechanisms still remain to be studied and ever increasing proteonomic- and genomicgenerated data suggest these as complex mechanisms.

Using I-TASSER (Threading/ASSEmbly/Refinement) web server [104, 111, 112] I fabricated 3-D protein models (figures 1-6), but because of limited parent structures in the protein data bank (PDB), some models presented in this chapter display low complexity regions (e.g. indicated primarily by the lighter colored region in the background of figure 1; subsequent figures are not highlighted as such, though). To choose the best model for this chapter, predicted models by I-TASSER were compared by superimposing crystallography structures from the PDB; superimposition was aided 
by the structure based sequences alignment program (STRAP) and Pymol for visualizing the superimposition (see table 1 for accession number used to compare each predicted model). For predicting transmembrane regions I used the TransMembrane prediction using Hidden Markov Models (TMHMM) web server to locate and specify transmembrane domains by representing a predicted hydrophobicity chart (specifically for figure 5A). Literature mining and using the BLAST conserved domain web server (NCBI) assisted in locating specific amino acids specifying binding residues to produce the hypothetical protein-protein interactions in this chapter. Figures depicting these protein-protein interactions were provided by the PatchDock web server [24, 94].

\section{Table 1.}

Predicted Protein NCBI Accession \# Comparison Protein PDB Accession \#

$\begin{array}{cccc}\text { CREB Isoform B } & \text { NP_604391.1 } & \begin{array}{c}\text { CREB Leucine } \\ \text { Zipper }\end{array} & \text { 1dh3 } \\ \text { GSK-3 } \beta & \text { NP_002084.2 } & \text { GSK-3 } \beta & 1 \mathrm{q} 41 \\ \text { ER- } \alpha & \text { NP_000116.2 } & \text { ER- } \alpha & 112 \mathrm{i} \\ \text { GPR30 } & \text { NP_001091671.1 } & \text { Rhodopsin } & \text { 2J4Y }\end{array}$

Table 1. Specific amino acid sequences used to fabricate 3-D protein models. These predicted models were superimposed with crystallography structures from PDB to justify predicted structures. 


\subsection{Neurosteroids and Estrogen Replacement Therapy}

Menopause is marked by a massive drop in circulating estrogen. The growing concern with estrogen deficiency is the increase incidence of neurodegenerative diseases and cognitive decline. Circulating estrogen permeates the blood-brain barrier [61], and some speculate $\alpha$-fetoprotein, a fetal plasma protein with a high affinity for estrogen, facilitates estrogen neuromechanisms [6, 68]. Estrogen is primarily produced by the gonads and the adrenal gland, but hormones, known as neurosteroids, are also produced in the brain [98]. Production of steroids by the gonads requires steroidogenic acute regulatory protein (StAR) to facilitate intermembrane passage of cholesterol, and StAR is ubiquitously expressed in the brain, but at low levels [98]. Women with a mutation in the StAR gene suffer from hormone deficiency leading to spontaneous puberty and an early onset of menopause [9]. Cholesterol is transported by StAR to the inner mitochondrial membrane where cytochrome P450 converts cholesterol into pregnenolone, the steroidal precursor [98]. Astrocytes are a source for steroidogenesis and glia-mediated steroidal production is linked to neuronal synaptic formation and to facilitating synaptic transmission [46]. Interestingly, StAR are expressed in glia and this co-localization is linked to glia-mediated steroidogenesis [98]. Little is known about how ERT affects StAR or how ERT affects the production of neurosteroids. Should research be directed towards replacing estrogen in post-menopausal women, or geared towards enhancing neurosteroidogenisis and estrogen-mediated brain cell signaling pathways?

The benefits of ERT are a controversial topic. As mentioned, women undergoing ERT increase their risk of breast cancer [76], but there also lies a dichotomy with ERT in 
relation to enhancing cognitive function and reducing neurodegenerative diseases. For instance, Henderson et al. in 1994 concluded that ERT may reduce the risk of AD and cognitive decline during post-menopause, but in 2009 Henderson [43] is skeptical of ERT neuroprotective and neuroenhancing properties. There is also a debate about a critical window hypothesis. The hypothesis states that if ERT is initiated at a younger age, prior to menopause, it will improve cognitive functioning [96]; but Henderson considers these studies systematically bias [43]. Selective estrogen receptor modulators (SERMs) do provide an alternative to ERT, and studies show a decrease in breast cancer incidence and slows the progression of osteoporosis [51]. But SERMS use does not seem to improve cognitive functioning $[75,83]$. If SERMs do not influence cognitive functioning an alternative treatment should be investigated, since estrogen does affect several brain cell signaling pathways involved in learning, memory and neuroprotection.

4.3 Learning, Memory and Neuroprotection via Estrogen/Estrogen Receptor-mediated Pathways

Estrogen facilitates brain cell signaling pathways that enhance synaptic plasticity [62], reduce glutamate excitotoxicity [44], increase neuroprotection of adult hippocampal cells [63], regulate neurotrophic factors [100], and facilitate transcription factor activation [67]. Learning and memory are products of gene regulation by transcription factors. For example, cyclic adenosine monophosphate (cAMP) response element binding protein (CREB) regulates genes responsible for critical brain functions, including synaptic plasticity, learning, memory and neuroprotection [44, 53, 88, 102]. Activation of CREB is facilitated by estrogen [67] leading to the transcription of immediate early genes (e.g. 
$c$-fos and $c$-jun), which in turn promotes phenotypical changes - e.g. synaptic plasticity [92]. In fear conditioning experiments mice exhibit an upregulation of immediate early genes in the hippocampus and this upregulation is mediated in the amygdala - the emotion processing center of the brain [47]. Mice with targeted mutations of CREB exhibit deficiencies in long-term memory storage, but not short-term memory storage [10]. Activation of CREB's signaling pathway is initiated by adenylyl cyclase which catalyzes adenosine triphosphate (ATP) into cAMP that then activates cAMP dependent protein kinase (PKA) - PKA then phosphorylates CREB at its serine 133 site (figure 1) [12]. Estrogen and its receptors (ER) facilitate non-genomic molecular pathways by increasing CREB activity [67] and estrogen is known to increase cAMP levels by binding to G-protein coupled receptors (GPCR) that stimulate adenylyl cyclase activity [27].

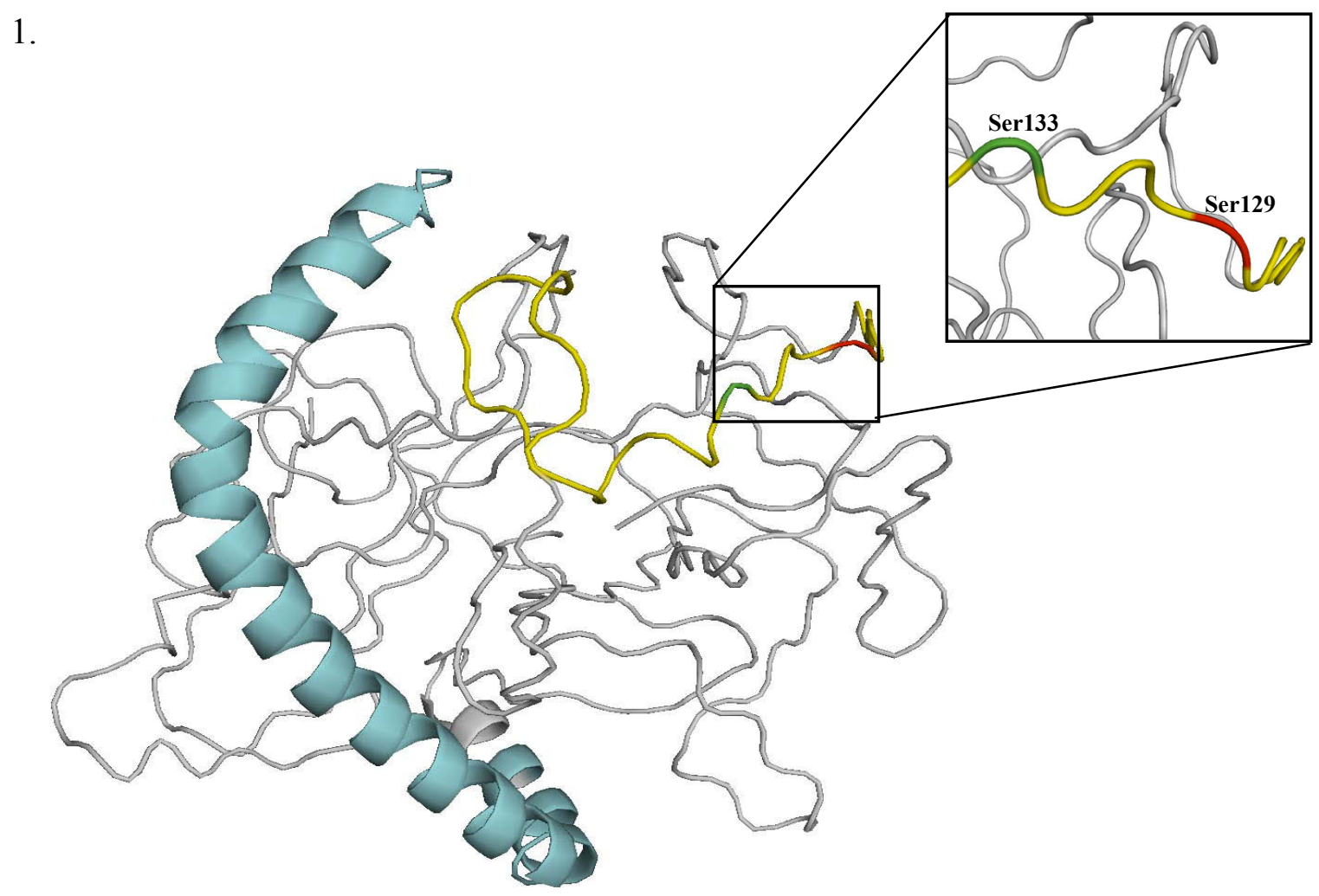


Figure 1. Phosphorylating CREB at its serine 133 (green) causes a conformational change in its leucine zipper region (cyan) causing CREB to dimerize with CREB binding protein. This dimerization facilitates CREB response element binding. The conformational change that occurs, however, exposes CREB's serine 129 region (red) allowing a subsequent phosphorylation attenuating CREB's response element binding. (The yellow depicts the kinase inducible domain of CREB. The light colored region indicates the low complexity region)

2.

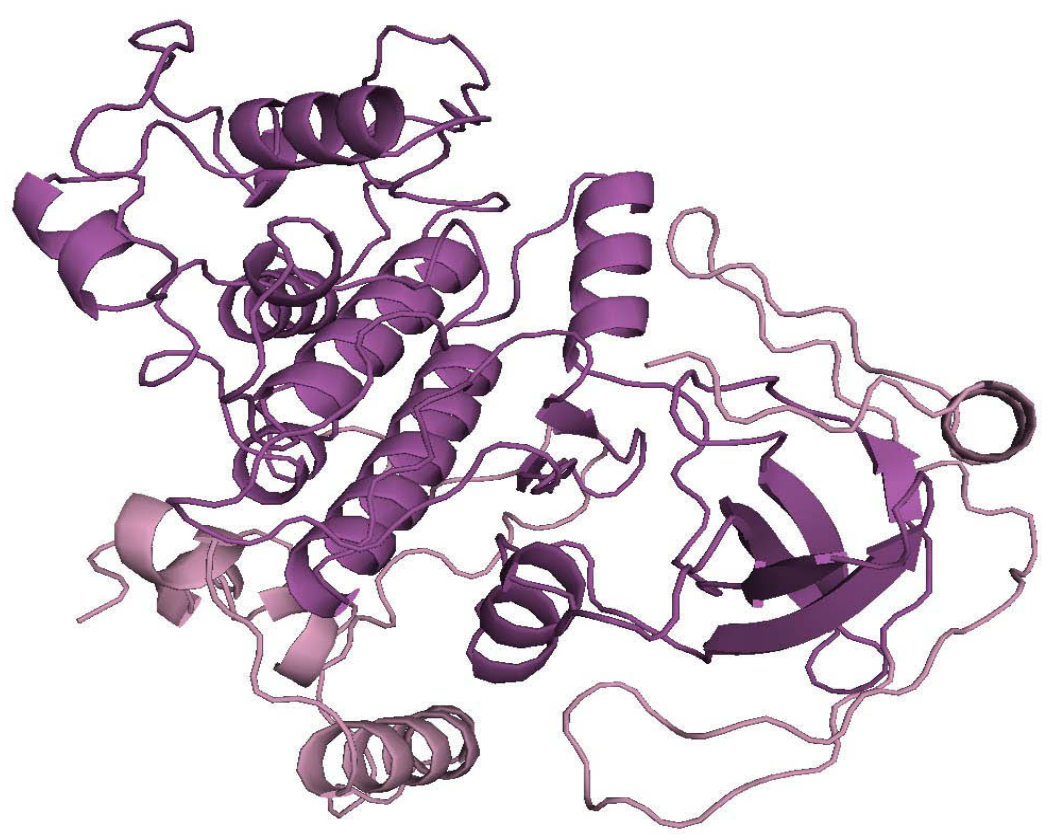

Figure 2. GSK-3 $\beta$. The darker magenta areas depict the protein kinase domains of GSK3ß. These regions possess ATP binding, catalytic, activation and substrate binding domains. 


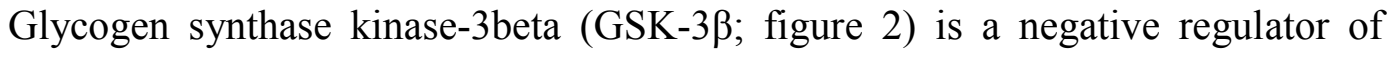
CREB via subsequent phosphorylation of CREB at serine 129 (figure 3) and this subsequent phosphorylation can only occur after the initial phosphorylation of serine 133 $[12,35]$. The serine 129 phosphorylation attenuates CREB transcriptional properties thus inhibiting CREB's neuroprotective mechanisms $[12,35]$. Classically, GSK-3 $\beta$ is well known for its inhibition of the transcription factor $\beta$-catenin in the $W n t$ signaling pathway [36]. $\beta$-catenin is necessary for activating genes responsible in general for embryonic development and more specifically for central nervous system development [36]. When bound by its ligand estrogen, ER- $\alpha$ causes an ephemeral inhibition of GSK- $3 \beta$ via phosphorylation of its serine residues [14]. ERs also act as ligand-activated transcription factors for the promoter region estrogen response element (ERE) [30, 64].

To date, there are two known ERs: ER $\alpha$ and ER $\beta$ [97]. In the nervous system, ERs are mainly located in the hypothalamus and amygdala (two areas responsible for the gonadal distribution of hormones), but are also located in regions of the cerebral cortex [70] and hippocampus [30,97]. Hippocampal expression of ERs are noted in pyramidal cells and Solum and Handa (2002) measured brain derived neurotrophic factor (BDNF) mRNA expression in gonadectomized rats and found that BDNF mRNA decreased in the hippocampus of these gonadectomized rats, but was reversed with a single injection of estrogen. This group also found that ER- $\alpha$ is co-localized with BDNF in pyramidal cells of the hippocampus [100], suggesting that ERs may play a role in memory and cognition $[28,67,97]$. By increasing the activation of second messenger signaling, such as calcium and cAMP that activate protein kinases [37], which in turn activate CREB, estrogen 
indirectly increases CREB activation [67]. Wu et al. (2005) proposed that estrogen/ER complex leads to neuroprotection by recruiting phosphatidylinositol-3 kinase (PI3K). The recruitment of PI3K by ERs increases intracellular calcium; calcium acts as a second messenger involved in several cell signaling pathways. One specific downstream target of calcium is protein kinase $\mathrm{C}$ (PKC) that activates the Src/extracellular signal-regulated kinase (ERK) signaling pathway, leading to the transcription of B-cell lymphoma/leukeimia-2 (Bcl-2), via phosphorylated CREB [105]. PI3K also facilitates Bcl-2 anti-apoptotic activity by activating Akt which inhibits attenuating factors of Bcl-2 [105]. Promotion of intracellular calcium levels via ER-mediated signaling is debatable since evidence show a rapid increase in intracellular calcium mediated by estrogen binding to GPR30, a serpentine transmembrane GPCR [7, 87]. Human keratinocytes treated with estrogen increases phosphorylated CREB levels and GPR30 anti-sense oligonucleotides attenuates this increase [52]. The difference in calcium influx mediated by ERs or GPR30 may be that ER- $\alpha$ has a binding affinity for a Src recruiter known as proline-, glutamic acid-, and leucine-rich protein-1 (PELP1) [11]. The recruitment of PELP1 binds Src and may lead to the PI3K/ERK/CREB pathway proposed by Wu et al. (2005). 
3.

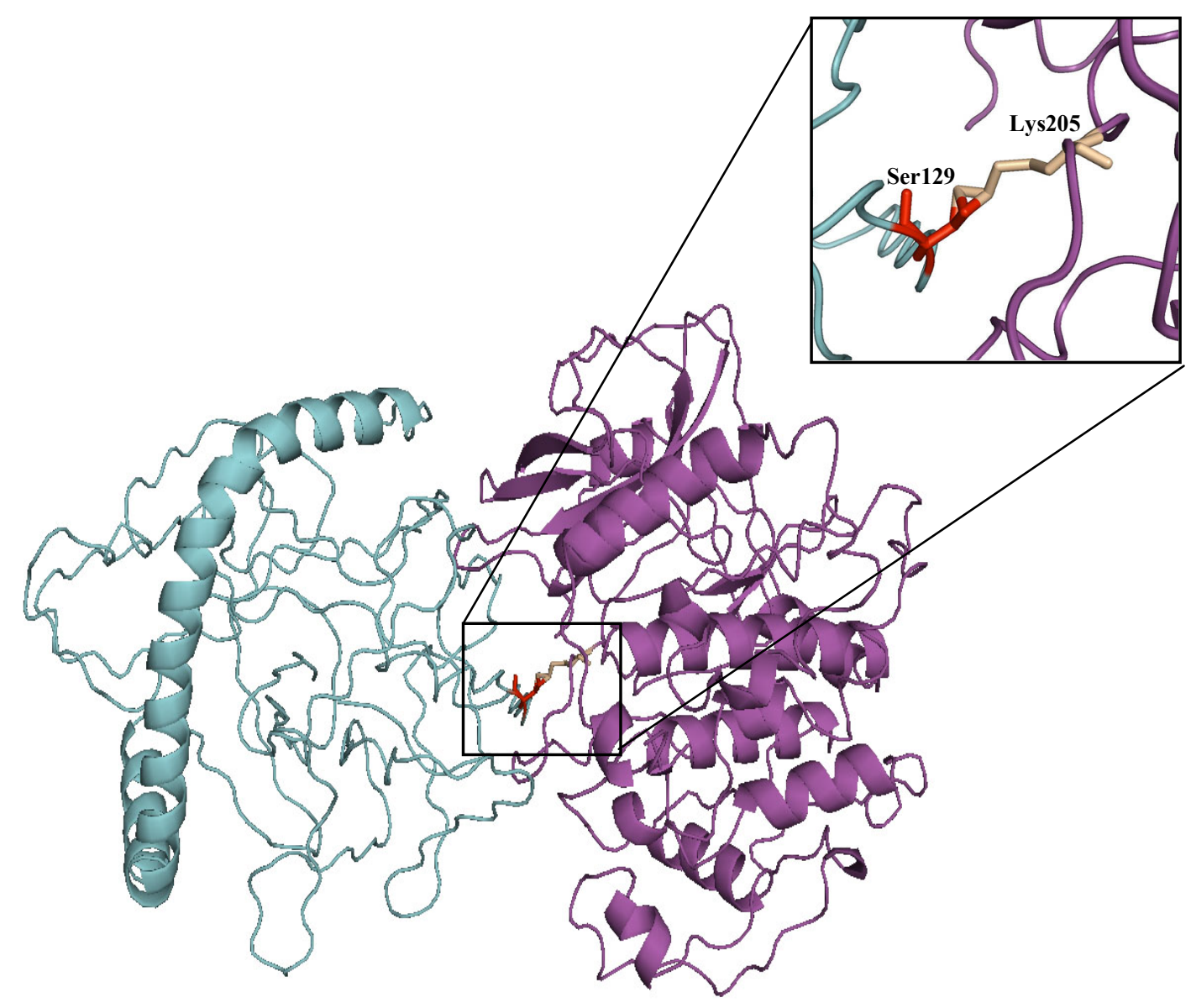

Figure 3. Protein-protein interaction of CREB and GSK-3 $\beta$. Subsequent phosphorylation of CREB (cyan) at serine 129 (red) attenuates response element binding, thereby reducing cAMP-dependent transcription. Subsequent phosphorylation is mediated by GSK-3 $\beta$ (magenta) and interaction is noted at lysine 205 (wheat) of GSK$3 \beta$. 
The dominant form of estrogen, $17 \beta$-estradiol (E2), has an affinity for ER- $\alpha$ (figure 4) leading to transcription factor activation, but E2 can mediate protein signaling pathways through ERs and non-ERs. As mentioned, PELP1 is a co-regulator of ER- $\alpha$ and this interaction leads to Akt/PI3K signaling pathways [11] - a pathway facilitated by lithium involving GSK-3 $\beta$ inhibition [20]. But E2 also binds to the GPCR, GPR30 a serpentine receptor. Expression of GPR30 is noted on the plasma membrane but it is also recognized in the endoplasmic reticulum [89]. The rhodopsin family are GPCRs possessing the seven transmembrane $\alpha$-helices and GPR30 share these conserved domains (figure 5A). Ligand binding of E2 activates GPR30 (figure 5B) and this binding facilitates cAMP production [89]. Figure 5B depicts ligand binding of E2 to the outer and inner membrane - these are hypothetical binding sites using PatchDock web server.

Response element binding by ER- $\alpha$ relies on GSK- $3 \beta$ phosphorylation and this phosphorylation is inhibited in the presence of lithium. Medunjanin et al. [69] suggested that when GSK-3 $\beta$ is phosphorylated at serine 9 it will disassociate itself from ER- $\alpha$, allowing ER- $\alpha$ to migrate to the nucleus for a subsequent phosphorylation by GSK-3 $\beta$ consequently activating ER- $\alpha$ transcriptional properties (figure 6). Palindromic DNA sequences are recognized by ER- $\alpha$, and expressed in promoter regions for NMDA receptor subunits [103]; thus, estrogen has a direct genomic role in NMDA receptor subunit expression. 
4.

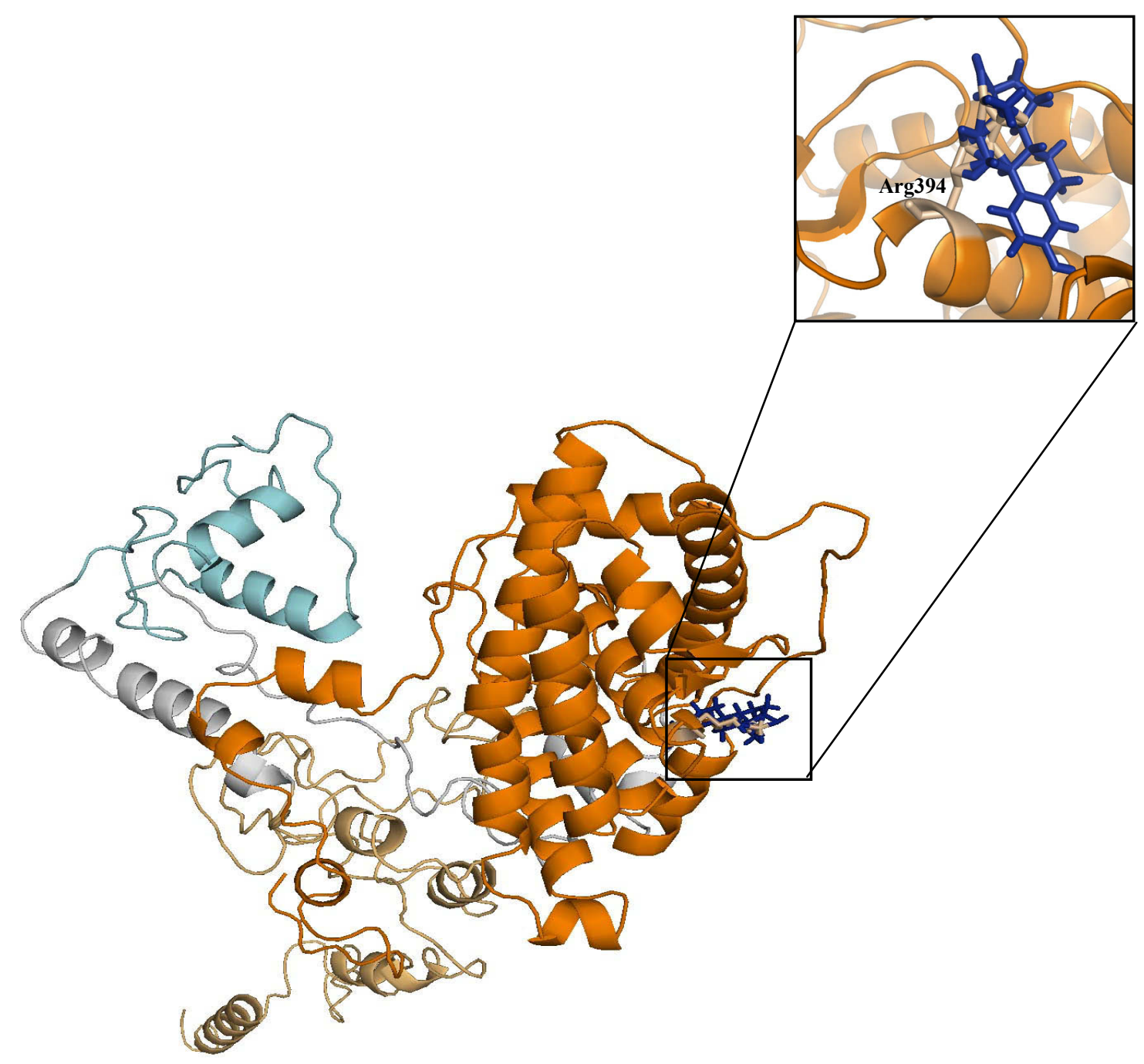

Figure 4. ER- $\alpha$. This figure depicts ER- $\alpha$ bound by E2 (blue) at arginine 394 within the ligand binding domain (foreground; orange). The ligand binding domain also contains the co-activator recognition site and dimer interface. Domains are conserved in ER- $\alpha$ classifying it as part of the ER family (background; light orange) and as a transcription factor due to its zinc finger domain (cyan). 
5A.
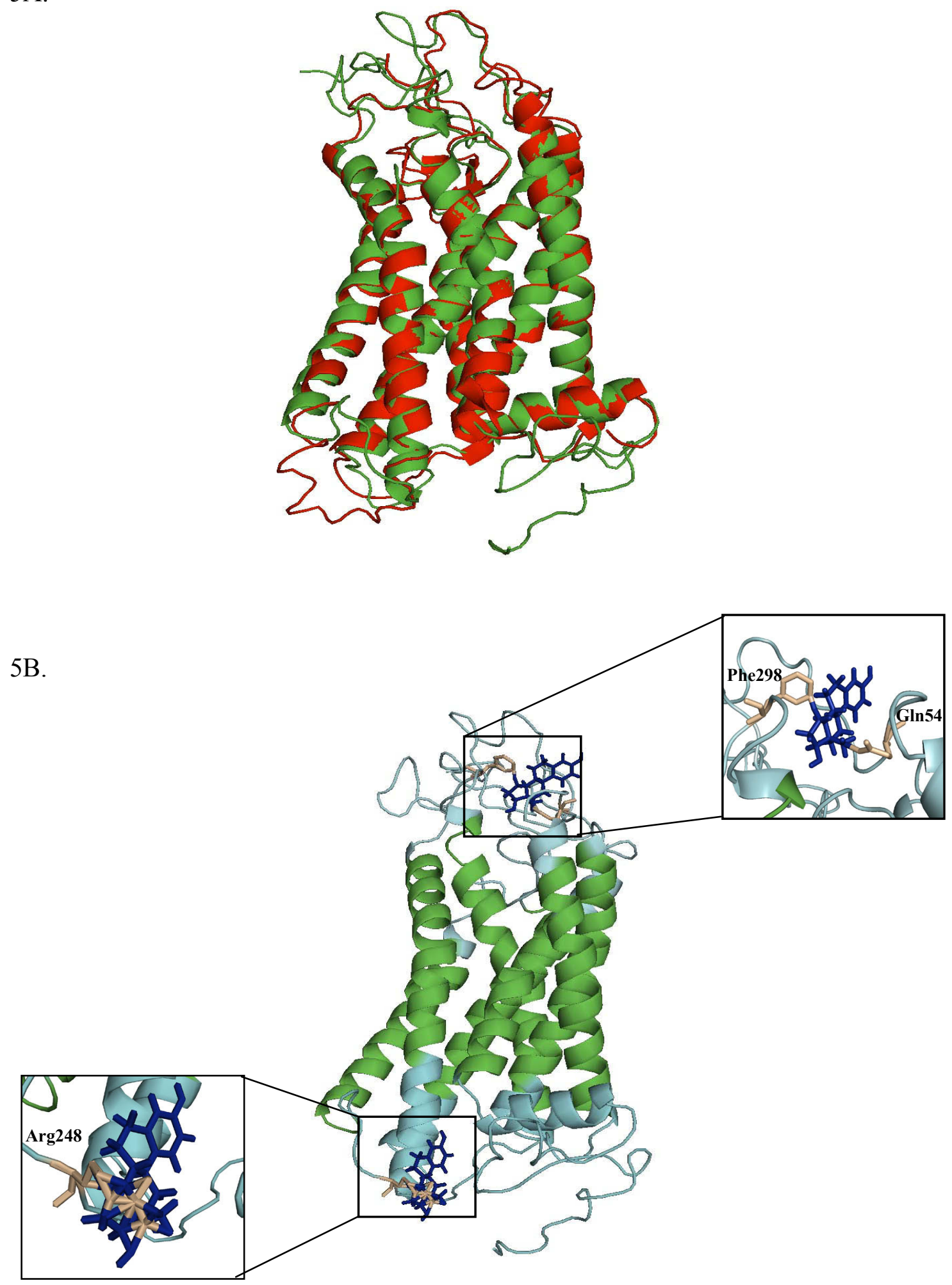
Figure 5A-5B. GPR30. This superimposition depicts GPR30 (green) sharing similar structure to rhodopsin (red) (A). GPR30 express seven $\alpha$-helices transmembrane domains (green) and putative binding of E2 (blue) is shown on the outer membrane (cyan) at phenylalanine 298 and glutamine 54, and inner membrane (cyan) at arginine 248 (B).

6.

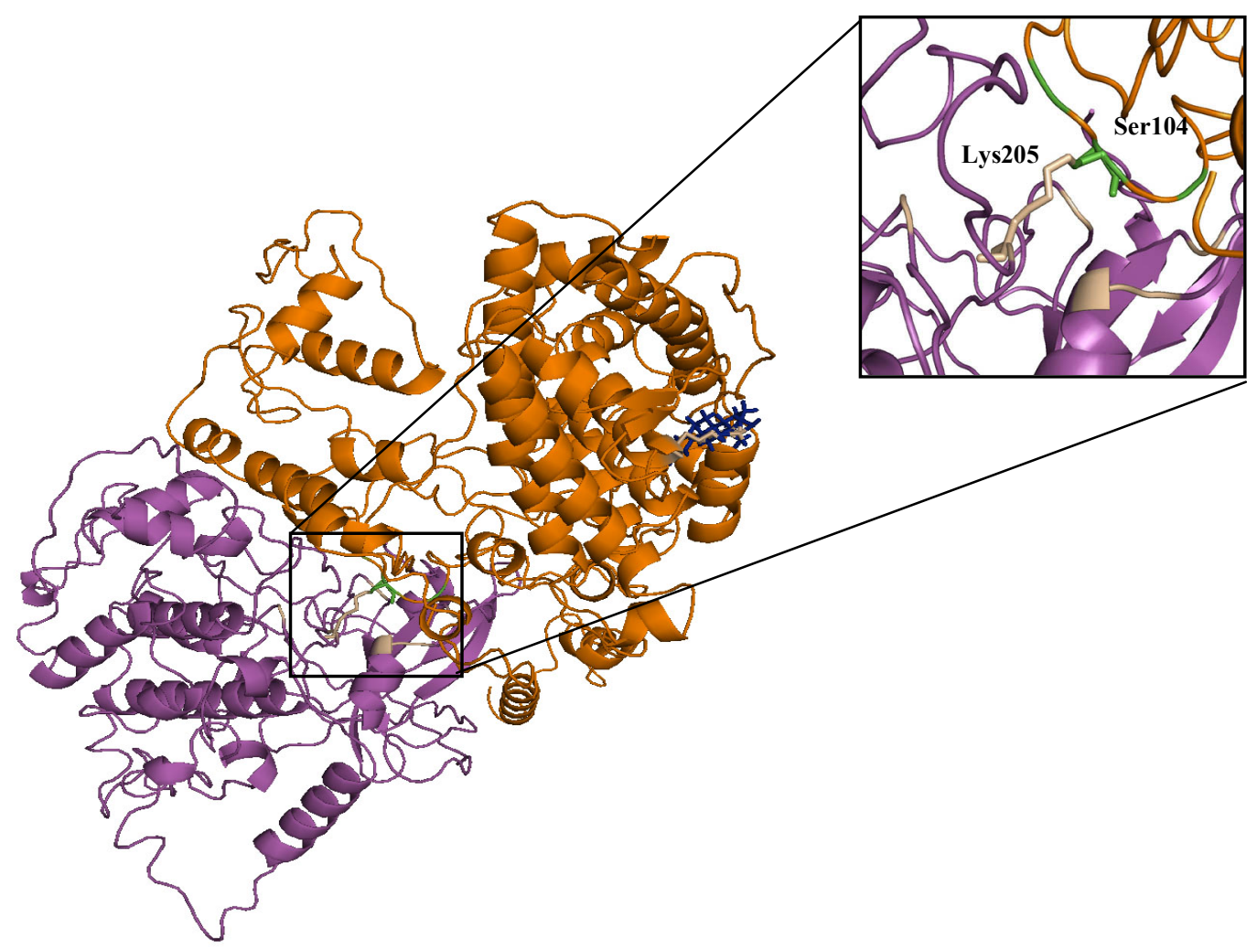

Figure 6. Protein-protein interaction of ER- $\alpha$ and GSK-3 $\beta$. Once bound by estrogen (blue), ER- $\alpha$ (orange) mediates cell signaling pathways or acts as a transcription factor. Response element binding of ER- $\alpha$ is facilitated by GSK-3 $\beta$ (magenta) phosphorylation. This figure depicts binding of ER- $\alpha$ at serine 104 (green) by lysine 205 (wheat) of GSK- 
$3 \beta$. The non-bound residues in green (ER- $\alpha)$ and wheat (GSK-3 $\beta)$ are the binding sites described by Medunjanin et al. [69] and Ilouz et al. [48], respectively. The GSK-3 $\beta$ amino acid residue responsible for phosphorylating ER- $\alpha$ depicted in this figure is the same residue that phosphorylates CREB at serine 129 (figure 3).

\subsection{Lithium}

To elucidate lithium's prophylactic properties for bipolar disorder, investigators postulated mechanisms involving inositol depletion [39] and GSK-3 $\beta$ inhibition [33]. Inositol depletion hypothesis states that lithium inhibits inositol monophosphatase thus depleting the amount of free inositol [39]. Inositol signaling ultimately releases calcium stored in the endoplasmic reticulum affecting several signaling pathways. Inositol signaling via glutamate receptor increases protein kinase activity, transcription factor activation [78] and is highly involved in synaptic plasticity [26]. Using Dictyostelium and human neutrophil cell line (HL60), King et al. [55] systematically investigated the hypothesis that lithium suppresses inositol-mediated signaling. This group showed that lithium reduces phosphoinositide and this reduction is reversed by over expressing inositol monophosphatase [55]. Two inositol monophosphatases have been identified (IMPA1 and IMPA2) and IMPA2 is highly associated not only with bipolar disorder, but schizophrenia as well [108]. A high concentration of magnesium and a high $\mathrm{pH}$ are required for IMPA2 compared with IMPA1 [81]. Ohnishi et al. (2007) showed that lithium also inhibits IMPA2 and this inhibition hinders magnesium concentrations. Bipolar patients treated with lithium show a decrease in inositol monophosphatase 
activity in red blood cells compared with non-treated bipolar patients [58], but cerebrospinal fluid from lithium-treated patients suffering from bipolar or schizophrenia show an increase in inositol monophosphatase activity [5].

For over a decade though, studies demonstrate lithium specifically inhibiting GSK-3 $\beta[25,56]$ and this inhibition is associated with reducing apoptotic activity [45], enhancing neurotrophic factors [4], and facilitating CREB DNA binding [35, 82]. Interestingly, learning and memory centers of the brain are influenced by lithium, since lithium increases performance in hippocampal-dependent spatial memory tasks [95]. An extensive study using GSK-3 $\beta$ heterozygous knockout mice analyzed behavioral parameters from apomorphine-induced stereotypic behavior to startle response and found no distinct difference in behavior [8]. This may lead one to postulate that lithium may affect learning and memory through GSK-3 $\beta$ independent mechanisms.

Though the mechanism remains elusive, GSK-3 $\beta$ inhibition by lithium is described as acting through both direct and indirect mechanisms. Indirectly, lithium inhibits GSK-3 $\beta$ by activating protein kinases that phosphorylate the kinase at its inhibitory serine 9 residue or by inactivating phosphatases that remove this phosphate group [50]. Enzymatic activity is highly dependent on magnesium and lithium directly inhibits GSK-3 $\beta$ by acting as a competitive inhibitor of magnesium; magnesium being a cofactor for ATP in GSK-3 $\beta$ activation [91]. Thus, GSK-3 $\beta$ inhibition by lithium protects/rescues the brain from apoptotic cell death; and neural dysfunction results from 
the failure to completely inhibit GSK-3 $\beta$ [35]. In addition, lithium-treated rats show an upregulation of Bcl-2 in layers II and III of the frontal cortex, dentate gyrus and striatum [65]. I can reasonable assume that long-term administration of lithium could provide neuroprotection by increasing neuronal survival. Neuroprotective qualities of lithium are also associated with increasing BDNF expression and facilitating BDNF signaling via tyrosine kinase receptor. Rat cortical neurons treated with lithium or BDNF had similar neuroprotective qualities; however, lithium required a chronic treatment (6 days) as opposed to an acute action by BDNF (1 day) [42]. These neuroprotective qualities are attenuated by BDNF neutralizing antibodies and specific inhibitors for tyrosine kinase [42]. The signaling cascade of BDNF/tyrosine kinase receptor also activates PI3K/Akt signaling pathways, ultimately leading to neuronal survival and increasing Bcl-2 expression [85]. Neuroprotection of cerebellar granule neurons by lithium via tyrosine kinase activity is also documented, since this neuroprotection is abolished with tyrosine kinase inhibitors [34].

Phencyclidine (PCP), also known as angel dust, is an NMDA receptor antagonist and its actions result in schizophrenic-like behavior [16]; clinically, lithium is also prescribed for schizophrenia [17]. PCP inhibits PI3K/Akt and ERK signaling pathways, and PCP activates GSK-3 $\beta$ by facilitating the dephosphorylation of its serine 9 residue, however, lithium reverses PI3K /Akt and ERK inhibition and GSK-3 $\beta$ activation [106]. Lithium indirectly effects NMDA receptor signaling pathway by reducing phosphorylation and activation of Src-tyrosine kinase activity. Furthermore, phosphorylation of NR2 subunits of NMDA receptor by Src tyrosine kinases is essential 
for the receptor's signal transduction activity and Hashimoto et al. [40] demonstrates that phosphorylated levels of Src tyrosine kinase decreases in a time-dependent fashion when treated with lithium. Although NMDA receptor is highly involved in learning and memory it also mediates glutamate excitotoxicity, and this mediation reduces phosphorylated CREB levels [59]. Diminished phosphorylated CREB is regulated by protein phosphatase 1 [59], a factor involved in GSK-3 $\beta$ activation [110]. When Kopnisky et al. [59] chronically treated neuronal cultures with lithium, protein phosphatase 1 activity decreased, thereby increasing phosphorylated CREB levels; lithium also increased ERK signaling pathway. Post-synaptic glutamate receptors, like NMDA receptor, facilitates synaptic connectivity and conductivity, and lithium enhances this facilitation; interestingly, enhanced synaptic plasticity is correlated with phosphoinositide depletion and not GSK-3 $\beta$ inhibition [54]. Lithium is double-edged in interacting with glutamate receptors, but only to balance the properties of glutamate receptor signaling pathways. This means that lithium attenuates glutamate receptormediated excitoxicity [41], but also facilitates, maintains and strengthens glutamate receptor-mediated synaptic connectivity and communication [54]. If lithium is a competitive inhibitor of magnesium [91] and glutamate receptor channels bind magnesium [18], could lithium then directly affect glutamate receptor? Would lithium's direct interaction lead to glutamate receptor inhibition or facilitate its activity, or both? 
4.5 Estrogen and Lithium; or, Lithium as a Selective Estrogen-Mediated Signaling Modulator

To date, few studies focus on the neurobiological affects of combined estrogen and lithium. Several studies employ lithium in taste aversion task and in inducing seizures. Seizures are induced by injecting lithium in specific stereotactic brain regions causing status epilepticus (e.g. seizures) to occur. Estrogen protects rat hippocampus from these induced seizures; however, this protection is gender specific [29]. Lithium permeates cells through sodium-potassium ATPase pumps and this permeation is dependent on sodium-lithium counterflow and exchange [84], which increases cytoplasmic $\mathrm{pH}$ levels thus altering cell activity [57]. Sodium-lithium counterflow is increased by long-term use of oral contraceptives [2]; interestingly, lithium does not alter ER- $\alpha$ expression in murine uterine tissue, but ovariectomized mice treated with combined estrogen and lithium reduces uterine ER- $\alpha$ expression [38].

Taste aversion tasks use lithium to cause an adverse reaction to a rewarding stimulus (e.g., sucrose water) and studies show that estrogen hinders ovariectomized rats ability to detect dilute sucrose solutions [19]. Estrogen accelerates extinction of conditioned taste aversion behavior, but this is dependent on when estrogen was administered (e.g., before or during extinction) [109]. Combined lithium and estrogen decreases inflammation of stomach lining, but individual treatment does not affect gastric erosions [1]. Both estrogen and lithium affect enkephalins, a regulator of nociceptic responses (e.g., noxious stimuli). In analyzing rat anterior pituitary, Yoshikawa and Hong (1983), found that enkephalin expression is sex dependent - males express higher 
levels than females. Administering estrogen to male rats decreases enkephalins, but testosterone increases enkephalins in the anterior pituitary of female rats [107]. Rats were also administered lithium and Yoshikawa and Hong [107] noted a decrease in enkephalins of the anterior pituitary for both male and female rats. This led them to conclude that the enkephalin system is mediated by the dopamine pathway [107]. Parkinson disease and clinical disorders, such as bipolar disorder, are highly associated with the dopamine pathway, a pathway affected by both estrogen and lithium [74, 99].

An increase in intracellular sodium concentration mediated by dopaminergic pathways is a characteristic of bipolar disorder and lithium normalizes this increase [90]. Studies show that combined estrogen and lithium alter serotonin and dopamine metabolites. Estrogen does not change serotonin levels, dopamine or dopamine metabolites in the frontal cortex of ovariectomized rats, but when estrogen is combined with lithium, dopamine drastically decreases [73]. This decrease is associated with higher serotonin levels and dopamine metabolites [73]. Apomorphine is a dopaminergic agonist that increases stereotyped-behavior (e.g., Parkinsonian symptoms) as noted in ovariectomized rats after discontinuing chronic treatment of estrogen; but this increase in stereotyped-behavior is diminished with lithium [23].

Lithium does not affect basal levels of cAMP, but when stimulated by dopamine, lithium inhibits adenylyl cyclase activity and this is shown in vitro and in vivo [72]. Lithium's inhibition of dopamine-stimulated adenylyl cyclase is not through GPCR signaling pathway, as indicated using the dopamine receptor agonist, quinpirole [72]; 
interestingly, GTP hydrolysis is decreased by lithium, but not when stimulated by catecholamines (i.e. dopamine and epinephrine) [79]. There instead seems to be a direct inhibition of adenylyl cyclase by lithium but only when adenylyl cyclase is activated [66]. Studies show that lithium hinders hormone and dopamine-stimulated adenylyl cyclase activity in rat cerebral cortex and this group concluded that lithium is causing this hindrance via competitive inhibition (e.g. magnesium) [77]. Will lithium inhibit GPR30stimulated adenylyl cyclase activity?

There is a correlation of adenylyl cyclase activity and progression of AD. Postmortem hippocampi of AD patients showed a decrease in adenylyl cyclase activity that resulted from a hindrance in the catalytic domain [80]. Progression of AD is associated with producing excessive amounts of the insoluble amyloid beta - a proteolytic product of amyloid precursor protein (APP) cleaved by $\beta$-secretase [31]. Cleavage of APP by $\alpha-$ secretase can produce a soluble product rendering it benign. Estrogen does increase $\alpha$ secretase mediated cleavage and lithium mimics this increase - potentially through GSK$3 \beta$ inhibition [32]. Post-mortem AD brains also show a decrease in NMDA receptor subunit mRNA for NR1 and NR2B in the hippocampal formation during advancement of the disease [71].

Estrogen facilitates calcium influx that promotes factors involved in neuronal survival and synaptic plasticity [93]. Neurodegenerative diseases, like AD, are marked by increased excitotoxicity, because of high intracellular calcium levels in brain cells [22], and postmenopausal women suffer from AD [43]. Should women with a higher 
likelihood of progressive neurodegenerative functions be prescribed ERT? Or should postmenopausal therapy be directed towards modulating estrogen brain cell signaling pathways? Lithium is extremely toxic if serum levels exceed therapeutic range (0.6 - 1.4 $\mathrm{mM}$ ) as shown by treating rats for up to 28 days and lithium increases estrogen levels via antagonizing ERs [3]. Recent studies, however, indicate that lithium facilitates proliferation of epithelial cells and these cells show an increased ER expression [86]; lithium also increases estrogen production [15]. Although lithium is classically used to treat bipolar syndrome it has an incredible propensity for stabilizing molecular mechanisms. Jope (1999) proposes a bimodal model for lithium, since lithium regulates positive and negative cell signaling mechanisms resulting in raising basal activities and reducing maximal activities or by increasing basal levels and reducing maximal levels of cell signaling mechanisms [49]. Lithium's bimodal mechanism may facilitate ERmediated brain cell signaling during post-menopause by increasing the activity level in a system deprived of its basal level of estrogen.

\subsection{Closing Remarks}

Although ERT is used to treat post-menopausal women, studies recognize that ERT does not alleviate cognitive decline or the advancement of neurodegenerative diseases. Therapies should be directed towards enhancing estrogen-mediated neuromechanisms instead of supplementing the system with estrogen (or hormones in general). SERMs do provide an alternative to ERT, and, although advancement of neurodegenerative diseases are attenuated [21], SERMs do not improve cognitive functioning [75, 83]. Over 60 years ago John Frederick Joseph Cade, an Australian 
psychiatrist, first recognized the calming effects of lithium on small animals and on himself (Cade, 1949). Since then lithium has been used to treat bipolar disorder and over a decade has past since the molecular mechanisms for lithium began to be recognized [56]. These molecular implications have expanded lithium's profile as a cognitive enhancer and an anti-neurodegenerative agent [65].

As discussed in this chapter, both estrogen and lithium facilitate a plethora of signaling transduction pathways resulting in anti-apoptosis, protein expression, learning and memory. Figure 7 depicts the multitude of pathways affected by estrogen and suggests ways in which lithium interacts with these signaling transduction pathways. I noted in chapters one and two, that the combined effects of E2 and $\mathrm{LiCl}(\mathrm{E} 2 / \mathrm{LiCl})$ reduced NMDAR subunit NR1 gene expression and increased glutamate excitotoxicity in embryonic mouse hippocampal and cortical primary mixed cultures, predominated by glia [101]. These results were accompanied by noting that combined $\mathrm{E} 2 / \mathrm{LiCl}$ also increased BDNF and ER- $\alpha$ genetic expression (chapter two). I also showed that lithium treatment alone can increase episodic memory and that this coincides with enhanced expression of markers involved in learning, memory and neuroprotection (chapter three). The research presented in this dissertation is still in its infancy and care must be taken in considering these results applicability towards any clinical implications; but I believe to further study the involvement of antidepressants and hormones will provide a better treatment regime for post-menopausal women. 
7.

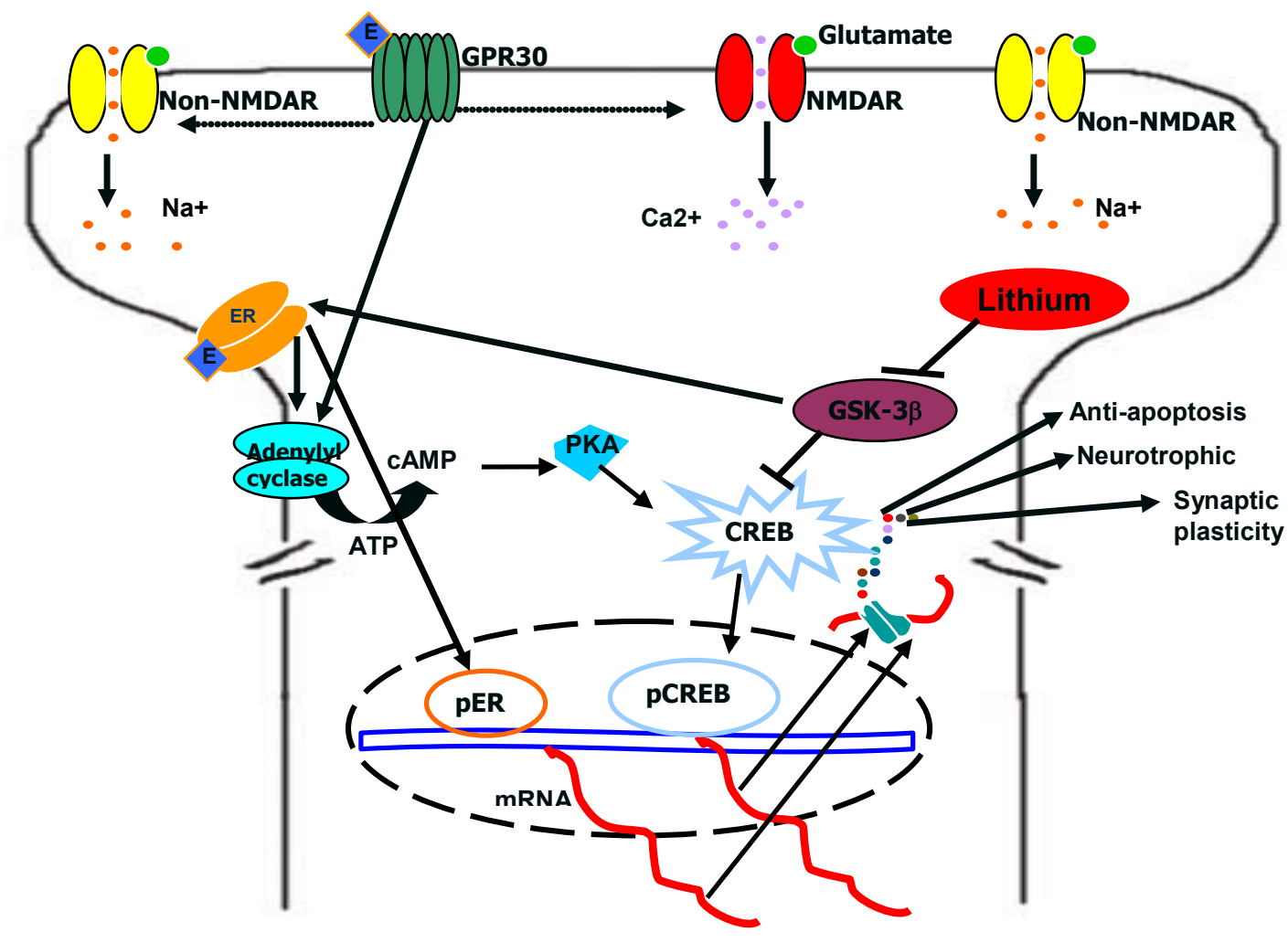

Figure 7. A post-synaptic cell signaling schematic of the mechanism described in this chapter. ATP, adenosine triphosphate; CREB, cyclic adenosine monophosphate (cAMP) response element binding protein; ER, estrogen receptor; GPR30, G-protein coupled receptor 30; GSK-3 $\beta$, glycogen synthase-3beta; NMDAR, $N$-methyl-D-aspartate; PKA, cAMP dependent protein kinase. ( $\leftrightarrow \cdots \rightarrow$, putative interaction; $\rightarrow$, activating/interacting; $\mathbf{H}$, inhibitory) 


\section{REFERENCES}

[1] M. Abouzeit-Har, T. Verimer, J. Long, Effect of long term estrogen and lithium treatment on restraint induced gastric erosion in intact and ovariectomized rats, Die Pharmazie 37 (1982) 593-595.

[2] G. Adebayo, L. Norris, M. Devitt, J. Bonnar, J. Feely, Effects of oral contraceptives containing different progestogens on sodium-lithium countertransport in normal females., Journal of Human Hypertension 12 (1998) 235-238.

[3] M. Allagui, N. Hfaiedh, C. Vincent, F. Guermazi, J. Murat, F. Croute, A. El Feki, Changes in growth rate and thyroid- and sex-hormones blood levels in rats under sub-chronic lithium treatment., Hum. Exp. Toxicol. 25 (2006) 243-250.

[4] F. Angelucci, L. Aloe, P. Jiménez-Vasquez, A.A. Mathé, Lithium treatment alters brain concentrations of nerve growth factor, brain-derived neurotrophic factor and glial cell line-derived neurotrophic factor in a rat model of depression, Int. J. Neuropsychopharmacol. 6 (2003) 225-231.

[5] J.R. Atack, J. Levine, R.H. Belmaker, Cerebrospinal fluid inositol monophosphatase: elevated activity in depression and neuroleptic-treated schizophrenia, Biol. Psychiatry 44 (1998) 433-437.

[6] J. Bakker, M.J. Baum, Role for estradiol in female-typical brain and behavioral sexual differentiation, Front. Neuroendocrinol. 29 (2008) 1-16.

[7] S.M. Belcher, Rapid signaling mechanisms of estrogens in the developing cerebellum, Brain Res. Rev. 57 (2008) 481-492.

[8] Y. Bersudsky, A. Shaldubina, N. Kozlovsky, J.R. Woodgett, G. Agam, R.H. Belmaker, Glycogen synthase kinase-3 $\beta$ heterozygote knockout mice as a model of findings in postmortem schizophrenia brain or as a model of behaviors mimicking lithium action: negative results, Behav. Pharmacol. 19 (2008) 217-224 210.1097/FBP.1090b1013e3282feb1099.

[9] A. Bhangoo, E. Buyuk, K. Oktay, S. Ten, Phenotypic features of 46, XX females with StAR protein mutations., Pediatr. Endocrinol. Rev. 5 ( 2007 ) 633-641.

[10] R. Bourtchuladze, B. Frenguelli, J. Blendy, D. Cioffi, G. Schutz, A.J. Silva, Deficient long-term memory in mice with a targeted mutation of the cAMPresponsive element-binding protein, Cell 79 (1994) 59-68.

[11] D.W. Brann, Q.-G. Zhang, R.-M. Wang, V.B. Mahesh, R.K. Vadlamudi, PELP1 A novel estrogen receptor-interacting protein, Mol. Cell. Endocrinol. 290 (2008) 2-7. 
[12] B.P. Bullock, J.F. Habener, Phosphorylation of the cAMP Response Element Binding Protein CREB by cAMP-Dependent Protein Kinase A and Glycogen Synthase Kinase-3 Alters DNA-Binding Affinity, Conformation, and Increases Net Charge, Biochemistry 37 (1998) 3795-3809.

[13] V.K. Burt, N. Rasgon, Special considerations in treating bipolar disorder in women, Bipolar Disord. 6 (2004) 2-13.

[14] P. Cardona-Gomez, M. Perez, J. Avila, L.M. Garcia-Segura, F. Wandosell, Estradiol inhibits GSK3 and regulates interaction of estrogen receptors, GSK3, and beta-catenin in the hippocampus, Mol. Cell. Neurosci. 25 (2004) 363-373.

[15] S.-Y. Choe, S.-J. Kim, H.-G. Kim, J.H. Lee, Y. Choi, H. Lee, Y. Kim, Evaluation of estrogenicity of major heavy metals, The Science of The Total Environment 312 (2003) 15-21.

[16] Y. Choi, S. Snigdha, M. Shahid, J. Neill, F. Tarazi, Subchronic Effects of Phencyclidine on Dopamine and Serotonin Receptors: Implications for Schizophrenia, J. Mol. Neurosci. 38 (2009) 227-235.

[17] L. Citrome, Adjunctive lithium and anticonvulsants for the treatment of schizophrenia: what is the evidence?, Expert Reviews 9 (2009) 55-71.

[18] R.J. Clarke, J.W. Johnson, Voltage-dependent gating of NR1/2B NMDA receptors, J. Physiol. (Lond.) 586 (2008) 5727-5741.

[19] K.S. Curtis, J.M. Stratford, R.J. Contreras, Estrogen increases the taste threshold for sucrose in rats, Physiol. Behav. 86 (2005) 281-286.

[20] P. De Sarno, X. Li, R.S. Jope, Regulation of Akt and glycogen synthase kinase3 [beta] phosphorylation by sodium valproate and lithium, Neuropharmacology 43 (2002) 1158.

[21] K.M. Dhandapani, D.W. Brann, Protective Effects of Estrogen and Selective Estrogen Receptor Modulators in the Brain, Biol. Reprod. 67 (2002) 1379-1385.

[22] X.-x. Dong, Y. Wang, Z.-h. Qin, Molecular mechanisms of excitotoxicity and their relevance to pathogenesis of neurodegenerative diseases, Acta Pharmacol. Sin. 30 (2009) 379-387.

[23] V.A.C. Dorce, J. Palermo-Neto, Lithium effects on estrogen-induced dopaminergic supersensitivity in rats, Brain Res. Bull. 29 (1992) 239-241.

[24] D. Duhovny, R. Nussinov, H. Wolfson, Efficient Unbound Docking of Rigid Molecules. In: E. Gusfield et al. (Ed.), Lecture Notes in Computer Science, Vol. 2452, Springer Verlag, Rome, Italy, 2002, pp. 185-200. 
[25] T. Engel, P. Goñi-Oliver, E. Gómez de Barreda, J.J. Lucas, F. Hernández, J. Avila, Lithium, a Potential Protective Drug in Alzheimer's Disease, Neurodegenerative Diseases 5 (2008) 247-249.

[26] D. Fernandez de Sevilla, A. Nunez, M. Borde, R. Malinow, W. Buno, Cholinergic-Mediated IP3-Receptor Activation Induces Long-Lasting Synaptic Enhancement in CA1 Pyramidal Neurons, J. Neurosci. 28 (2008) 1469-1478.

[27] E.J. Filardo, J.A. Quinn, A.R. Frackelton, Jr., K.I. Bland, Estrogen Action Via the G Protein-Coupled Receptor, GPR30: Stimulation of Adenylyl Cyclase and cAMP-Mediated Attenuation of the Epidermal Growth Factor Receptor-to-MAPK Signaling Axis, Mol. Endocrinol. 16 (2002) 70-84.

[28] H.N. Fugger, T.C. Foster, J.-A. Gustafsson, E.F. Rissman, Novel effects of estradiol and estrogen receptor $\alpha$ and $\beta$ on cognitive function, Brain Res. 883 (2000) 258-264.

[29] A.S. Galanopoulou, E.M. Alm, J. Veliskova, Estradiol reduces seizure-induced hippocampal injury in ovariectomized female but not in male rats, Neurosci. Lett. $342(2003) 201$.

[30] L.M. Garcia-Segura, I. Azcoitia, L.L. DonCarlos, Neuroprotection by estradiol, Prog. Neurobiol. 63 (2001) 29-60.

[31] G. Glenner, Alzheimer's disease (senile dementia) a research update and critique with recommendations., Journal of Geriatric Society 30 (1982) 59-62.

[32] S. Goodenough, M. Schafer, C. Behl, Estrogen-induced cell signalling in a cellular model of Alzheimer's disease, J. Steroid Biochem. Mol. Biol. 84 (2003) 301-305.

[33] T.D. Gould, H.K. Manji, The Wnt Signaling Pathway in Bipolar Disorder, Neuroscientist 8 (2002) 497-511.

[34] S. Grignon, N. Levy, F. Couraud, B. Bruguerolle, Tyrosine kinase inhibitors and cycloheximide inhibit $\mathrm{Li}+$ protection of cerebellar granule neurons switched to non-depolarizing medium, Eur. J. Pharmacol. 315 (1996) 111-114.

[35] C.A. Grimes, R.S. Jope, CREB DNA binding activity is inhibited by glycogen synthase kinase-3 $\beta$ and facilitated by lithium, J. Neurochem. 78 (2001) 12191232.

[36] C.A. Grimes, R.S. Jope, The multifaceted roles of glycogen synthase kinase $3 \beta$ in cellular signaling, Prog. Neurobiol. 65 (2001) 391-426. 
[37] G. Gu, A.A. Rojo, M.C. Zee, J. Yu, R.B. Simerly, Hormonal Regulation of CREB Phosphorylation in the Anteroventral Periventricular Nucleus, J. Neurosci. 16 (1996) 3035-3044.

[38] A.G. Gunin, V.U. Emelianov, I.U. Mironkin, M.P. Morozov, A.S. Tolmachev, Lithium treatment enhances estradiol-induced proliferation and hyperplasia formation in the uterus of mice, European Journal of Obstetrics, Gynecology and Reproductive Biology 114 (2004) 83-91.

[39] A.J. Harwood, Lithium and bipolar mood disorder: the inositol-depletion hypothesis revisited, Mol. Psychiatry 10 (2004) 117-126.

[40] R. Hashimoto, K. Fujimaki, M.R. Jeong, L. Christ, D.-M. Chuang, Lithiuminduced inhibition of Src tyrosine kinase in rat cerebral cortical neurons: a role in neuroprotection against N-methyl-D-aspartate receptor-mediated excitotoxicity, FEBS Lett. 538 (2003) 145-148.

[41] R. Hashimoto, C. Hough, T. Nakazawa, T. Yamamoto, D.-M. Chuang, Lithium protection against glutamate excitotoxicity in rat cerebral cortical neurons: involvement of NMDA receptor inhibition possibly by decreasing NR2B tyrosine phosphorylation, J. Neurochem. 80 (2002) 589-597.

[42] R. Hashimoto, N. Takei, K. Shimazu, L. Christ, B. Lu, D.-M. Chuang, Lithium induces brain-derived neurotrophic factor and activates TrkB in rodent cortical neurons: An essential step for neuroprotection against glutamate excitotoxicity, Neuropharmacology 43 (2002) 1173.

[43] V.W. Henderson, Menopause, cognitive ageing and dementia: practice implications, Menopause International 15 (2009) 41-44.

[44] K. Honda, S. Shimohama, H. Sawada, T. Kihara, T. Nakamizo, H. Shibasaki, A. Akaike, Nongenomic antiapoptotic signal transduction by estrogen in cultured cortical neurons, J. Neurosci. Res. 64 (2001) 466-475.

[45] V. Hongisto, N. Smeds, S. Brecht, T. Herdegen, M.J. Courtney, E.T. Coffey, Lithium Blocks the c-Jun Stress Response and Protects Neurons via Its Action on Glycogen Synthase Kinase 3, Mol. Cell. Biol. 23 (2003) 6027-6036.

[46] R. Hu, W.Q. Cai, X.G. Wu, Z. Yang, Astrocyte-derived estrogen enhances synapse formation and synaptic transmission between cultured neonatal rat cortical neurons, Neuroscience 144 (2007) 1229-1240.

[47] N.C. Huff, M. Frank, K. Wright-Hardesty, D. Sprunger, P. Matus-Amat, E. Higgins, J.W. Rudy, Amygdala Regulation of Immediate-Early Gene Expression in the Hippocampus Induced by Contextual Fear Conditioning, Journal of Neuroscience, 26 (2006) 1616-1623. 
[48] R. Ilouz, N. Kowalsman, M. Eisenstein, H. Eldar-Finkelman, Identification of Novel Glycogen Synthase Kinase-3beta Substrate-interacting Residues Suggests a Common Mechanism for Substrate Recognition. Vol. 281, 2006, pp. 3062130630 .

[49] R.S. Jope, A bimodal model of the mechanism of action of lithium, Mol. Psychiatry 4 (1999) 21-25.

[50] R.S. Jope, Lithium and GSK-3: one inhibitor, two inhibitory actions, multiple outcomes, Trends Pharmacol. Sci. 24 (2003) 441-443.

[51] V.C. Jordan, S. Gapstur, M. Morrow, Selective Estrogen Receptor Modulation and Reduction in Risk of Breast Cancer, Osteoporosis, and Coronary Heart Disease, J. Natl. Cancer Inst. 93 (2001) 1449-1457.

[52] N. Kanda, S. Watanabe, 17ß-Estradiol Stimulates the Growth of Human Keratinocytes by Inducing Cyclin D2 Expression, J. Investig. Dermatol. 123 (2004) 319-328.

[53] E.R. Kandel, The Molecular Biology of Memory Storage: A Dialogue Between Genes and Synapses, Science 294 (2001) 1030-1038.

[54] H.J. Kim, S.A. Thayer, Lithium Increases Synapse Formation between Hippocampal Neurons by Depleting Phosphoinositides, Mol. Pharmacol. 75 (2009) 1021-1030.

[55] J.S. King, R. Teo, J. Ryves, J.V. Reddy, O. Peters, B. Orabi, O. Hoeller, R.S.B. Williams, A.J. Harwood, The mood stabiliser lithium suppresses PIP3 signalling in Dictyostelium and human cells, Disease Models and Mechanisms 2 (2009) 306-312.

[56] P.S. Klein, D.A. Melton, A molecular mechanism for the effect of lithium on development, PNAS 93 (1996) 8455-8459.

[57] Y. Kobayashi, T. Pang, T. Iwamoto, S. Wakabayashi, M. Shigekawa, Lithium activates mammalian $\mathrm{Na}+\mathrm{H}+$ exchangers: isoform specificity and inhibition by genistein, Pflügers Archiv European Journal of Physiology 439 (2000) 455-462.

[58] O. Kofman, R. Belmaker, Biochemical, behavioral, and clinical studies of the role of inositol in lithium treatment and depression, Biol. Psychiatry 34 (1993) 839852.

[59] K.L. Kopnisky, E. Chalecka-Franaszek, M. Gonzalez-Zulueta, D.M. Chuang, Chronic lithium treatment antagonizes glutamate-induced decrease of phosphorylated CREB in neurons via reducing protein phosphatase 1 and increasing MEK activities, Neuroscience 116 (2003) 425. 
[60] A. Kukopulos, G. Minnai, B. Muller-Oerlinghausen, The influence of mania and depression on the pharmacokinetics of lithium: A longitudinal single-case study, J. Affect. Disord. 8 (1985) 159-166.

[61] S.J. Lee, B.S. McEwen, Neurophic and Neuroprotective Actions of Estrogens and their Therapeutic Implications, Annu. Rev. Pharmacol. Toxicol. 41 (2001) 569591.

[62] C. Leranth, M. Shanabrough, D.E. Redmond Jr., Gonadal hormones are responsible for maintaining the integrity of spine synapses in the CA1 hippocampal subfield of female nonhuman primates, The Journal of Comparative Neurology 447 (2002) 34-42.

[63] Z. Liu, Myriam Gastard, Tatyana Verina, Susan Bora, Peter R. Mouton, Vassilis E. Koliatsos Estrogens modulate experimentally induced apoptosis of granule cells in the adult hippocampus, J. Comp. Neurol. 441 (2001) 1-8.

[64] J.I. Macgregor, V.C. Jordan, Basic Guide to the Mechanisms of Antiestrogen Action, Pharmacol. Rev. 50 (1998) 151-196.

[65] H.K. Manji, G.J. Moore, G. Chen, Lithium at 50: have the neuroprotective effects of this unique cation been overlooked?, Biol. Psychiatry 46 (1999) 929-940.

[66] L. Mann, E. Heldman, G. Shaltiel, R.H. Belmaker, G. Agam, Lithium preferentially inhibits adenylyl cyclase $\mathrm{V}$ and VII isoforms, Int. J. Neuropsychopharmacol. 11 (2008) 533-539.

[67] B.S. McEwen, Genome and Hormones: Gender Differences in Physiology: Invited Review: Estrogens effects on the brain: multiple sites and molecular mechanisms, J. Appl. Physiol. 91 (2001) 2785-2801.

[68] B.S. McEwen, L. Plapinger, C. Chaptal, J. Gerlach, G. Wallach, Role of fetoneonatal estrogen binding proteins in the associations of estrogen with neonatal brain cell nuclear receptors, Brain Res. 96 (1975) 400-406.

[69] S. Medunjanin, A. Hermani, B. De Servi, J. Grisouard, G. Rincke, D. Mayer, Glycogen Synthase Kinase-3 Interacts with and Phosphorylates Estrogen Receptor $\alpha$ and Is Involved in the Regulation of Receptor Activity, J. Biol. Chem. 280 (2005) 33006-33014.

[70] I. Merchenthaler, M.V. Lane, S. Numan, T.L. Dellovade, Distribution of estrogen receptor $\alpha$ and $\beta$ in the mouse central nervous system: In vivo autoradiographic and immunocytochemical analyses, J. Comp. Neurol. 473 (2004) 270-291.

[71] A.J. Mishizen-Eberz, R.A. Rissman, T.L. Carter, M.D. Ikonomovic, B.B. Wolfe, D.M. Armstrong, Biochemical and molecular studies of NMDA receptor subunits 
NR1/2A/2B in hippocampal subregions throughout progression of Alzheimer's disease pathology, Neurobiol. Dis. 15 (2004) 80-92.

[72] L.P. Montezinho, A. Mørk, C.B. Duarte, S. Penschuck, C.F.G.C. Geraldes, M.M.C.A. Castro, Effects of mood stabilizers on the inhibition of adenylate cyclase via dopamine D(2)-like receptors, Bipolar Disord. 9 (2007) 290-297.

[73] M. Morissette, T. Di Paolo, Acute effect of 17ß-estradiol and lithium on ovariectomized rat brain biogenic amines metabolism, J. Psychiatr. Res. 30 (1996) 95-107.

[74] M. Morissette, M. Le Saux, M. D'Astous, S. Jourdain, S. Al Sweidi, N. Morin, E. Estrada-Camarena, P. Mendez, L.M. Garcia-Segura, T. Di Paolo, Contribution of estrogen receptors alpha and beta to the effects of estradiol in the brain, J. Steroid Biochem. Mol. Biol. 108 (2008) 327-338.

[75] V. Natale, P. Albertazzi, N. Missiroli, D. Pedrini, M. Salgarello, Effects of raloxifene on mood, sleep, libido and cognitive function in postmenopausal healthy women: a pilot study, Maturitas 48 (2004) 59-63.

[76] L.M. Newcomer, P.A. Newcomb, J.D. Potter, Y. Yasui, A. Trentham-Dietz, B.E. Storer, M.P. Longnecker, J.A. Baron, J.R. Daling, Postmenopausal hormone therapy and risk of breast cancer by histologic type United States, Cancer Causes \& Control 14 (2003) 225-233.

[77] M.E. Newman, R.H. Belmaker, Effects of lithium in vitro and ex vivo on components of the adenylate cyclase system in membranes from the cerebral cortex of the rat, Neuropharmacology 26 (1987) 211-217.

[78] K.J. O'Riordan, I.C. Huang, M. Pizzi, P. Spano, F. Boroni, R. Egli, P. Desai, O. Fitch, L. Malone, H. Jin Ahn, H.-C. Liou, J.D. Sweatt, J.M. Levenson, Regulation of Nuclear Factor \{kappa\}B in the Hippocampus by Group I Metabotropic Glutamate Receptors, J. Neurosci. 26 (2006) 4870-4879.

[79] Y. Odagaki, N. Nishi, T. Koyama, Lack of Interfering Effects of Lithium on Receptor/G Protein Coupling in Human Platelet and Rat Brain Membranes, Biol. Psychiatry 42 (1997) 697-703.

[80] T. Ohm, J. Bohl, B. Lemmer, Reduced basal and stimulated (isoprenaline, Gpp(NH)p, forskolin) adenylate cyclase activity in Alzheimer's disease correlated with histopathological changes., Brain Res. 540 (1991) 229-236.

[81] T. Ohnishi, H. Ohba, K.-C. Seo, J. Im, Y. Sato, Y. Iwayama, T. Furuichi, S.-K. Chung, T. Yoshikawa, Spatial Expression Patterns and Biochemical Properties Distinguish a Second myo-Inositol Monophosphatase IMPA2 from IMPA1, J. Biol. Chem. 282 (2007) 637-646. 
[82] N. Ozaki, D.-M. Chuang, Lithium Increases Transcription Factor Binding to AP-1 and Cyclic AMP-Responsive Element in Cultured Neurons and Rat Brain, J. Neurochem. 69 (1997) 2336-2344.

[83] J. Palmer, T. Trotter, A. Joy, L. Carlson, Cognitive effects of Tamoxifen in premenopausal women with breast cancer compared to healthy controls, Journal of Cancer Survivorship 2 (2008) 275-282.

[84] G.N. Pandey, B. Sarkadi, M. Haas, R.B. Gunn, J.M. Davis, D.C. Tosteson, Lithium transport pathways in human red blood cells, J. Gen. Physiol. 72 (1978) 233-247.

[85] A. Patapoutian, L.F. Reichardt, Trk receptors: mediators of neurotrophin action, Curr. Opin. Neurobiol. 11 (2001) 272-280.

[86] A.J. Polotsky, L. Zhu, N. Santoro, J.W. Pollard, Lithium chloride treatment induces epithelial cell proliferation in xenografted human endometrium, Hum. Reprod. (2009) dep115.

[87] E.R. Prossnitz, M. Maggiolini, Mechanisms of estrogen signaling and gene expression via GPR30, Mol. Cell. Endocrinol. In Press, Corrected Proof (2009).

[88] S. Pugazhenthi, A. Nesterova, C. Sable, K.A. Heidenreich, L.M. Boxer, L.E. Heasley, J.E.B. Reusch, Akt/Protein Kinase B Up-regulates Bcl-2 Expression through cAMP-response Element-binding Protein, J. Biol. Chem. 275 (2000) 10761-10766.

[89] L. Raz, M.M. Khan, V.B. Mahesh, R.K. Vadlamudi, D.W. Brann, Rapid Estrogen Signaling in the Brain, NeuroSignals 16 (2008) 140-153.

[90] R.J. Roberts, R. Repass, R.S. El-Mallakh, Effect of dopamine on intracellular sodium: A common pathway for pharmacological mechanism of action in bipolar illness, World Journal of Biological Psychiatry 24 (2009) 1-7.

[91] W.J. Ryves, A.J. Harwood, Lithium Inhibits Glycogen Synthase Kinase-3 by Competition for Magnesium, Biochem. Biophys. Res. Commun. 280 (2001) 720725 .

[92] S. Sanyal, D.J. Sandstrom, C.A. Hoeffer, M. Ramaswami, AP-1 functions upstream of CREB to control synaptic plasticity in Drosophila, Nature 416 (2002) 870 .

[93] S.N. Sarkar, R.-Q. Huang, S.M. Logan, K.D. Yi, G.H. Dillon, J.W. Simpkins, Estrogens directly potentiate neuronal L-type Ca2+ channels, Proceedings of the National Academy of Sciences 105 (2008) 15148-15153. 
[94] D. Schneidman-Duhovny, Y. Inbar, R. Nussinov, H. Wolfson, PatchDock and SymmDock: servers for rigid and symmetric docking., Nucleic Acids Res. 33 (2005) W363-367.

[95] M. Sharifzadeh, M. Aghsami, S. Gholizadeh, K. Tabrizian, M. Soodi, S. Khalaj, A. Ranjbar, A. Hosseini-Sharifabad, A. Roghani, M.H. Karimfar, Protective Effects of Chronic Lithium Treatment against Spatial Memory Retention Deficits Induced by the Protein Kinase AII Inhibitor H-89 in Rats, Pharmacology 80 (2007) 158-165.

[96] B.B. Sherwin, Estrogen and Cognitive Functioning in Women, Endocr. Rev. 24 (2003) 133-151.

[97] P.J. Shughrue, M.V. Lane, I. Merchenthaler, Comparative distribution of estrogen receptor- $\alpha$ and $-\beta$ mRNA in the rat central nervous system, J. Comp. Neurol. 388 (1997) 507-525.

[98] A. Sierra, Neurosteroids: The StAR Protein in the Brain, J. Neuroendocrinol. 16 (2004) 787-793.

[99] T. Silverstone, Dopamine in manic depressive illness : A pharmacological synthesis, J. Affect. Disord. 8 (1985) 225-231.

[100] D.T. Solum, R.J. Handa, Estrogen Regulates the Development of Brain-Derived Neurotrophic Factor mRNA and Protein in the Rat Hippocampus, J. Neurosci. 22 (2002) 2650-2659.

[101] J.J. Valdés, O.I. Weeks, Estradiol and lithium chloride specifically alter NMDA receptor subunit NR1 mRNA and excitotoxicity in primary cultures, Brain Res. 1268 (2009) 1-12.

[102] M.R. Walton, M. Dragunow, Is CREB a key to neuronal survival?, Trends Neurosci. 23 (2000) 48-53.

[103] T. Watanabe, S. Inoue, H. Hiroi, A. Orimo, M. Muramatsu, NMDA receptor type 2D gene as target for estrogen receptor in the brain, Mol. Brain Res. 63 (1999) $375-379$.

[104] S. Wu, J. Skolnick, Y. Zhang., Ab initio modeling of small proteins by iterative TASSER simulations, BMC Biology 5 (2007) 17

[105] T.W. Wu, J.M. Wang, S. Chen, R.D. Brinton, $17 \beta$-estradiol induced $\mathrm{Ca}^{2+}$ influx via L-type calcium channels activates the Src/ERK/cyclic-AMP response element binding protein signal pathway and BCL-2 expression in rat hippocampal neurons: A potential initiation mechanism for estrogen-induced neuroprotection, Neuroscience 135 (2005) 59-72. 
[106] Y. Xia, C.Z. Wang, J. Liu, N.C. Anastasio, K.M. Johnson, Lithium Protection of Phencyclidine-Induced Neurotoxicity in Developing Brain: The Role of Phosphatidylinositol-3 Kinase/Akt and Mitogen-Activated Protein Kinase Kinase/Extracellular Signal-Regulated Kinase Signaling Pathways, J. Pharmacol. Exp. Ther. 326 (2008) 838-848.

[107] K. Yoshikawa, J. Hong, The enkephalin system in the rat anterior pituitary: regulation by gonadal steroid hormones and psychotropic drugs, Endocrinology 113 (1983) 1218-1227.

[108] T. Yoshikawa, M. Kikuchi, K. Saito, A. Watanabe, K. Yamada, H. Shibuya, M. Nankai, A. Kurumaji, E. Hattori, H. Ishiguro, H. Shimizu, Y. Okubo, M. Toru, S. Detera-Wadleigh, Evidence for association of the myo-inositol monophosphatase 2 (IMPA2) gene with schizophrenia in Japanese samples, Mol. Psychiatry 6 (2001 ) 202-210.

[109] D.L. Yuan, K.C. Chambers, Estradiol Accelerates Extinction of Lithium Chloride-Induced Conditioned Taste Aversions Through Its Illness-Associated Properties, Horm. Behav. 36 (1999) 287.

[110] F. Zhang, C.J. Phiel, L. Spece, N. Gurvich, P.S. Klein, Inhibitory Phosphorylation of Glycogen Synthase Kinase-3 (GSK-3) in Response to Lithium: Evidence for Autoregulation of GSK-3, J. Biol. Chem. 278 (2003) 33067-33077.

[111] Y. Zhang, I-TASSER server for protein 3D structure prediction., BMC Bioinformatics 9 (2008) 40

[112] Y. Zhang, Template-based modeling and free modeling by I-TASSER in CASP7, Proteins Struct. Funct. Bioinformat. 8 (2007) 108-117. 
VITA

JAMES JASON VALDÉS

1996-1998

A.A., Psychology

Miami-Dade Community College

Miami, FL

1998-2001

B.A., Psychology

Florida International University

Miami, FL

$2004-2005$

Teaching Assistant

Florida International University, Department of Biological Sciences

Miami, FL

2003-2009

Laboratory Manager and Research Assistant Florida International University, Department of Biological Sciences, Miami, FL

\section{SELECTED PEER-REVIEWED PUBLICATIONS, PRESENTATION AND POSTERS}

Valdés, J.J. and Weeks, O.I. (2009). Estradiol and Lithium Chloride Specifically Alter NMDA Receptor Subunit NR1 mRNA and Excitotoxicity in Primary Cultures. Neuroscience Letters. (Under Review).

Valdés, J.J. and Weeks, O.I. (2009). Estradiol and Lithium Chloride Specifically Alter NMDA Receptor Subunit NR1 mRNA and Excitotoxicity in Primary Cultures. Brain Research. 1268:1-12.

Valdés, J.J. and Weeks, O.I. (2004). Lithium and Estrogen: A Synergistic Relationship? A presentation at the Minority Biomedical Research Support Annual symposium, Florida International University, Miami, FL.

Valdés, J.J. and Weeks, O.I. (2004).Lithium: A Memory Enhancer? A presentation at the Comparative Immunology $5^{\text {th }}$ Annual Symposium (Florida International University, Miami, FL) 
Valdés, J.J. and Weeks, O.I. (2007). From Behavior to Molecules: Preliminary Observation on Lithium's effect on Learning, Memory and Neuroprotection. A presentation at the Department of Biological Sciences Annual Symposium, Florida International University, Miami, FL.

Valdés, J.J. and Weeks, O.I. (2007). An Odyssey to Better Understand Morphological and Molecular Processes Involved in Learning and Memory. A presentation at the Comparative Immunology $8^{\text {th }}$ Annual Symposium, Florida International University, Miami, FL.

Valdés, J.J. and Weeks, O.I. (2007). Observations of Lithium's and Estrogen's Effect on Gene Expression Involved in Learning, Memory and Neuroprotection. A presentation at the Minority Biomedical Research Support Annual symposium, Florida International University, Miami, FL.

Valdés, J.J. and Weeks, O.I. (2008). Exposure of cultured murine brain cells to both lithium and estrogen results in altered NR1 and GSK-3 beta mRNA expression. Platform presentation at the American Association of Anatomists (Federation of American Societies for Experimental Biology (FASEB)) annual meeting, San Diego, CA.

Valdés, J.J. and Weeks, O.I. (2008). Estrogen and Lithium Alter NMDAR subunit NR1 mRNA and Cell Viability in Cortical and Hippocampal Brain Cell Cultures. A presentation at the Minority Biomedical Research Support Annual symposium, Florida International University, Miami, FL.

Valdés, J.J. and Weeks, O.I. (2005). Lithium: A Memory Enhancer. Poster Presentation at the American Association of Anatomists (Federation of American Societies for Experimental Biology (FASEB)) annual meeting, San Diego, CA.

Valdés, J.J. and Weeks, O.I. (2006). Lithium Chloride Upregulates Bcl-2 Protein Expression in the Frontal Cortex, Hippocampus and Amygdala of C57BL/6J mice. Poster Presentation at the $36^{\text {th }}$ Annual Society for Neuroscience meeting, Atlanta, GA.

Valdés, J.J. and Weeks, O.I. (2009). Viability of estrogen and lithium-treated primary brain cell cultures following glutamate insult and NR1 mRNA expression of pretreated cultures. Poster Presentation at the American Association of Anatomists (Federation of American Societies for Experimental Biology (FASEB)) annual meeting, New Orleans, LA. 